https://helda.helsinki.fi

\title{
Immune Cell Membrane-Coated Biomimetic Nanoparticles for Targeted Cancer Therapy
}

\section{Oroojalian, Fatemeh}

2021-03

Oroojalian , F , Beygi , M , Baradaran , B , Mokhtarzadeh , A \& Shahbazi , M-A 2021 , ' Immune Cell Membrane-Coated Biomimetic Nanoparticles for Targeted Cancer Therapy ' , Small , vol. 17 , no. 12 , 2006484 . https://doi.org/10.1002/smll.202006484

http://hdl.handle.net/10138/340192

https://doi.org/10.1002/smll.202006484

unspecified

acceptedVersion

Downloaded from Helda, University of Helsinki institutional repository.

This is an electronic reprint of the original article.

This reprint may differ from the original in pagination and typographic detail.

Please cite the original version. 


\section{Immune Cell Membrane-Coated Biomimetic Nanoparticles for Targeted Cancer Therapy}

Fatemeh Oroojalian, Mohammad Beygi, Behzad Baradaran, Ahad Mokhtarzadeh*, and Mohammad-Ali Shahbazi*

F. Oroojalian

Department of Advanced Sciences and Technologies in Medicine, School of Medicine, North Khorasan University of Medical Sciences, Bojnurd, Iran

Natural Products and Medicinal Plants Research Center, North Khorasan University of Medical Sciences, Bojnurd, Iran

M. Beygi

Department of Agricultural Engineering, Isfahan University of Technology (IUT), Isfahan, Iran

Dr. B. Baradaran

Immunology Research Center, Tabriz University of Medical Sciences, Tabriz, Iran

[*] Dr. A. Mokhtarzadeh

Immunology Research Center, Tabriz University of Medical Sciences, Tabriz, Iran

E-mail: mokhtarzadehah@ tbzmed.ac.ir

[*] Dr. M.-A. Shahbazi

Drug Research Program, Division of Pharmaceutical Chemistry and Technology, Faculty of Pharmacy, University of Helsinki, FI-00014 Helsinki, Finland

E-mail: m.a.shahbazi@helsinki.fi

[*] Dr. M.-A. Shahbazi

Zanjan Pharmaceutical Nanotechnology Research Center (ZPNRC), Zanjan University of Medical Sciences, 45139-56184 Zanjan, Iran

E-mail: m.a.shahbazi@helsinki.fi

Keywords: Nanoparticles; Biomimetic, Immune cell membrane; Macrophages; Neutrophils; T cells 


\title{
WILEY-VCH
}

\begin{abstract}
Nanotechnology has provided great opportunities for managing neoplastic conditions at various levels, from preventive and diagnostic to therapeutic fields. However, when it comes to clinical application, nanoparticles (NPs) have some limitations in terms of biological stability, poor targeting, and rapid clearance from the body. Therefore, biomimetic approaches, utilizing immune cell membranes, have been proposed to solve these issues. For example, macrophage or neutrophil cell membrane coated NPs have been developed with the ability to interact with tumor tissue to suppress cancer progression and metastasis. The functionality of these particles largely depends on the surface proteins of the immune cells and their preserved function during membrane extraction and coating process on the NPs. Proteins on the outer surface of immune cells can render a wide range of activities to the NPs, including prolonged blood circulation, remarkable competency in recognizing antigens for enhanced targeting, better cellular interactions, gradual drug release, and reduced toxicity in vivo toxicity. In this review, nanobased systems coated with immune cells-derived membranous layers, their detailed production process, and the applicability of these biomimetic systems in cancer treatment are discussed. In addition, future perspectives and challenges for their clinical translation are also presented.
\end{abstract}




\section{WILEY-VCH}

\section{Introduction}

Cancer is one of the preeminent causes of morbidity and mortality across the world, with a remarkable burden and strain on individuals and communities (WHO). Several conventional and novel modalities have been employed in recent decades to overcome these conditions, depending on the type of cancer and how advanced it is. Meanwhile, the endless incidence of cancer advocates for the fast and novel techniques underpinning effective cancer therapy programs. Thereon, the advent of nanoparticle-based drug delivery systems (NDDSs) in recent years has inaugurated a new area in cancer theranostics through targeted drug delivery. ${ }^{[2-7]}$ NDDS strategies have gained considerable attention compared to conventional therapeutic and diagnostic approaches, but artificially synthesized nanoparticles (NPs) come with inherent limitations, including rapid clearance from blood circulation and poor ability to overcome physiological barriers, ${ }^{[8]}$ which hinder efficient site-specific targeting of tumor cells. Besides these, bioavailability concerns, toxicological outcomes, and budgetary considerations ${ }^{[9-11]}$ necessitate next-generation techniques in this field.

In recent years, most of the novel therapeutic approaches have exploited the enhanced permeability and retention (EPR) effect ${ }^{[12]}$ due to abnormalities of tumor vasculature. ${ }^{[9,13]} \mathrm{EPR}$ effect is characterized by the elevated release of vascular endothelial growth factors (VEGFs), hypervascularity, aberrant vascular architecture, and lack of lymphatic drainage. ${ }^{[14,15]}$ Such an effect allows nanoparticles to passively target the tumor and selectively expand permeation of macromolecules and NPs to the tumor stroma, while they are retained in the tumor due to the lack of lymphatic drainage. ${ }^{[16,17]}$ This EPR effect is intrinsically affected by some factors including angiogenesis, lymphangiogenesis, perivascular tumor growth, stromal response, intratumor pressure, structural disorganization, abnormal fenestrations, serpentine structure, 


\section{WILEY-VCH}

irregular branching, irregular perfusion, uneven distribution density, impaired lymphatic drainage, permeability enhancing factors (PEFs) and also characteristics of nanocarriers. ${ }^{[17-23]}$ Although the EPR-based passive targeting has been a pillar for the evolution of macromolecular anticancer therapy, it is applicable only for macromolecules larger than $40 \mathrm{kD}^{[17]}$ and, thereby, there is a need for alternative approaches for smaller drugs to gain long circulation, active targeting, and more efficient drug delivery ${ }^{[24,25]}$.

To straighten out these drawbacks, the application of cell membrane coated nanoparticles (NPs) is a novel strategy for drug delivery in which NPs are coated and/or camouflaged with cell membranes for the effective delivery of therapeutic agents. Hence, most of the newly developed modalities are largely focus on active targeting to achieve more efficient delivery of drugs, genes, and theranostics to the sites of interest as well as elevated quantity of drug accumulation in the target cell(s). ${ }^{[17,26]}$ Active targeting is through the coating and/or camouflaging of nanoparticles and nanocarriers with cell membranes, and particularly with ligands such as antibodies (e.g., a-Herceptin and Rituxan), ${ }^{[27]}$ peptides (e.g., a-RGD and b-NGR), nucleic acids, aptamers, ${ }^{[28,29]}$ folic acid (FA), b-CD19, a-Transferrin LHRH, a-Pegaptanib, a-Folate, and bGalactose ${ }^{[17]}$ aiming to enhance specific binding to receptors overexpressed in the tumor microenvironment (TME). Several receptors have been reported to be utilized for active targeting applications, including TfR, nAChRs, HER2, CD20, CD19 antigen, av $\beta 3$ integrin, Aminopeptidase N, folate receptors (FAR), Asialoglyco-protein receptor, LHRH receptor, and VEGF receptor. ${ }^{[17]}$ With an elevated affinity for the surface of target cells, active targeting enhances penetration and accumulation of drugs in TME.

Despite considerable progressions reported in the literature, in modern applications, NPs are camouflaged mainly with cellular membranes. This allows researchers and therapists to work 


\section{WILEY-VCH}

with nanoparticles exhibiting cell-like behaviors. From the literature, it is well established that biomimetic functionalization of NPs and other materials can resolve many problems in medical settings. ${ }^{[30-35]}$ This allows researchers to propose new strategies by imitating biological solutions at macro and nanoscales. In the field of cancer therapy, the surface of NPs is modified by cell membranes to provide NPs with improved biointerfacing properties and reach efficient drug delivery. ${ }^{[36]}$ The overlaid cell layer imitates the antigenic diversity of the source cells and, thereby, provides a range of source cells related-functions, including immune evasion, long circulation, efficient drug delivery, and active targeting. ${ }^{[37-40]}$ Camouflaged NPs can evade the reticuloendothelial system (RES), which enhances the blood circulation time of NPs and allows them to reach their target. ${ }^{[38]}$ Also, cell membrane-cloaked NPs can exhibit complex biointerfacing functions. Different source cells are used for this purpose, including non-nucleated cells (erythrocytes and platelets), prokaryotes, and eukaryotes (e.g., leukocytes), which are coated onto NPs by co-extrusion, extrusion/sonication, freeze-thaw/sonication, extrusion/sonication and stirring, and more. ${ }^{[38]}$ Recently, Cancer immunotherapy has received increasing attention in order to achieve promising clinical success. ${ }^{[41]}$

Leukocytes, also known as white blood cells, are the largest blood cells with a diameter ranging from 7 (small lymphocytes) to $20 \mu \mathrm{m}$ (monocytes). In order to fulfill their duties which, include migrating to inflamed extravascular sites and eradicating pathogens, leukocytes are capable of amoeboid movements and passing through blood vessels. Overall, to ensure intact and timely responses to any invasion, numerous leukocytes are generally present in the blood, as well as secondary lymphoid tissues and potentially any prone part of the body. On the other hand, chronic inflammation is a characteristic feature of neoplasms. ${ }^{[42]}$ It has been asserted that inflammatory cells (e.g., macrophages, dendritic cells, granulocytes, mast cells, and 


\section{WILEY-VCH}

lymphocytes) have key roles in the development and progression of cancerous lesions. ${ }^{[43]}$ Generally, many leukocytes are tricked by tumor cells and recruited to tumor sites (partly via the effects of tumor-derived chemotactic mediators that modulate the function of leukocytes), which then these leukocytes contribute to cancer progression. ${ }^{[44]}$ For example, it has been shown that tumor-recruited macrophages or fibroblasts may assist tumor growth and facilitate the development of metastasis and neovascularization. Despite this, leukocytes have shown the potential to be employed as excellent carriers for targeted delivery of drugs to tumors secondary to this inflammatory chemotactic phenomenon. In this regard, using the nanoparticles (NPs) incorporated with leukocyte-derived membranes has been promising in the field of targeted immunotherapy. ${ }^{[37,45,46]}$

In the present review, we aim to prepare a comprehensive survey of immune cells membranecoated NPs for tumor-targeted chemotherapy, with an especial reflection on leukocytes. We first describe cell-specific targeting with cell membrane coating to ascertain types of NPs, membrane derivation methods, core particles, and their applications in medical settings. Then we discuss preparation methods and their characterizations and describe the principle of various cell membrane coating processes, including isolation of the cell membrane, coating of cell membrane onto NPs, and in vitro verification of cell-membrane cloaked NPs. Finally, we focus on cellular and molecular mechanisms involved in tumor targeting by leukocytes, namely, macrophages, monocytes, neutrophils, T-cells, dendritic cells. The paper is concluded with potential future trends for these newly-developed strategies. 


\section{WILEY-VCH}

\section{Cell-specific targeting via cell membrane coating}

Nanoparticles (NPs) are broadly used in diagnostic and therapeutic applications. They exhibit considerable potential in chemotherapy, photothermal therapy (PTT), detection of circulating tumor cells (CTCs), radiotherapy (RT), diagnostic imaging, drug delivery, photodynamic therapy, nucleic acid delivery, implantable devices, atherosclerosis therapy, heart repair, cancer vaccination, immunotherapy, tissue engineering, and HIV therapy ${ }^{[47-56]}$. After entering the body, however, NPs face multiple barriers, including rapid recognition as a foreign agent by inducing immune responses, fast degradation and elimination from the bloodstream, limited biocompatibility and elevated cytotoxicity, and quick uptake by the reticuloendothelial system (RES). For effective drug delivery, NPs must remain durable in the bloodstream, escape from mononuclear phagocyte system (MPS) and RES clearance, accumulate in TME, penetrate the TME or tumor interstitial fluid (TIF), enter the active site, and interact with the target cells. ${ }^{[17]}$ There have been several synthetic and non-synthetic carriers proposed thus far, but in today's applications, most of the attention is toward using live cells and cell derivatives. Hence, researchers are excited to design and develop NPs showing more cell-like behavior. This is achieved by decorating NPs with the source cell membrane, which enhances specific interaction with the environment, improves specific targeting, overcoming bio-adhesion in the bloodstream, and grants biocompatibility, long circulation time, and preferential accumulation in TME. ${ }^{[17,38,57}$, 58]

Cell membrane coated NPs are made of a core NP decorated with a cell membrane. Several types of NPs are used as a core (Table 1). For instance, we can highlight micelles (for hydrophobic drugs) and liposomes (for hydrophilic drugs). Micelles can easily form a monolayer vesicle in aqueous solutions with a hydrophobic core. When the concentration of drug-carrying micelle drop below the critical micelle concentration (CMC), micelle disassembles, and releases its drugs. ${ }^{[59]}$ 


\section{WILEY-VCH}

However, micelles come with some limitations. For instance, they can lead to cytotoxicity due to using complementary polymers for increased micelle stability and possible immunological obstacles. ${ }^{[60]}$ Also, they undergo rapid clearance by phagocytosis and are not efficient enough to target cells. ${ }^{[59]}$

Liposomes are vesicular structures having bilayer membranes, and thereby have some applications to deliver hydrophilic drugs. ${ }^{[59,61]}$ In medical settings, liposomes are designed to load drugs and control the rate of drug release, avoid rapid clearance from the bloodstream, intracellular delivery and triggered the release of drugs, nucleic acids, receptor-mediated endocytosis of ligand-targeted liposomes, site-avoidance delivery, site-specific targeting, sustained drug delivery and release, and intraperitoneal administration. ${ }^{[61]}$ The membrane of liposomes can be decorated with chemical molecules, enzymes, aptamers, and antibodies for specific targeting. ${ }^{[59,62]}$

Despite considerable progress with synthetic vesicles, in today's applications, cells and their derivatives are of great importance due to special features. Immune cells, for instance, are a promising choice because they make the immune system and do not cause adverse immune responses. Also, they show minimal interactions with normal cells, actively target cells and sites of interest, and therefore, attributes-higher biocompatibility. ${ }^{[59]}$ 


\section{WILEY-VCH}

Table 1. Various immune cell membrane camouflaged NPs applied in cancer therapy.

\begin{tabular}{|c|c|c|c|c|c|c|}
\hline Source cell & $\begin{array}{c}\text { Cell membrane } \\
\text { separation }\end{array}$ & $\begin{array}{c}\text { Core } \\
\text { nanoparticle }\end{array}$ & Application & Properties & Limitations & Ref. \\
\hline Macrophage & $\begin{array}{l}\text { Hypotonic lysis and } \\
\text { extrusion }\end{array}$ & $\begin{array}{l}\text { Upconverting } \\
\text { nanoparticles } \\
\text { (UCNPs); Au } \\
\text { nanoshells } \\
\text { coated } \\
\text { mesoporous } \\
\text { silica NPs; } \\
\text { Liposomes with } \\
\text { emtansine; } \\
\text { Targeting } \\
\text { polymer } \\
\text { conjugated with } \\
\text { insulin. }\end{array}$ & $\begin{array}{l}\text { Effective cancer } \\
\text { imaging; Enhanced } \\
\text { cancer photothermal } \\
\text { therapy; Specific } \\
\text { metastasis targeting; } \\
\text { Tumor targeted } \\
\text { chemotherapy }\end{array}$ & $\begin{array}{l}\text { Efficient cell-mediated drug } \\
\text { delivery }\end{array}$ & $\begin{array}{l}\text { Tissue-resident } \\
\text { macrophages } \\
\text { limitation. In addition, } \\
\text { for M1 type } \\
\text { macrophages, the } \\
\text { specific induction } \\
\text { remains challenge. }\end{array}$ & $\begin{array}{l}{[38,59,63-} \\
67]\end{array}$ \\
\hline Platelet & $\begin{array}{l}\text { Repeated freeze-thaw } \\
\text { followed by sonication; } \\
\text { sonication }\end{array}$ & $\begin{array}{l}\text { PLGA NPs; } \\
\text { Verteporfin } \\
\text { loaded PLGA } \\
\text { NPs; Docetaxel } \\
\text { and Vancomycin } \\
\text { loaded PLGA } \\
\text { NPs; Si NPs; } \\
\text { DOX loaded } \\
\text { Melanin NPs; } \\
\text { Magnetic NPs; }\end{array}$ & $\begin{array}{l}\text { Cancer targeted } \\
\text { delivery; Cancer } \\
\text { therapy; } \\
\text { Photodynamic } \\
\text { therapy; } \\
\text { Phototherapy; Cancer } \\
\text { therapy; Disease } \\
\text { treatment; Multiple } \\
\text { myeloma therapy; } \\
\text { Atherosclerosis }\end{array}$ & $\begin{array}{l}\text { Adhere to the pathogen to kill } \\
\text { them; Affinity to cancer cell; } \\
\text { Bone binding; Myeloma cell- } \\
\text { selective module; Targeting to } \\
\text { plaque; Accumulating in injured } \\
\text { tissue; Homing to plaques; } \\
\text { Infract-homing ability; Long } \\
\text { systemic circulation (around 7-10 } \\
\text { days); Immune evasion; Survey } \\
\text { for damage; Expresses of CD47, }\end{array}$ & $\begin{array}{l}\text { Small proportion of } \\
\text { blood; Undesirable } \\
\text { activation }\end{array}$ & $\begin{array}{l}{[38,63,64,} \\
68-71]\end{array}$ \\
\hline
\end{tabular}


WILEY-VCH

\begin{tabular}{|c|c|c|c|c|c|c|}
\hline & & $\begin{array}{l}\text { Dextran; } \\
\text { Nanogel; } \mathrm{Au} \\
\text { NPs. }\end{array}$ & therapy; Heart repair & $\begin{array}{l}\text { CD55, and CD59; Attaching at } \\
\text { tumor sites; Self-aggregation. }\end{array}$ & & \\
\hline Neutrophil & $\begin{array}{l}\text { Precoll gradient } \\
\text { separation followed by } \\
\text { emulsion/ solvent } \\
\text { evaporation }\end{array}$ & $\begin{array}{l}\text { Carfilzomib } \\
\text { loaded PLGA } \\
\text { NPs }\end{array}$ & $\begin{array}{l}\text { Targeting circulating } \\
\text { tumor cells (CTCs) } \\
\text { and premetastatic } \\
\text { niche }\end{array}$ & $\begin{array}{l}\text { Efficient cellular immunity in } \\
4 \mathrm{~T} 1 \text { bearing mice } \\
\text { High in vivo CTC-capturing } \\
\text { efficiency } \\
\text { Selective depletion of blood } \\
\text { CTCs } \\
\text { Preventing the formation of new } \\
\text { metastatic lesions and the } \\
\text { progression of previously-formed } \\
\text { nodules } \\
\text { Preventing the formation of } \\
\text { metastatic niches by depleting } \\
\text { circulatory CTCs }\end{array}$ & $\begin{array}{l}\text { An important question } \\
\text { needs to be answered } \\
\text { (e.g., what is the best } \\
\text { time for delivering the } \\
\text { coated NPs for higher } \\
\text { targeting of infiltered } \\
\text { neutrophil? } \\
\text { Researches are } \\
\text { needed for } \\
\text { understanding the } \\
\text { dynamics of } \\
\text { neutrophil for } \\
\text { efficient delivery. }\end{array}$ & $\begin{array}{l}{[38,63,64,} \\
72]\end{array}$ \\
\hline NK cell & Extrusion & $\begin{array}{l}\text { DOX loaded } \\
\text { fusogenic } \\
\text { liposomes }\end{array}$ & $\begin{array}{l}\text { Targeted drug } \\
\text { delivery }\end{array}$ & & $\begin{array}{l}\text { The imperfect ability } \\
\text { of NK cells to reach } \\
\text { solid tumors. } \\
\text { The capacity of } \\
\text { different tumors to } \\
\text { escape NK cells } \\
\text { control. }\end{array}$ & $\begin{array}{l}{[38,63,64,} \\
67,73]\end{array}$ \\
\hline & $\begin{array}{l}\text { Hypotonic lysis and } \\
\text { extrusion }\end{array}$ & $\begin{array}{l}\text { PTX loaded } \\
\text { PLGA NPs }\end{array}$ & $\begin{array}{l}\text { Drug delivery and } \\
\text { enhanced tumor }\end{array}$ & $\begin{array}{l}\text { Potential artificial carriers to } \\
\text { promote the efficiency of }\end{array}$ & $\begin{array}{l}\text { Cytotoxic T Cell } \\
\text { cannot kill target cells }\end{array}$ & $\begin{array}{l}{[63,64,67,} \\
74-77]\end{array}$ \\
\hline
\end{tabular}




\section{WILEY-VCH}

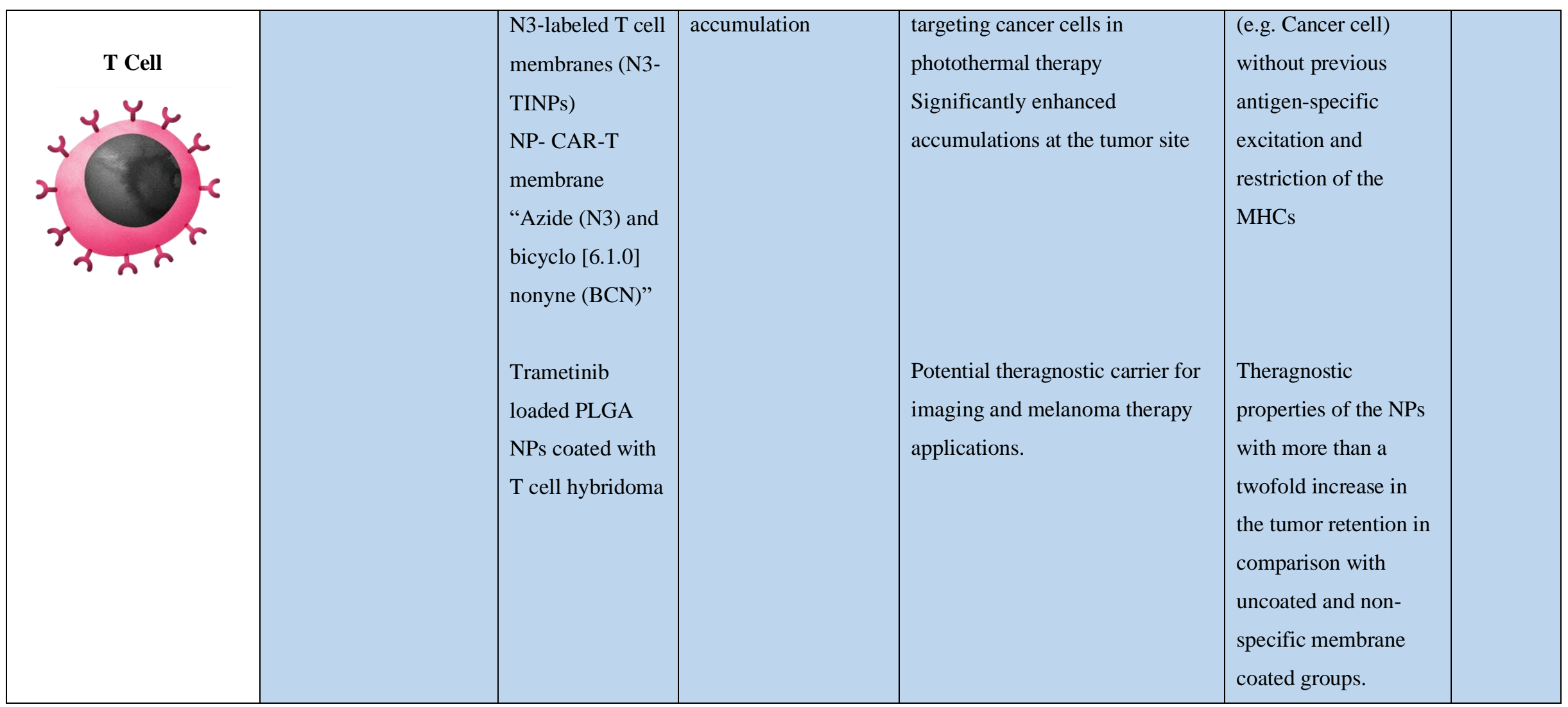




\section{WILEY-VCH}

Macrophages, $\mathrm{T}$ cells, platelets, RBCs, stem cells, exosomes, ${ }^{[78,}{ }^{79]}$ adipocytes, ${ }^{[80,}{ }^{81]}$ and leukocytes are amongst different source cells applied in targeted drug delivery. RBCs show long circulation life and hence provide prolonged circulation; they also can evade the immune system due to the existence of self-marker on their surfaces. Platelets can bind injured blood vasculature and stick to pathogens to kill them, and show immune-compatibility features. Leukocytes can evade the immune system and show target tissue localization property and act through cell-cell interactions. Macrophages act in TME and directly affect tumor progression and metastasis. Macrophage-camouflaged NPs facilitate cell-cell adhesion. Neutrophils can pass freely across tissues and walls of veins and target cancer cells. Natural killer (NK) cells are directly bound to activating and inhibitory receptors on the surface of the cancer cells and can kill them without prior sensitization. ${ }^{[82]}$ Table 1 provides information on different source cells, methods of separating cell membranes, and core nanoparticles coated by cell membranes.

\section{Preparation Methods, Coating, and Characterizations}

Cell disruption or lysis is a pivotal step to extract cell membrane vesicles from the source cells. It is performed by disrupting parts of the cell wall or the complete cell to prepare lysate (a fluid containing all the materials formed by the lysis of cells). Cell lysis protocols are classified into two main classes, including chemical and gentle cell lysis methods (e.g., osmotic and chemical lysis, temperature treatments) and more rigid protocols (e.g., mechanical, ultrasonic, pressure homogenization, mortal and pistil, and pipetting using a very narrow pipette) ${ }^{[83-92]}$ Chemical lysis uses lysis buffers, detergents, $\mathrm{pH}$, salts, and enzymes for cell lysis and does not require grinding or scraping. There are many factors to consider when choosing a cell lysis technique. It mainly depends on the cell type. For instance, hypotonic treatment/extrusion, sonication, 


\section{WILEY-VCH}

hypotonic treatment/sonication, microfluidic electroporation, and sonication/extrusion are amongst protocols proposed in the literature to extract cell membranes from RBCs (erythrocytes). Or repeated freeze-thaw followed by sonication, sonication has been used for the extraction of cell membrane vesicles from platelets. Table 1 summarizes widely used protocols and methods of extraction of cell membrane vesicles from different source cells. The second factor is the nature and location of the proteins of interest. Membrane proteins (e.g., integral, peripheral, and lipid-anchored proteins) account for around a third of the proteins in living organisms. Most extraction protocols intend to obtain a cell membrane with proteins in their native form, intact, and with full functionality. Mechanical lysis is usually recommended for large cell pellets or pieces of tissue. Mechanical homogenization uses direct physical force to provide lysate, either by freezing tissues and then grinding with a mortar and pestle (conventionally) or through bead-based and/or rotor-stator disruption. ${ }^{\text {[93-95] }}$

Once the cell membrane was extracted from the source cell, the second step is coating the cell membrane vesicle onto NPs. The aim is to provide NPs with enhanced biointerfacing capabilities. Different methods have been proposed for coating in recent years. One of the widely used methods is performed through physical extrusion by co-extruding NPs cores and purified membrane via a porous membrane. Sonication-based approaches are another choice, where a disruptive force provided by ultrasonic energy is applied to two components to form a core-shell nanostructure. A microfluidic system ${ }^{[96]}$ and in situ covering of NPs using live cells ${ }^{[97]}$ are also amongst techniques proposed.

The final step includes characteristic analyses to understand the unique properties of membranecoated NPs. Characterizations of biological and physiological functions on coated NPs are important before biological evaluation. The cell membranes can be differentiated from core NPs 


\section{WILEY-VCH}

in electron density, permeability, surface charge, and protein composition that allows determining if the cell membranes have been coated on the NPs or not.

In the following sections, drawing on the literature, we discuss some of the most broadly used cell disruption techniques, the coating methods, characterization approaches, as well as their applications (Figure 1). 


\section{WILEY-VCH}

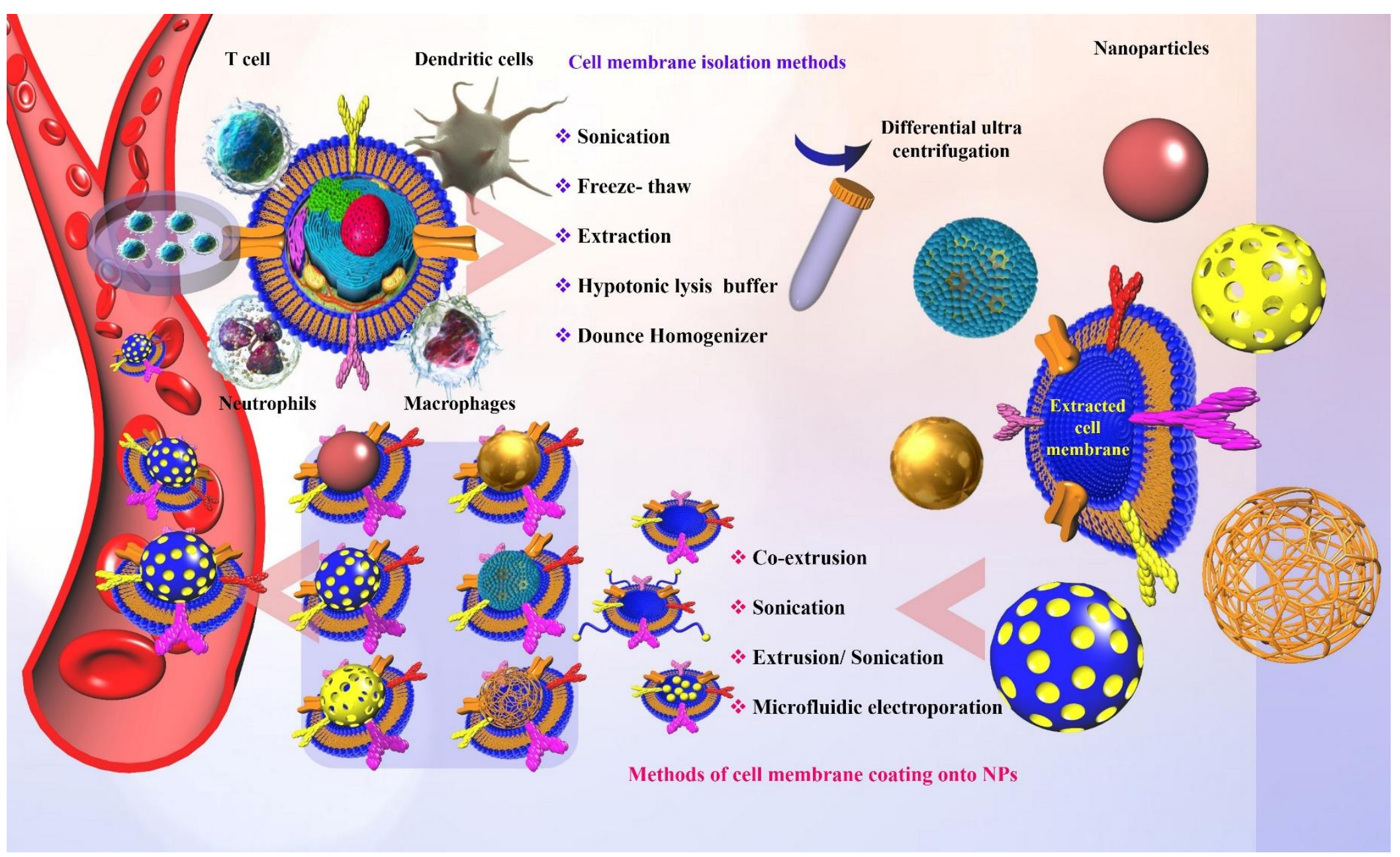

Figure 1. Different source immune cells and various types of NPs formed via camouflaging different cell membranes. First, immune cell membranes are isolated from blood or their other sources and then extruded to obtain membrane vesicles. Finally, the vesicles fuse with core NPs to form membrane-camouflaged NPs. 


\section{WILEY-VCH}

\subsection{Cell membrane isolation methods}

\subsubsection{Sonication}

Sonication is the process of applying sound energy for agitating the cells and their components, mainly through using ultrasonic frequencies ranging from 20 to $50 \mathrm{kHz}$. Simply, it applies an ultrasonic bath or probe sonicator to use sound energy to a liquid containing cells of interest. Depending on the frequency applied, propagated waves produce alternate cycles of compression (high pressure) and rarefaction (low pressure). ${ }^{[98]}$ During rarefaction cycles, small empty bubbles (also known as small vapor-filled cavities or voids) are generated in the liquid by highly intense ultrasonic waves. At the threshold, i.e., when bubbles were no longer capable of absorbing energy applied, they collapse abruptly during compression cycles through cavitation. Cavitation refers to the formation of bubbles in liquid flow upon rapid changes of pressure. When such bubbles are subjected to the compression cycle, the formation of a strong shock wave (inertial or transient cavitation ${ }^{[99]}$ and also micro-jets of up to $1000 \mathrm{~km} / \mathrm{h}$ will be the result. ${ }^{[98]}$ During sonication, electronic sound energy is generated by the power source attached to the sonicator. Such energy is converted to mechanical energy, which traverses the metal prob inserted into the (cell containing) sample or through the water in an ultrasonic bath. Thereby, the process of cavitation causes cell rupture and cell lysis. Sonication results in an impressive temperature of around $5000 \mathrm{~K}$ and pressures of up to around 2000 atm. ${ }^{[98]}$ Cavity collapse inflicts high- speed bursts of liquid to the cell surfaces and causes damage to the already heated cells. Acoustic droplet vaporization (ADV) refers to the vaporization of a superheated droplet emulsion into gas bubbles through ultrasonic. ${ }^{[99]}$ In recent years, ADV has been used for embolotherapy, drug delivery, ultrasonic diagnostics and imaging, transdermal non-invasive drug delivery, therapeutics, thermal therapy, and histotripsy. ${ }^{[99-102]}$ 


\section{WILEY-VCH}

Despite widespread application in medical settings, sonication comes with some shortcomings, including heating samples, potential variations in yield, and the generation of free radicals. This technique is used for the rapid homogenization of samples, but the power and frequency applied, as well as the duration of the process, should be carefully determined to avoid any irreversible sample damage. Additionally, ultrasonic homogenization can alter the molecular make-up of the solution during sonication. High energy also can heat samples and result in the denaturation of proteins, which could be decreased by using ice-cold lysis buffers. Hence, the duration, wattage, and frequency applied for ultrasonic homogenization are influential factors which shall be specially considered.

\subsubsection{Freeze \& Thaw}

The freeze-thaw process is performed by subjecting the sample suspension to multiple cycles of freezing (in ethanol bath or dry ice) and then thawing (at $37^{\circ} \mathrm{C}$ or room temperature). During this process, the cells swell along with the formation of ice crystals and then contract during thawing. This leads the cell walls to ultimately give in and break. This process is a mild homogenization and usually is used with other homogenization protocols. Usually, two or three cycles of freezing and thawing are required for desired cell disruption. However, it can affect the

activity of some sensitive enzymes. ${ }^{[103]}$ Also, subjecting proteins to freezing and thawing can cause protein damage and cryoconcentration.

\subsubsection{Extrusion}

Extrusion is a widely used forming process in which a material with a large cross-sectional area is reduced to a smaller one by pushing it through a die of the desired cross-section. For instance, it is used for nanosizing liposomes ${ }^{[104]}$ by pushing liposomal suspension through the membrane 


\section{WILEY-VCH}

filter embedded on the extrusion apparatus. In this case, applied pressure, number of cycles, and pore size are factors affecting the mean diameter and size distribution of extruded liposomes. Extrudates (the products of extrusion) can be formed under hot or cold settings. Hot extrusion is performed under elevated temperatures (i.e., above the material's recrystallization temperature) to allow for easier pushing the material through the die. Cold extrusion is performed at room temperature or near room temperature. Hot-melt extrusion (HME) has shown considerable potential in the pharmaceutical industry. ${ }^{[105]}$ Plasticizers, fillers, $\mathrm{pH}$ and release modifiers, stabilizers, surfactants, antioxidants, and processing aids are excipients that can be included in the powder blend and extruded. Such excipients are forced through a die under controlled conditions to be converted into products of uniform shape and density. The molten excipient functions as a thermal binder and release retardants upon cooling and solidification of the extrudate. Suspended drug particles are avoided from aggregation in the molten excipient through strong mixing and agitation by the rotating screws to gain a more uniform dispersion of

drug particles. ${ }^{[105]}$ HME is an anhydrous process with fewer processing steps that improve bioavailability by dispersing drugs at the molecular level in the final dosage forms. In recent years it has been used in combination with nanotechnology, powder coating, and complexation, ${ }^{[105]}$ mainly for oral drug delivery (due to rapid, immediate, enteric, sustained, controlled, and targeted release), trans-drug delivery (transdermal, transmucosal, and transungual drug deliveries), and implants. ${ }^{[105-108]}$

\subsubsection{Hypotonic Lysis Buffer}

A hypotonic solution contains a fewer concentration of impermeable solutes than the solution on the other side of the membrane. When the cytoplasm of a cell is more hypotonic than the 


\section{WILEY-VCH}

surrounding environment, then water will be drawn out of the cytoplasm. Lysis will occur if water molecules continue to diffuse into the cell that it causes cell swelling. Lysis buffer is a buffer solution for breaking cells, mainly containing buffering salts (e.g., Tris-HCl) and ionic salts (e.g., $\mathrm{NaCl}$ ) for regulating the $\mathrm{pH}$ and osmolarity of the lysate. It might also contain detergents (e.g., Triton X-100 or SDS) for breaking up membrane structure and/or protease inhibitors (in the case of extracting proteins). The type of lysis buffer used depends on the types and source of cells (tissue culture, plant, bacteria, fungi, etc.), the desired final molecule or structure, and the level of their functionality. Most lysis buffers contain one or more detergents. The choice of detergent is usually determined empirically. Frequently nonionic or zwitterionic detergents are used in the cell lysis buffers (like deoxycholate, Triton ${ }^{\mathrm{TM}}$ X-100, NP40, and Tween 20). For the extraction of nucleic acids, the lysis buffer commonly contains SDS. Hypotonic lysis buffer (10 mM Tris- $\mathrm{HCl}, \mathrm{pH} 7.5)$ is a detergent-free, ready-to-use solution for cell lysis and subsequent isolation of the crude cytoplasmic fraction. It is performed by resuspending the cell pellets in hypotonic lysis buffer and incubating on ice for 15 minutes, followed by disrupting the cell through homogenization and pelleting the cellular debris to finally reach a supernatant containing the crude cytoplasmic extract. The protocol is compatible with a variety of downstream applications (e.g., Western blotting, ELISA procedures, and protein assays) and is performed simply.

In conventional applications, ${ }^{[109]}$ for example, erythrocytes were exposed to a $0.4 \% \mathrm{NaCl}$ hypotonic solution to remove cellular contents in the exchange of hypotonic solution containing desired drugs.

\subsubsection{Dounce Homogenizer}




\section{WILEY-VCH}

Homogenization (micronization or particle size reduction) is the process of decreasing particle size to a microscopic diameter to facilitate the desire emulsions and dispersions. Dounce homogenizer (also named as tissue grinder) ${ }^{[110]}$ is a cylindrical glass tube with two glass pestles designed for gentle homogenization of eukaryotic cells and isolation of cellular organelles.

Dounce homogenizers are particularly used in enzyme studies where heat build-up needs to be avoided. Pestles have different diameters. Soft tissue is broken into smaller pieces and then placed into the glass cylinder with a suitable volume of an appropriate lysis buffer. Homogenization is performed by a defined number of passes of the pestles, first with loose (A) pestle, and then with tight (B) pestle, up and down the cylinder, normally with five to ten passes. The "B" pestle is tightly fitted within the shaft of the dounce that allows for maximum friction and cell disruption, while the "A" pestle has a looser fit and works suitable to create a homogenous sample. The lysis of adherent and suspension cells can be facilitated by combining dounce homogenization with hypotonic buffers, where the addition of hypotonic buffer causes the cell's cytoplasm to swell and allows for gentle rupture of the cell membrane by mechanical force. ${ }^{[111]}$

\subsection{Methods of immune cell membrane coating onto nanoparticles}

After preparation, the membrane and the inner core NPs must be merged to obtain a membranecoated core and form cell membrane biomimetic NPs. Several methods have been proposed for the preparation of cell-membrane coated NPs. Amongst the proposed approaches, coextrusion (by mechanical force), extrusion/sonication and freeze-thaw/ sonication (by ultrasonic energy), extrusion/ sonication and stirring (by ultrasonic energy/ endocytosis and exocytosis), extrusion/electroporation and extrusion/microfluidic electroporation (by electric pulse), and in 


\section{WILEY-VCH}

situ packaging (by natural endocytosis \& exocytosis) ${ }^{[38]}$ have been widely established. Here we summarize the most commonly used methods of cell-membrane coating onto NPs.

\subsubsection{Co-extrusion}

Co-extrusion (or co-injection) is performed by using an extruder and an auxiliary system to obtain a single product from two distinct materials, where one material is extruded and continuously filled with another. However, some products are produced by the so-called "true co-extrusion" that works by using two extruders attached for the simultaneous extruding of two products into a single product. In clinical applications, prepared NPs are fused with membranes through mechanical extrusion. Before bath sonication, the "NP-membrane" mixture is regularly extruded through size-varying porous membranes for several minutes. NPs are passed through a lipid bilayer to achieve the vesicle-particle fusion. Following several extrusions, the surplus vesicles are centrifuged and discarded, and precipitates are collected, then these precipitates are

used as final products. ${ }^{[112]}$ Co-extrusion has been used for coating NPs with RBCs (e.g., on PLGA, AuNP, Mesoporous silica, $\mathrm{Cu}_{2}-\mathrm{xSe}$, upconversion NP, and nano drugs), platelets (on magnetic NPs), cancer cells (on PLGA, gold NPs, and PGL), stem cells (on gelatin NPs), and immune cells (on liposome and PLGA). ${ }^{[38]}$ Very recently, co-extrusion has been used for the preparation of erythrocyte membrane camouflaged anti-cancer drug delivery systems ${ }^{[113]}$ where red blood cell membrane-derived vesicles (RDVs) have been coated on poly (acrylic acid)cystamine hydrochloride-D- $\alpha$-tocopherol succinate (PAAssVES) NPs. In this application, polycarbonate membranes were used to prepare homogenous, uniform, and co-extruded mixtures of RDVs and sorafenib (SFN)-PAAssVES NPs. In another application, CCM vesicles derived from MDA-MB-231 breast cancer cells were applied for the co-extrusion and coating of TOPSi 


\section{WILEY-VCH}

NPs in which were engulfed in the polymeric particles of either AcDEX or SpAcDEX ${ }^{[64]}$ Coextrusion is widely used for the preparation of synthetic liposomes ${ }^{[38]}$ where the mechanical force applied collapses the membrane integrity and allow it to be reconstructed around the NP core. Using multilayer co-extrusion and multiplication methodologies and applying [polystyrene/polypropylene (PS/PP) and polypropylene/nylon 6 (PP/PA6)] polymeric pairs, cellular membranes with two domains of several layers each consisting of numerous (up to thousands) altering layers have been produced uniaxially (delivering narrow pore size) and biaxially (delivering narrow pore size). ${ }^{[14]}$ The capability of making multi-layer and multifunctional structures, reduction in the number of steps, and providing targeted performance by using definite membranes are amongst the advantages of the co-extrusion technology.

\subsubsection{Sonication/extrusion}

Extrusion/sonication has been used for coating NPs with RBCs (on PLGA and metal-organic framework), stem cells, platelet and platelet/RBCs (on PLGA), cancer cell (on liposome and mesoporous silica NPs), and immune cells (on PLGA). ${ }^{[38]}$ The core NP and cell membrane are subjected to the disrupting force of ultrasonic energy and then are simultaneously formed into a core-shell nanostructure. This method confers some advantages. ${ }^{[38]}$ First of all, the product is compatible with the properties of the NPs synthesized by physical extrusion, and there is low material waste. Second, we can use several membranes simultaneously by adopting multiple cell membrane fusion techniques and thereby incorporate functionalities of several cell types. Third, combinations of membranes (with features such as stability and charge asymmetry) and NPs (which can confer structural stability) can be used to reach a configuration with an appropriate (right-side-out) membrane orientation and optimal energetics. In an effort to overcome the 


\section{WILEY-VCH}

problem of heterogeneity of biomembranes when preparing PLGA-NPs coated with lipids, or membranes from either exosome (EM) or cancer cells (CCM), NPs were filled with imaging substances applying a relatively easy microfluidic sonication-based method ${ }^{[15]}$ which in comparison with CCM-PLGA NPs which had similar specifications (size, core structure, etc.) delivered a more proficient homotypic targeting due to incorporating endosomal and plasma membrane proteins which have been incorporated into their structure.

\subsubsection{Microfluidic electroporation}

Recently, the potential of microfluidic electroporation to present an optimal strategy to produce cell-based CM-NPs has been evaluated by infusing $\mathrm{Fe}_{3} \mathrm{O}_{4}$ magnetic nanoparticles (MNs) and RBC-vesicles through a microfluidic device. ${ }^{[96]}$ In this system, the electric pulse facilitates the penetration of MNs into RBC-vesicles when these components are flowing through the electroporation zone. Finally, RBC membrane-capped MNs (RBC-MNs) were gathered from the chip. As stated by the authors, core-shell RBC-MNs can efficiently be used in MRI and PTT applications because of incorporating better photothermal and magnetic features of $\mathrm{MN}$ cores and higher circulatory half-life of RBC-derived membranes. The proposed system consists of two channels (one for merging ( $\mathrm{Y}$ shape) and the other for mixing ( $\mathrm{S}$ shape)), an outlet, and an electroporation segment. Components are first merged together in the merging and then enter the second channel for mixing, and finally, the zone of electroporation. The driving form for microfluidic electroporation is provided by electric pulses.

\subsubsection{Other coating methods}




\section{WILEY-VCH}

Freeze-thaw/sonication method (for coating platelet on PLGA), extrusion/sonication \& stirring (for coating platelet on nanogel and dextran), extrusion/electroporation (for coating platelet on AuNR), and in situ packaging (for coating RBC on perfluorocarbon-PLGA as well as coating cancer cell on PLGA) ${ }^{[38]}$ are other methods used for coating cell membrane on NPs. In situ packaging $^{[97]}$ is a hybrid nano-based platform with biological properties, designed to engulf a variety of NPs with different shapes and chemical features, where cells are first incubated with NPs (e.g., NPs of ferric and ferrous oxides or gold NPs, or quantum dots) and then into a culture medium without serum to secrete hybrid nanovesicles containing exogenous NPs (such as magnetic-metallic, magnetic-metallic or magnetic vesicles). As stated by the authors, we can manipulate these vesicles and monitor and imaged them by fluorescence or magnetic resonancebased procedures. Recently, extrusion has been used for fabricating tumor-specific membraneNPs applying CAR-T Cells, which the researchers isolated and used the membranes of these immune cells to coat IR780-loaded MSNs (IMs). ${ }^{[16]}$ As stated by the authors, CIMs, with great safety and effectiveness, could specifically target the tumor and showed high blood circulation time. In another work, hybrid cells were first constructed by fusing tumors and DCs to produce cytomembranes (FMs) by ultrasonic treatment. This reaction was conducted at a low temperature (in cold water) and on PCN-224, a metal-organic platform. ${ }^{[17]}$ According to the authors' opinion, FMs a full antigenic profile of tumor cells and stimulatory molecules from immune cells. These structures also are able to promote a tumor self-targeting feature coming from original tumor cells. Also, it is believed that this system can be developed to be widely used in different cancers and to incorporate a wide range of functional and immunological activities.

\subsection{In vitro verification of cell membrane coated NPs}




\section{WILEY-VCH}

The next and vital step after the successful coating of NPs with the cellular membrane is to verify the characterizations of proteins, chemical structures of the cell membrane, morphological and physicochemical properties, and other factors in vitro to ensure the correct orientation of the membrane and optimal efficiency of the coating process. Here we discuss some of the most important factors to verify the coating process in vitro.

\subsubsection{Surface morphology}

Recently, the potential of PLGA NPs to increase the infiltration capability of neutrophils and their ability to express pro-inflammatory mediators within alginate platforms has been shown in mice, ${ }^{[118]}$ a feature that was not observed with RBC-membrane coated or PLGA NPs which were able to eliminate short-term inflammatory responses. The failure of PLGA or RBC-membrane coated NPs to affect the penetrating capability of neutrophils and macrophages is presumably due to their removal via infiltrating cells. PLGA and RBCM-PLGA NPs have been subjected to analyses to characterize the surface potential and size of NPs and scaffolds in $\mathrm{H}_{2} \mathrm{O}$. Also, the morphology of particles has been imaged by TEM. From the results, the encapsulation of NPs within cell-derived membranes alters their zeta potential and size, the former being a determinant of NPs' surface charge in a colloidal solution. The surface charge of NPs enables them to attract thin layers of counter ions on their stern layer. NPs with this double layer of ions diffuse throughout the solution. The zeta potential refers to the electric potential surrounding the double layer. This potential, which can be variable within a range of $\pm 100 \mathrm{mV}$, is an important predictor of solution stability in a colloid environment. ${ }^{[119]}$ Generally, NPs with a zeta potential of more than $+30 \mathrm{mV}$ or less than $-30 \mathrm{mV}$ are highly stable. Contrarily, dispersions with a zeta potential of $<+25 \mathrm{mV}$ or $>-25 \mathrm{mV}$, which leads to the formation of various interparticle bonds (e.g., 


\section{WILEY-VCH}

hydrophobic, van der Waals, and hydrogen interactions) gradually are aggregated. Strictly speaking, this parameter estimates particles' surface potential at pre- and post-coating phases. It has been stated. ${ }^{[118]}$ that NPs' zeta potential rises about $10 \mathrm{mV}$ following coating NPs with the RBC membrane. In another study, ${ }^{[113]}$ appropriate stability $(-10.7 \mathrm{mV}$ zeta potential) has been reported for NPs covered with RDV (RDV-NPs). Furthermore, the average particle of RDV-NPs was $113.5 \mathrm{~nm}$. Furthermore, dynamic light scattering (DLS), which presents a non-invasive method to assess NPs' size distribution (from $<1$ to $500 \mathrm{~nm}$ ) in solutions or emulsions, was exploited to examine the size and potential values of NPs. Using this technique, recently, the diameter of RV-coated NPs has been reported to increase by 10 to $20 \mathrm{~nm}$, with an around $8 \mathrm{~nm}$ thickness of the bilayer lipid membrane. Also, the surface charge of NP has been reported to be close to the RVs following surface covering. ${ }^{[112]}$ Indeed, DLS is a measurement of NP size, where the size of coated NPs is increased as compared to the uncoated NPs.

\subsubsection{Verification of surface proteins}

Characteristics of surface proteins can provide coated NPs with immune escape property and allow NPs to circulate for a longer time. It is, therefore, crucial to verify that encapsulated NPs are carrying specific proteins. Characterization of proteins involves the detection, isolation, and purification of proteins and the evaluation of their structure and function. Multiple techniques have been proposed for these applications. For instance, amino acid analysis involves the quantitative determination of the protein concentration, amino acid composition, or content of proteins and peptides. Ultraviolet-visible (UV-Vis) spectroscopy is another analytical technique with high versatility. UV-Vis can be used to quantitatively detect functional groups and, therefore, the nature of materials via comparing their absorbance patterns and determine the 


\section{WILEY-VCH}

protein content of a specimen by measuring its absorption at $280 \mathrm{~nm}$. Or mass spectrometry (MS) is used as an analytical technique to measure the intact molecular weight. MS works principally based on measuring the mass-to-charge ratio $(\mathrm{m} / \mathrm{z})$ of proteins in a solution. Determining the amino acid sequence of a whole protein or its $\mathrm{N}$ - and $\mathrm{C}$ - terminal domains can be conducted by N-terminal Edman chemistry sequencing and mass spectrometry, respectively. ${ }^{[120,121]}$ Peptide mapping by chemical or enzymatic digest, RP-HPLC, and TANDEM MS (MS/MS) are other techniques used for further characterization of proteins. Electrophoresis on either one- or two-dimension (1D or 2D) polyacrylamide gels (PAGE) and blotting technology (Electro- or Western-blotting) are mainly employed for initial steps to isolate or separate proteins from other proteins, impurities, or metabolites. For instance, western blotting is used for further analysis of specific protein markers. ${ }^{[12]}$ Besides, other methods, such as liquid chromatographic techniques (e.g., reversed-phase, ion-exchange, one- or two-dimension) have been proposed. For example, by using SDS-PAGE and then Coomassie staining, it is possible to assess NPs-coated with either RV, RBCM, or RBC ${ }^{[112]}$ which all of them deliver a band pattern close to the pattern of RBCs. As demonstrated, CD235a (a glycoprotein rich in sialic acid, expressing a large part of $\mathrm{ABO}$ antigens on RBCs) presents in the electrophoretic patterns of NPs coated with RBCM and RVs. And CD47 is present on RBCs, RVs, and RBCM-coated NPs to nearly the same degree.

\subsubsection{Fluorescence colocalization}

Fluorescence microscopy is a powerful tool to monitor cell physiology and elucidate the cellular functions of proteins and other molecules. Colocalization is used to observe the spatial overlap between fluorescent labels, which each of them has a distinct emission spectrum. Indeed, 


\section{WILEY-VCH}

colocalization assesses the probability of colocalization of various targets in a similar or very close part of a cell. This technique determines the association between two molecules having the same structures, for instance, between a given protein with endosomes, mitochondria, or microtubules; also, it investigates whether two proteins are associated with the same subnuclear structures or the same plasma membrane domains. ${ }^{[122,}{ }^{123]}$ Colocalization of probes may be recognized by the appearance of structures whose color reflects the combined contribution of both probes when merging images of each probe. The superposition of fluorescence is frequently used for the evaluation of colonization. Fluorescence colocalization results can be illustrated graphically in scatterplots. In this method, the intensity of one color is plotted against the second

color for each pixel. ${ }^{[122]}$ Recently, RVs and polymeric cores were loaded with the dyes of lipophilic green rhodamine-DMPE and hydrophobic red DiD, respectively, before fusion. ${ }^{[12]}$ The which had been NPs- labeled with a dual-fluorophore then were incubated with HeLa cells for six hours. From the fluorescence microscope results, DiD and rhodamine DMPE overlaps at the same position. Also, NPs have an integrated core-shell structure following cellular internalization, indicating that the coating process of RBCM has been successfully performed.

\subsubsection{UV-vis absorption spectra}

Biomimetic camouflaged NPs can be verified by UV-vis. ${ }^{[124,125]}$ In addition to the absorption profile related to the primary NPs, biomimetic particles possess additional absorption peaks related to the membranous vesicles used in the construction of these compounds. ${ }^{[124]}$ The appearance of new absorption peaks indicates the successful incorporation of membranous vesicles with NPs, and it also shows that this process has no destructive effect on the functional bio-features of NPs for a wide variety of in vitro and in vivo studies. ${ }^{[110,124,125]}$ 


\section{WILEY-VCH}

Either a diffraction grating or a prism can be used to diffract light beams (high or low frequency, visible, UV, etc.), which is an optical component with a periodic structure for splitting and diffracting light into numerous beams that are traveling in various directions. By using a halfmirrored device, it is possible to break any monochromatic beam into two components with the same intensity. These two similar beams are 1) the one related to the sample (magenta) that goes through the target solution, which is presented along with a transparent solvent in a small cuvette the reference beam (blue) presented in the same way of the prior; however, with a solventcontaining cuvette without target sample. An electronic detector is then used to measure and compare the beams' intensities and to define I0 (generally zero absorption, the value corresponding to the reference beam) and I (the beam related to the sample). Shortly afterward, the wavelength of all components is scanned automatically by a spectrometer. The wavelengths spectra of 200 to $400 \mathrm{~nm}$ and 400 to $800 \mathrm{~nm}$ generally correspond to UV and visible light, respectively. In some cases, I can be equal to I0 (i.e., the absorption of the target sample is zero); otherwise, I value is $<\mathrm{I} 0$, which can be used to draw a curve against wavelengths on a graph. Another way to present light absorption is to use transmittance, which is calculated as a ratio of $\mathrm{I} / \mathrm{I} 0$ or as $A($ Absorbance $)=\log \mathrm{I} 0 / \mathrm{I})$. Under zero absorbance, $\mathrm{T}$ is considered to be one and $A$ to be zero. In the majority of devices, the vertical axis is used to show absorbance, which can deliver a variable value from zero to two (equivalent to the transmittance of 100 and $1 \%$, respectively). At a specific wavelength, the absorbance is the highest, which is known as $\lambda_{\max }$. There are various absorption maxima and absorbance for different compounds. Compounds with intense absorbance need to be measured in a dilute solution to allow receiving considerable light energy by the detector. For this, a fully transparent solvent is required. Water, ethanol, hexane, and cyclohexane are widely used solvents in these applications. Generally, solvents with high 


\section{WILEY-VCH}

molecular weights (due to the presence of heavy atoms such as $\mathrm{S}, \mathrm{Br}$, and I) or with double or triple bonds are not used. ${ }^{[110,125,126]}$

\section{Mechanisms involved in tumor targeting by leukocytes}

Leukocytes derivate from the differentiation of multipotent hematopoietic stem cells (HSCs). These cells and their progenitors pass this process within the microenvironment of bone marrow (BM). According to physical and functional characteristics, leukocytes are divided into two main types: polymorphonuclears (PMNs), which include neutrophil, eosinophil, and basophil, and mononuclear cells, which are lymphocytes and monocytes. T and B lymphocytes and NK cells comprise the main types of lymphocytic lineage in peripheral blood and lymphatic tissues. After maturation in the bone marrow, leukocytes enter the circulation. Recently, leukocytes have gained considerable attention in cancer immunotherapy. Leukocytes show migration properties that are comparable and close to those of cancerous cells (e.g., CTCs). Also, they have similar adhesion molecules with vascular endothelium, which facilitate interaction between them and activated endothelial cells.

In the bloodstream, for instance, the viability of circulating tumor cells (CTCs) is influenced by immunological stresses, a collision of blood cells, and fluid shear stress. However, it is not applicable to detect and eliminate CTCs that are present in peripheral blood as they are rare and in about one in a million leukocytes (and/or a billion erythrocytes) in the circulation. The migration of CTCs in the bloodstream is similar to leukocytes. ${ }^{[127]}$ In blood vessels, leukocytes mainly accumulate near the endothelial cell wall, not in the center of the vessel. This is by some rheological mechanisms contributing to leukocytes' margination. During margination, RBCs, which have great flexibility in changing their shape due to a high surface-volume ratio, repel 


\section{WILEY-VCH}

themselves from the margins and accumulate in the middle of vessels by undergoing a drift velocity, whilst at the same time, less deformable erythrocytes are pushed toward the periphery. ${ }^{[127]}$ Leukocytes then should interact with endothelial cells to easily enter soft tissues and targeted sites. Free-flowing leukocytes will take along the endothelial cell wall in the postcapillary venues. Leukocytes are initially captured by a so-called rolling adhesion phenomenon in which interactions are mediated by selectins (on endothelial cells) and their ligands (on leukocytes) such as P-selectin glycoprotein ligand-1 and L-selectin. ${ }^{[127]}$ Leukocytes can afterward shift from rolling to firm adhesion. This process is mediated by the binding of intercellular ICAM-1 adhesion molecule expressed on the vascular endothelium to leukocytes' $\beta 2$ integrins (e.g., lymphocyte function-associated antigen-1, macrophage-1 antigen). Chemoattractants are of particular importance for leukocytes to transmigrate within the endothelium and migrate to inflammatory sites and solid tumors. These attractive molecules are present in the tumor microenvironment and may be either attached to other molecules or present in soluble form. G-protein-coupled receptors are responsible chemoattractants and triggering signaling pathways that induce the membrane expression of $\beta 2$ integrins in leukocytes. Following cell-cell interactions with endothelial cells, actin filaments of the cytoskeleton are rearranged in leukocytes' cytoplasm, facilitating migration and polarization toward tumor cells and inflammatory sites. In the process of polarization, effector molecules are accumulated in specific locations within leukocytes, for example, Cdc42, small GTPases, PI3K, and Rac at the front, PTEN tyrosine/PIP3 phosphatases at the posterior, and Rho GTPases and associated molecules at the trailing edges. Consequently, migration begins with the contraction of actomyosin and their retraction in the tail. In the TME, elevated levels of chemokines are

produced by tumor epithelial cells, besides elevated expression of chemokine receptors, which 


\section{WILEY-VCH}

generates a highly inflammatory ME promoting the recruitment of leukocytes (e.g., neutrophils, lymphocytes, and macrophages). ${ }^{[127]}$ Unique features of leukocytes, such as their similarity with tumor cells (in terms of transportation within the bloodstream, adhesive interactions with vascular wall, and moving toward the tumor and inflammatory locations) allow us to use them for efficient drug delivery in cancer therapy. In the following sections, we discuss in detail the application of multiple types of leukocytes (e.g., granulocytes, monocytes, and lymphocytes) in targeted tumor therapy and explain associated contributing mechanisms.

The majority of white blood cells are able to pass through blood vessels (via diapedesis), and they are abundant in many locations and tissues throughout the body (e.g., blood, lymph, etc.). On the other hand, cancer is a disease characterized with chronic inflammation as one of its main pathologic processes. Therefore, tumor progression is a process, which needs the contribution of leukocytes (e.g., neutrophils, macrophages, and antigen presenting cells) that are involved in the induction and persistence of inflammatory reactions. ${ }^{[42,43]}$ Leukocyte chemo-attractants produced

by cancer cells play a major role in the recruitment of these cells by tumors. ${ }^{[44]}$ With regard to this, leukocytes that contribute to the persistence of inflammation in tumor microenvironments actually help cancer cells to propagate by facilitating metastasis and producing new blood vessels. ${ }^{[128]}$ If we can manage and omit this tumor assisting role of leukocytes, they can be valuable drug carriers for targeted cancer therapy as they can accurately deliver drugs to tumors via specific recognition of the surface markers of the cancer cells by the protein ligands naturally expressed on these leukocytes. ${ }^{[45]}$ For example, macrophages are among the main tumorassociated leukocytes ${ }^{[129]}$ that their membrane can be used to cover NPs for both targeting and extended circulatory half-life. ${ }^{[130]}$ For the first time, Tasciotti et al. coated porous silica particles with membranes from macrophages by hydrophobic and electrostatic interactions (the negative 


\section{WILEY-VCH}

charge of the biological membranes and the positive charge of particles). ${ }^{[131]}$ They managed to maintain important receptors (e.g., CD11a and glycans) on the membranes to enable the constructed particles to specifically migrate toward tumor cells (directed via the endothelial cells expressing inflammatory ligands) without their uptake and removal by other leukocytes. In another study, the role of inflammatory surface receptors, particularly CXCR1 (LFA-1) and CXCR2, in directing the NPs coated with macrophage derived membranes toward tumor site was highlighted. Zhang et al. showed that suppressing the above-mentioned receptors prevented the migration of biomimetic NPs to inflamed sites. ${ }^{[132]}$ Therefore, macrophage-derived membranes can be useful candidates for the development of therapeutic and diagnostic carriers. ${ }^{[133,134]}$

\subsection{Monocytes/macrophages}

Monocytes are mononuclear phagocytes generated from myelomonocytic progenitors present in the BM. After circulation in the bloodstream, these cells finally accumulate in tissues such as the spleen, liver, lungs, and bone marrow. Monocytes do not function until they are activated by pathogens and become macrophages. In the bloodstream, monocytes are not plentiful, but they play a vital role in defending the body against infections. In humans, monocytes generally express HLA-DR (MHC class II) receptor, CD11b (integrin $\alpha \mathrm{M}$ ), and CD86. ${ }^{[126]}$ These leukocytes compromise of three subsets, including classical monocytes, nonclassical monocytes, and intermediate monocytes. Monocytes are critical regulators in cancer development and progression. They act into various subsets with presumably opposing functions to enable tumor growth and prevent metastasis. Tumor-associated macrophages (TAMs) and dendritic cells (DCs) are two cell types that are primarily derived from monocytes. These cells, especially TAMs, which have long survival, cooperate in shaping the tumor microenvironment (TME). 


\section{WILEY-VCH}

Furthermore, monocytes participate in the remodeling of TME and triggering antitumor lymphocytes. These roles of monocytes, nevertheless, vary depending on the type of cancer, the features of TME, the experimental model, and the stage of tumor growth. The protumoral functions of classical monocytes include producing pro-tumor TAMs, seeding metastatic nodules, suppressing antitumor T lymphocytes, and ECM remodeling (in both mouse and human references), as well as recruitment of Tregs and angiogenesis (in mouse references). The antitumoral functions of classical monocytes include tumor cytotoxicity (in human references) and $\mathrm{Ag}$ presentation (in mouse references). Among the protumoral function of monocytes expressing Tie-2 (i.e., non-classical type) are induction of angiogenesis (in both human/mouse references) and suppressing the activity of $\mathrm{T}$ lymphocytes. And the antitumoral functions of Tie2 positive monocytes include inducing cytotoxicity and inhibition of Tregs (in human references), blocking metastatic lesions, the phagocytosis of tumor cells and their extracellular mediators (in mouse references), and activating antitumor NK cells (in both mouse and human references). ${ }^{[126]}$ The function of macrophages is mediated through phagocytosis and producing a variety of inflammatory mediators. In neoplastic tissues, however, TAMs function to favor tumor growth and angiogenesis (Figure 2). Based on the internal environment, macrophages are developed into TAMs in proper condition when they accumulate in the TME. ${ }^{[135]}$ 


\section{WILEY-VCH}

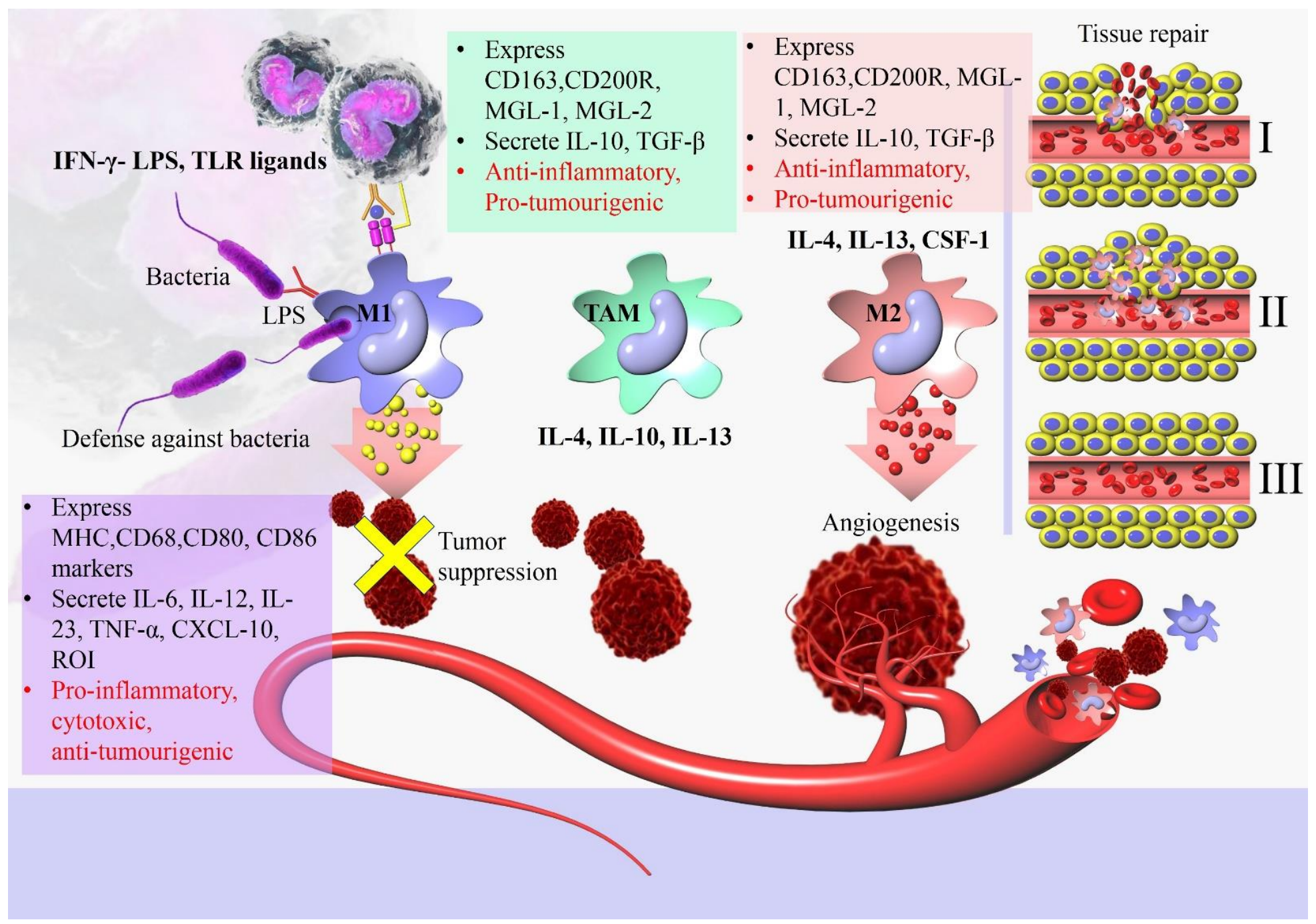

Figure 2. Two of the main macrophages: Classically activated macrophages (M1) and alternatively activated macrophages (M2) and tumorassociated macrophages (TAMs). M1 are activated by IFN- $\gamma$ - LPS, GM, CSF, and other cytokines. M1 are involved in the destruction of tissue through secreting pro-inflammatory cytokines that actively kill pathogens. M2 TAMs are activated by IL-4, IL-10, IL-13, CSF, etc.. They are involved in tissue remolding, parasite infection, allergic conditions, and angiogenesis. 


\section{WILEY-VCH}

It is thought that macrophages help cancer cells to proliferate by creating a favorable hypoxic state for cancer cells and promoting a persistent inflammatory state by expressing potent mediators such as tumor necrosis factor (TNF). TNF and similar compounds stimulate the gene switch NF-kB (nuclear factor-kappa B). After entering the nucleus of tumor cells, NF-kB triggers the activation of anti-apoptotic molecules, which confer cancerous cells a proliferative advantage and further augment the s status. ${ }^{[136]}$ The number of TAMs is correlated with the poor prognosis of some cancers. There is also an association between TAMs and elevated angiogenesis and/or lymph node metastasis in malignant tissues. Monocytes can differentiate into two types of TAMs, including M1 and M2 cells. While the first group is activated via a classical pathway, the second is called alternatively-activated macrophages (Figure 1). M2 TAMs act to trigger tumor growth by producing cytokines or stimulating endothelial cell proliferation and angiogenesis. M1 TAMs act to launch tumor rejection. In other words, M2 and a small portion of M1 TAMs lose the tumor cells phagocytizing property and also help tumor cells to escape from killing by the immune system and, thereby, spread to additional tissues and organs. ${ }^{[135]}$ Macrophages incite angiogenesis, tumor cell invasion, and intravasation at the primary site. Many studies have debated the antitumor function of TAMs and stated that these cells might actually help tumors to propagate and disseminate and even cause the failure of therapeutic interventions. Particularly, these cells are primed under the influence of the mediators produced by tumors. ${ }^{[137]}$ Macrophages and monocytes provide for the appearance of disseminated tumor cells and support their extravasation and survival at the metastatic site. This function is done by inhibiting immune-mediated clearance or by directly engaging with tumor cells to initiate prosurvival signaling pathways, as well as organizing supportive metastatic niche formation. Therefore, agents that inhibit the recruitment or the protumorigenic effector functions 


\section{WILEY-VCH}

of macrophages in both the primary tumor and at the metastatic site can improve cancer survival. ${ }^{[138]}$ Tumor immunotherapy has been broadly touched in recent years. It can convert immune cells to more actively respond to a variety of mediators and to regulate and augment immune defense function to ensure a counterbalance between anti- and pro-tumor immunerelated interactions. ${ }^{[135]}$ For this purpose, macrophages are important cells to be considered to develop immunologic therapeutic strategies. In the following, we discuss some original works conducted in recent years to target macrophages and their application prospects.

Nowadays in cancer nanotechnology, biohybrid vectors are used for a variety of applications such as producing anti-cancer vaccines, constructing synthetic organelles, detoxifying toxic agents, and delivering pharmaceutical agents. ${ }^{[139]}$

Recently, Bhattacharyya et al. ${ }^{[140]}$ initially anchored TNF $\alpha$ with macrophage-derived membranes to coat a non-toxic and chitosan-based NP. When macrophages are affected by LPS, they released inflammatory mediators (e.g., TNF $\alpha$ and ILs) after 4 to $5 \mathrm{~h}$ of exposure. Transmembrane TNF $\alpha$ is a central signaling cytokine with anti-cell proliferative capacity. The researchers, therefore, aimed to investigate the effects of the time of exposure to LPS to achieve membrane-bound TNF $\alpha$. Bhattacharyya et al. exploited bacteria-derived LPS to incite phorbol 12-myristate 13-acetate (PMA)-differentiated THP-1 cells and induce the expression of membrane-bound $\mathrm{TNF} \alpha$. Afterward, a TNF $\alpha$-expressed macrophage membrane was utilized to coat the as-synthesized chitosan NP core by extrusion. TEM, western blot, and SDS-PAGE electrophoresis were applied to ascertain the efficiency of coating chitosan NPs with the TNF $\alpha$ induced membrane. Using Calcein-AM (CAM)/Propidium Iodide (PI) staining, the viabilities of numerous cancer cell lines, such as breast cancer MCF-7, HeLa, and MDA-MB-231 were investigated to determine the toxicity of membrane-coated NPs against cancer cells. 


\section{WILEY-VCH}

Furthermore, the constructed NPs' biocompatibility was demonstrated by investigating the expression of multiple interleukins after treatment. The fabricated NPs showed dose-dependent apoptotic and toxicity effects against tumor spheroids, which shows the great effects of the NPs against tumor spheroids and suggests their potential as anti-cancer agents. In addition to cancer therapy, macrophage cell membrane has been used for the coating of NPs for other diseases like rheumatoid arthritis, which shows its versatile potential in the fabrication of targeted nanomedicines. ${ }^{[139]}$

Li et al. ${ }^{[141]}$ assessed the ability of Dox-MPK@MDL, a biomimetic cell-based system for the drug delivery system, to suppress lung metastasis of BC cells in vitro and in vivo. For this, they coated DNA tetrahedron dendrimers with membranes derived from macrophages and liposomes. The tetrahedron dendrimers were chosen because they conferred a stable skeleton to the system. Furthermore, this biomimetic system showed an ability to be self-assembled via tandem reactions (i.e., a hierarchical process). Then they synthesized a prodrug, Dox-MPK, with high sensitivity to $\mathrm{pH}$ fluctuations. Finally, these drugs were injected into the developed delivery system before the next anti-metastatic therapy. Sites of lung metastasis were specifically targeted by Dox-MPK@MDL through the biomimetic metastasis-homing outcomes. Also, the release of Dox at the metastatic cancer cells was intelligently provoked. Furthermore, Dox-MPK@MDL acquired the relevant functional features, which can be attributed to macrophages' membrane components, which include extended circulatory lifetime, great safety, potent and specific targeting capability, and an upgraded capacity for being internalized by cells.

Zhang et al. ${ }^{[142]}$ also exploited the membranes derived from macrophages in the form of vesicles to cover NPs (cskc-PPiP/PTX@Ma). Because of extensive pH variations within TEM, the researchers developed this system, hoping to execute a controlled and gradual drug release upon 


\section{WILEY-VCH}

$\mathrm{pH}$ changes. All the functional proteins of membrane vesicles were preserved during the process, and they were supposed to role as camouflage to enhance tumor cells' opsonization and removal by the reticuloendothelial system, and also as an attractant to guide and accumulate (i.e., homing) tumor cells. Paclitaxel (PTX) was used as a model drug to ascertain the capacity of this assembly and its therapeutic effect in a mouse model with orthotopic breast cancer. They fabricated polymers with amphiphilic bola-patterns exhibiting specific complementary attached groups through the dual-end PEGylation of poly( $\beta$-amino ester) (PBAE) to load water-insoluble drugs. From the results, the external membranous layers were released following morphological changes and after exposition to external stimuli from the environment (Figure 3), which resulted in the release of the NPs, which had extended penetrating ability due to an increase in their size and surface modifications. Loaded drugs were promptly released from NPs to respond to the endosome $\mathrm{pH}$. The fabricated assembly, due to the function of membranous layers, exhibited promising systemic tumor-homing capacity and excellent biological safety. PPiP materials, with their unique buffering property, additionally provided the assembly with a stimulus-dependent drug-release feature responding to intrinsic and extrinsic signals within TME.

Meng et al. ${ }^{[143]}$ developed a biomimetic nanoplatform with potent tumor-targeting capability and prolonged half-life in peripheral blood. Macrophage (RAW 264.7 cells were used which are similar to these phagocytic cells) membranes were converted into vesicles and then coated them onto pre-synthesized $\mathrm{Fe}_{3} \mathrm{O}_{4} \mathrm{NPs}$ to prepare $\mathrm{Fe}_{3} \mathrm{O}_{4} @ \mathrm{MM}$ (i.e., macrophage-mimicking). The size of the final assembly was around $18 \mathrm{~nm}$ greater in comparison with membrane-free NPs, according to DLS characterization. CCK-8 cell viability assay showed that the effect of the fabricated NPs against the MCF-7 cell line is insignificant even at elevated levels. Based on DLS findings, in addition to a unique light-to-heat-conversion (LTHC) feature, the fabricated 


\section{WILEY-VCH}

assembly showed promising immune hiding feature, potent tumor targeting ability, and acceptable biological safety. 


\section{WILEY-VCH}


$\mathbf{E}$
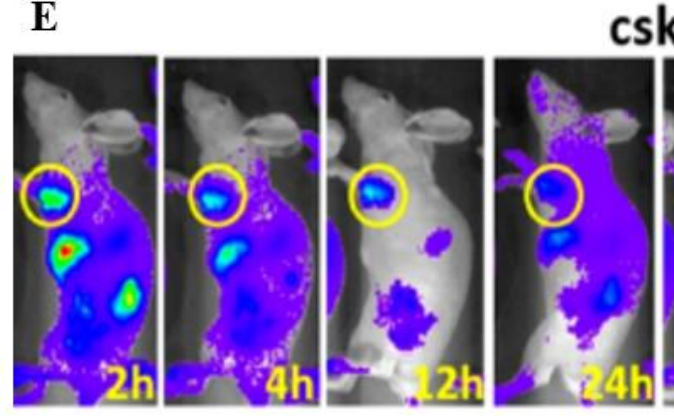

skc-PPiP

D $\div$ - Saline
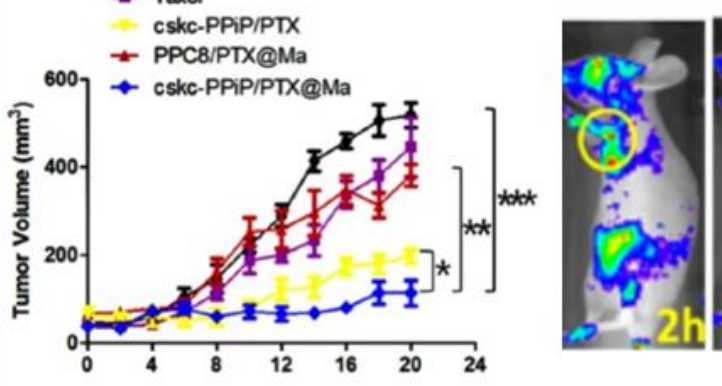

cskc-PPiP@Ma
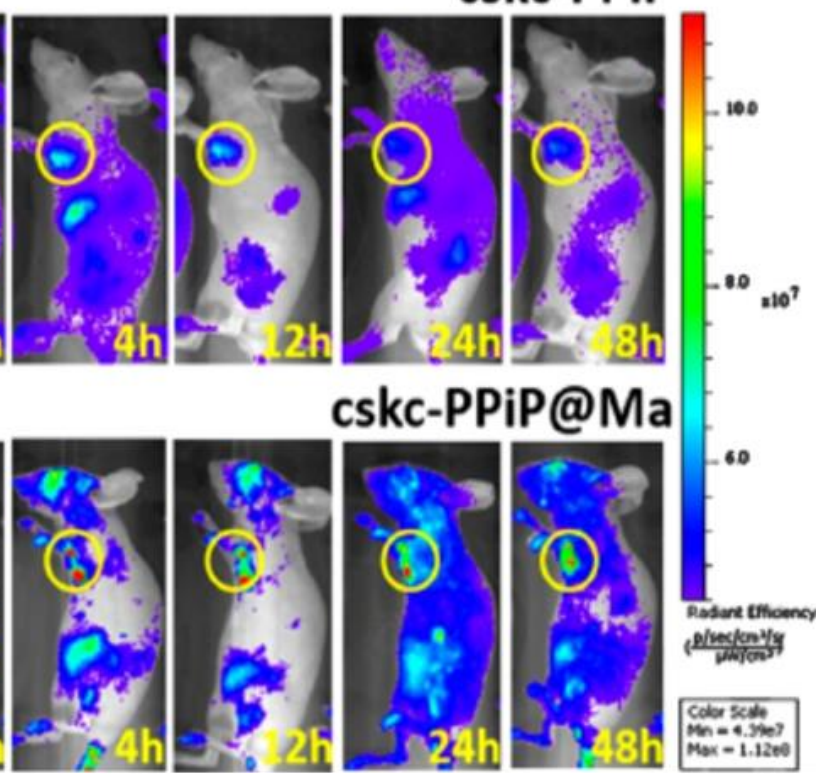

Figure 3. A) Particle fabrication and B) the mechanisms of drug release and membrane escape. Adapted from Zhang et al. with permission. ${ }^{[142]}$ Anti-cancer effects and biodistribution. C, D) The animals' body weight and tumor volume were regularly monitored during the first 21 days of treatment. E) IVIS images 


\section{WILEY-VCH}

were obtained from the mice infused with near-infrared probe-loaded cskc-PPiP and cskc-PPiP@Ma at different times.

\subsection{Neutrophils}

Besides being the most abundant leukocytes in peripheral blood, neutrophils are major contributors to proinflammatory reactions and immune responses against pathogens. Although their actions are beneficial to the host by eradicating foreign invaders, these functions sometimes promote tissue injury due to exaggerated inflammation. Therefore, modulating host-protecting functions of neutrophils is critical to avoid self-injures.

To effectively promote their functions, adequate numbers of neutrophils should first migrate towards infection sites. After that, neutrophils should be able to detect invading microorganisms, engulf them, and finally kill them by their anti-microbial mediators. A key step at this phase is to constrain the inflammatory process after the elimination of pathogens, but sometimes, proinflammatory responses continue to propagate, most commonly due to neutrophil dysfunction. This phenomenon may be seen in immunodeficiency syndromes, genetic defects of neutrophils, and the consumption of immunosuppressive drugs. Here, we discuss neutrophil biological features and the syndromes associated with its dysfunction. ${ }^{[144]}$

As components of innate immunity, neutrophils are among the first cells to fight pathogens. ${ }^{[145,}$ ${ }^{146]}$ Considering this, neutrophils have been suggested as potential drug vehicles for treating cancers. ${ }^{[147]}$ The role of neutrophils in the pathogenesis and metastasis of cancerous tumors has been suggested. Neutrophils differentiate from myeloid precursors in the bone marrow. On the other hand, the formation of a cellular premetastatic niche can be mediated by the myeloid

precursors of neutrophils. ${ }^{[148]}$ Subsequent to the formation of the niche, both neutrophils and circulating tumor cells (CTCs) are recruited through a granulocyte colony-stimulating factor (G- 


\section{WILEY-VCH}

CSF)-mediated pathway. Then via the action of adhesion molecules such as LFA-1, L-selectin, and $\beta 1$-integrin, which bind to their ligands (ICAM-1, CD44, and VCAM-1, respectively), neutrophils can direct CTCs toward the premetastatic niche and lure them into neutrophil extracellular traps. ${ }^{[149,150]}$ Based on these features of neutrophils, neutrophil-mimicking NPs such as neutrophil membrane-coated NPs (NM-NP) have been produced and investigated in cancer treatment experiments to suppress tumor growth and metastasis and induce apoptosis in premetastatic tumor masses and CTCs both in vitro and in vivo. The appearance rate of CTCs in premetastatic niches has been shown to be increased upon exposition to NM-NPs. ${ }^{[149]}$ Other developed systems such as neutrophil and macrophage membrane-coated nano-vehicles (NMNVs and MM-NVs) have been shown to be effective in suppressing tumor growth and migration by removing CTCs and preventing the development of metastatic nodules. Therefore, these nanocarrier systems have the potential to be used as antitumor and anti-metastatic agents. Figure 4 depicts the mechanisms exploited by NM-NVs and MM-NVs for identifying and eradicating tumor cells and masses. ${ }^{[150]}$ 


\section{WILEY-VCH}

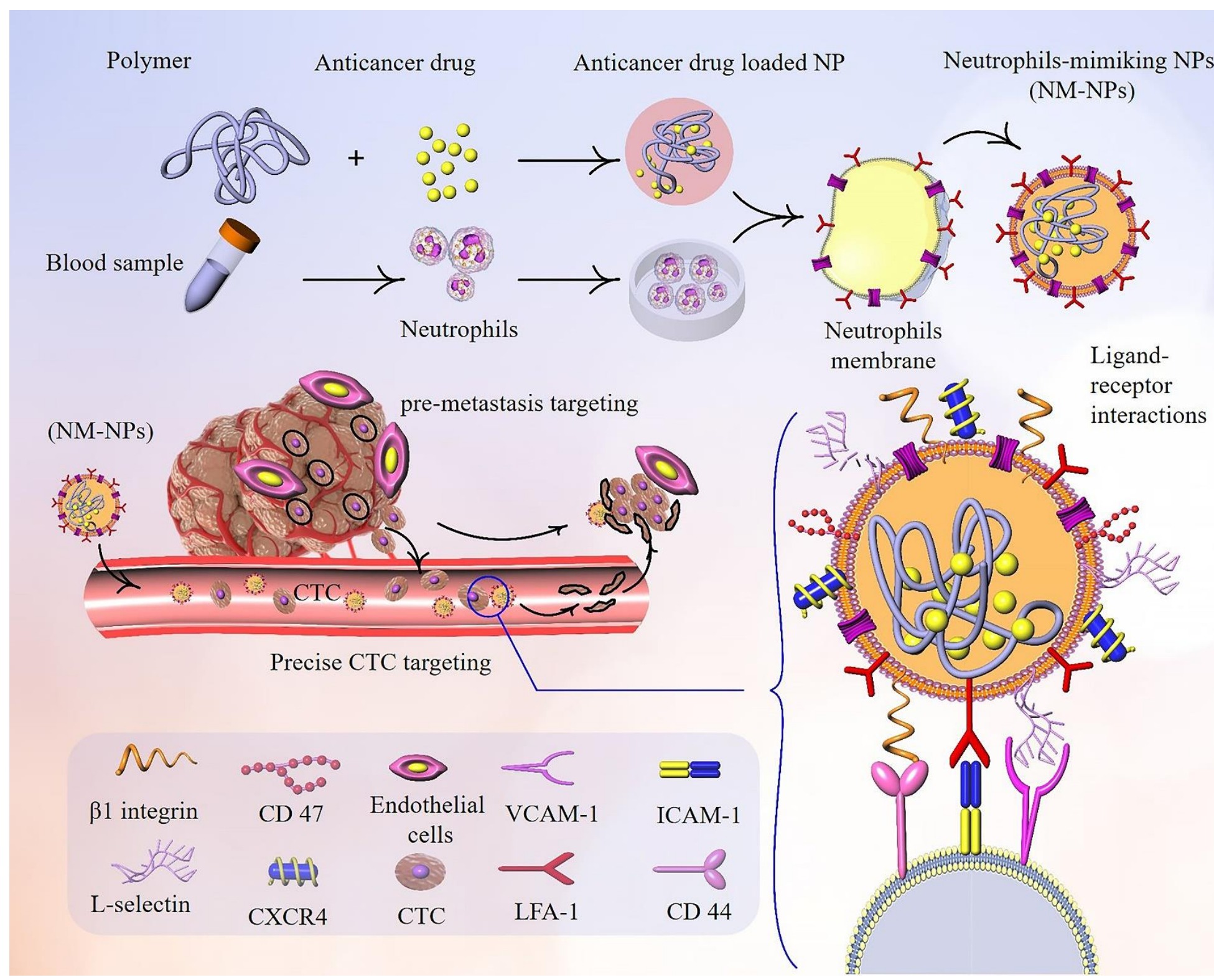

Figure 4. Schematic illustration of targeting CTCs and preventing them from forming new pre-metastatic clones through neutrophil-mimicking NPs (NM-NPs) used to deliver an anticancer drug. 


\section{WILEY-VCH}

Distant metastasis seems to be largely dependent on the capability of CTCs to propagate and colonize in far tissues. ${ }^{[149]}$ Therefore, to develop an efficient targeting strategy, preventing CTCs colonization in pre-metastatic niches is critical to extinguishing this process at the early stages. Activated neutrophils with proinflammatory features express specific cell-adhesion molecules on their surface, which can detect CTCs and pre-metastatic niches. Kang et al. employed these features to coat PLGA NPs with neutrophils' membranes and design a nano-sized neutrophilmimicking drug delivery system (NM-NP). During this process, the researchers successfully managed to avoid any structural damage to and functional disruption of the proteins expressed on neutrophils membranes, so the whole platform of an intact membrane with preserved molecular binding features was translocated on NM-NPs. In comparison with the control, which included NPs without neutrophil membranes, NM-NP showed significantly higher recruitment of immune cells to 4T1 tumors in vitro and more efficient targeting of CTCs and premetastatic niches in vivo. Furthermore, Carfilzomib (CFZ)-loaded NM-NPs (NM-NP-CFZ) were examined in the current study. The developed complex, including CFZ, which is a second-generation proteasome inhibitor, selectively targeted and eliminated CTCs from circulation. Moreover, significant reductions were observed in the rate of new metastatic nodules and also the progression of already-formed metastatic lesions. ${ }^{[149]}$

Incorporating plasma membranes of leukocytes with NPs (i.e., membranous functionalized NPs) can protect these nano-scale materials from being targeted and digested by immune cells such as phagocytes. ${ }^{[131]}$ Likewise, NPs attached to platelet-derived membranes have been beneficial to heal vascular bleeding sites. ${ }^{[151]}$

To target cancerous cells, NPs can be functionalized using neutrophil-derived membranes. These

leukocytes are major participants in a variety of immune responses ${ }^{[152,153]}$ and usually are first to 


\section{WILEY-VCH}

appear at inflammation sites. ${ }^{[153]}$ Neutrophils have already been applied as targeted carriers to treat cancer. ${ }^{[147,149,154]}$ Their wide use; however, requires to resolve restrictions such as short life span in circulation and complicated encapsulation process. ${ }^{[155]}$ It has been confirmed that Neutrophil membranes can be used to construct nano-vesicles to target NPs towards metastatic cancerous tissues or inflammation sites. ${ }^{[156]}$ In a study, Wnag et al. covered anti-viral loaded NPs with neutrophil membranes. This strategy resulted in the escape of the nanodrug from being detected by spleen and liver macrophages and, subsequently, accurate delivery to the inflamed site. In fact, NPs coated with neutrophil membranes were construed as neutrophils by the reticuloendothelial system (RES). Therefore, the researchers first obtained functional and natural neutrophil membranes (with preserving all physiological and structural properties). Then they covered sparfloxacin containing NPs with neutrophil membranes s (i.e., Neutrophil membranes NP-SPX complexes). The synthesized complexes successfully targeted inflammation sites (Figure 5A) and had the ability for gradual and controlled drug release, as well as a longer circulatory life span (Figure 5B). ${ }^{[153]}$ 


\section{WILEY-VCH}

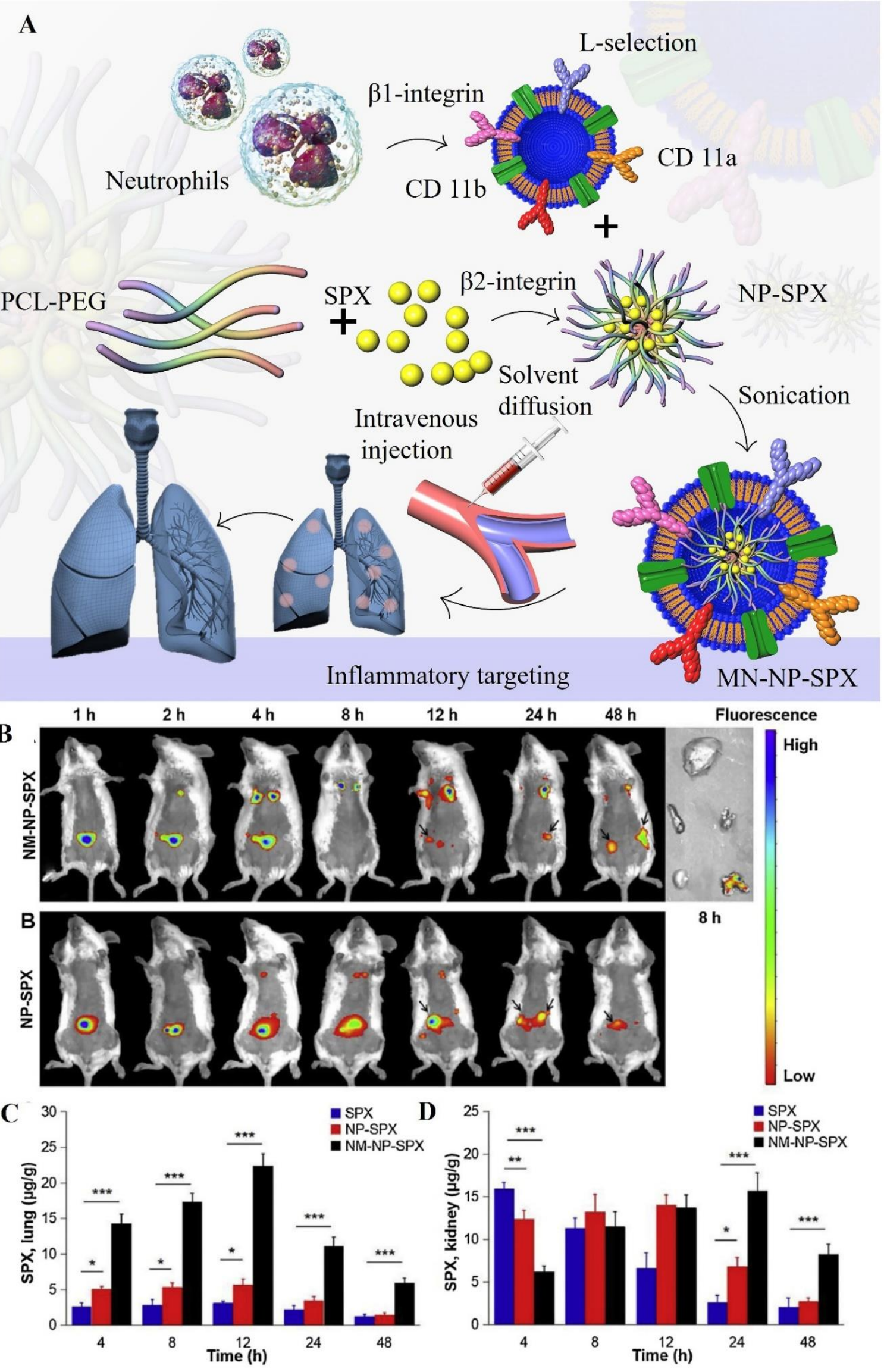




\section{WILEY-VCH}

Figure 5. A) Schematic for neutrophil membrane/NP-sparfloxacin (SPX) complex synthesis process and its delivery to inflammation site in the mouse model of pneumonia. Adapted with permission. ${ }^{[153]}$ After intravenous injection, NM-NP-SPX complexes were monitored and traced in the liver, spleen, heart, kidneys, and lungs at specific times (image order: top-left to bottomright). B) Fluorescence images of NM-NP-SPX complexes to evaluate their distribution in vivo C) lung, D) kidney. Mice were challenged with MRSA and then treated with either SPX alone, NP-SPX, or NM-NP-SPX.

Inflammation and carcinogenesis are two intercalated processes, which the former seems to facilitate the later. In a study, Cao et al. loaded neutrophil membrane-coated poly (ethylene glycol) methyl ether-block-poly (lactic-co-glycolic acid) (PEG-PLGA) NPs with celastrol to evaluate its anti- pancreatic cancer effects. In this setting, the utilized carrier system (i.e., NM coated NPs or NNPs) offered an excellent ability to cross the blood pancreas barrier and, therefore, a promising selective drug delivery. In comparison with free NPs, the NNPs successfully delivered the drug to the tumor tissue in the mouse xenograft model (orthotopic and ectopic) of pancreatic carcinoma. The therapeutic efficiency of NNPs-delivered celastrol was approved by decreased tumor growth, low hepatic metastasis rate, and longer survival of tumorbearing mice (Figure 6). ${ }^{[147]}$ 


\section{WILEY-VCH}

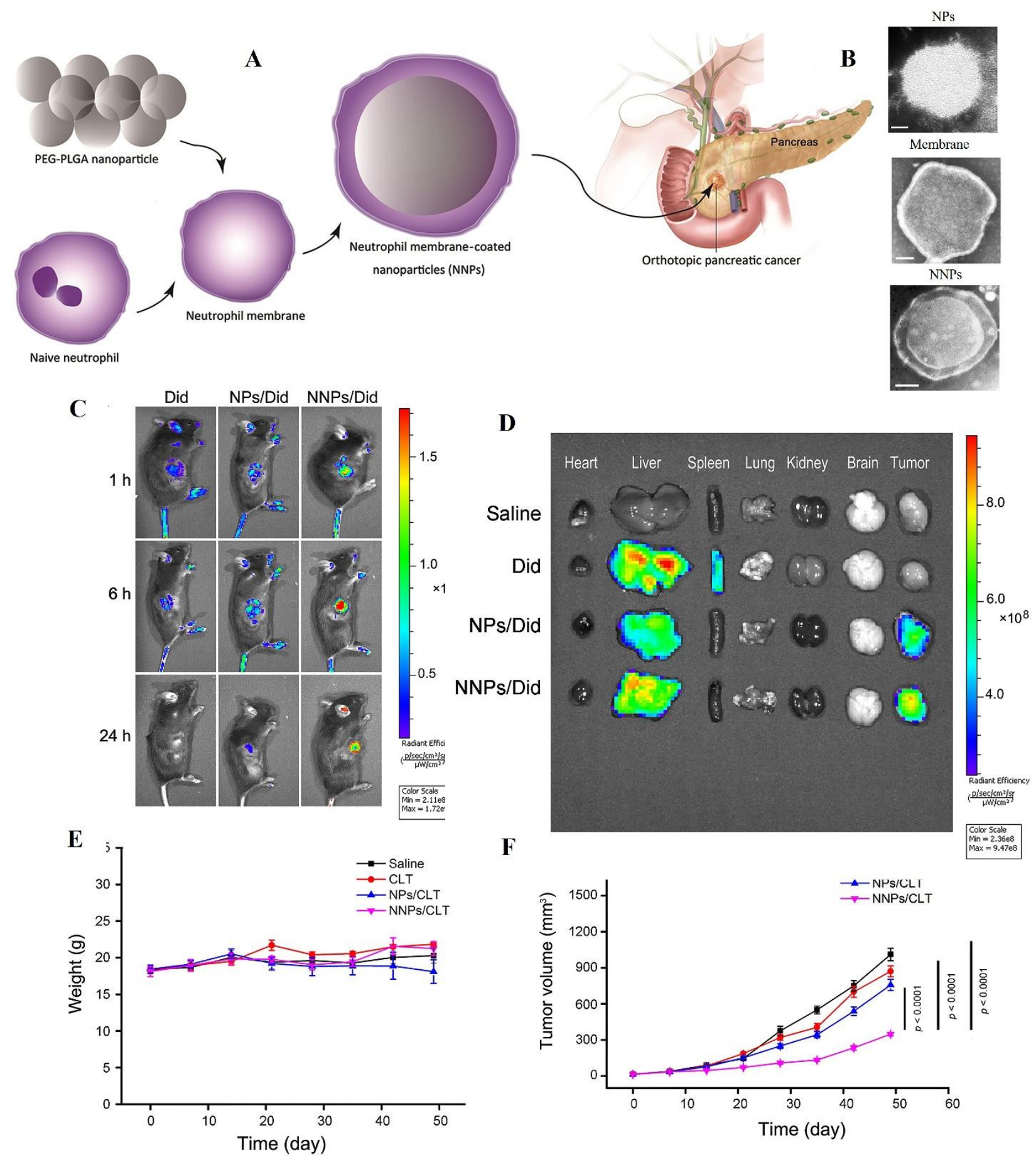

Figure 6. A) Schematic for preparation and administration of neutrophil membrane-coated nanoparticles (NNPs) in a mouse model of pancreatic carcinoma. The synthesized complex efficiently crossed the blood-pancreas barrier. B) NPs, neutrophil membrane, and NNPs under TEM microscopy (the scale bar equals to $30 \mathrm{~nm}$ ). C and D) DiD solution, NPs/Did, and NNPs/Did were injected intravenously and imaged 1, 6, and 24 hours afterward. E) Different doses and tumor volumes and F) body weights in tumor-bearing mice treated with different strategies at various time points. Reproduced with permission. 


\section{WILEY-VCH}

In a novel report, NMs were used to encapsulate black phosphorus (BP) and an inhibitor of transformation growth factor-b (TGF-b). In this study, Su et al. showed that BP, in both photodynamic therapy (PDT) and photothermal therapy (PTT), promoted acute inflammation and facilitated the recruitment of NPs to the tumor site by increasing NE membrane-mediated affinity (Figure 7A). In combination with TGF-b inhibitor, PDT and PTT strongly activated anti-tumor immune responses (Figure 7B) and prevented the invasion of tumor cells to the lungs. In comparison with non-positive feedback, the administration of NPs with a positive feedback strategy represented stronger anti-cancer effects, better inflammation-inducing capability, and finally, superior NM-mediated directing of therapeutics towards tumor tissues (evidenced by a dominant target signal). Furthermore, a positive feedback loop was observed upon repeated administration of the drug, which resulted in higher therapeutic effectiveness. A synergy between acute inflammatory response and TGF-b inhibitor further augmented anti-tumor immunity, as demonstrated by a significant elevation of temperature in infrared thermographic images in the NG/BP-PEI-LY group following two successive rounds of PTT. The higher efficiency of PTT following the positive feedback effect probably reflects the role of acute inflammation in regulating the distribution and retaining of NG/BP-PEI-LY complexes in tumor tissues. In turn, this phenomenon enhanced the therapeutic efficiency upon subsequent drug administration (i.e., a positive feedback loop). After 16 days of the administration, tumor volume was measured, and metastatic nodules were enumerated to assess the therapeutic efficiency of NG/BP-PEI-LY. The comparable numbers of metastatic nodules in control and NG/BP-PEI-LY without laser radiation groups (Figure 7C) and also similar growth curves indicated no significant anti-tumor activity for the complex. ${ }^{[157]}$ 

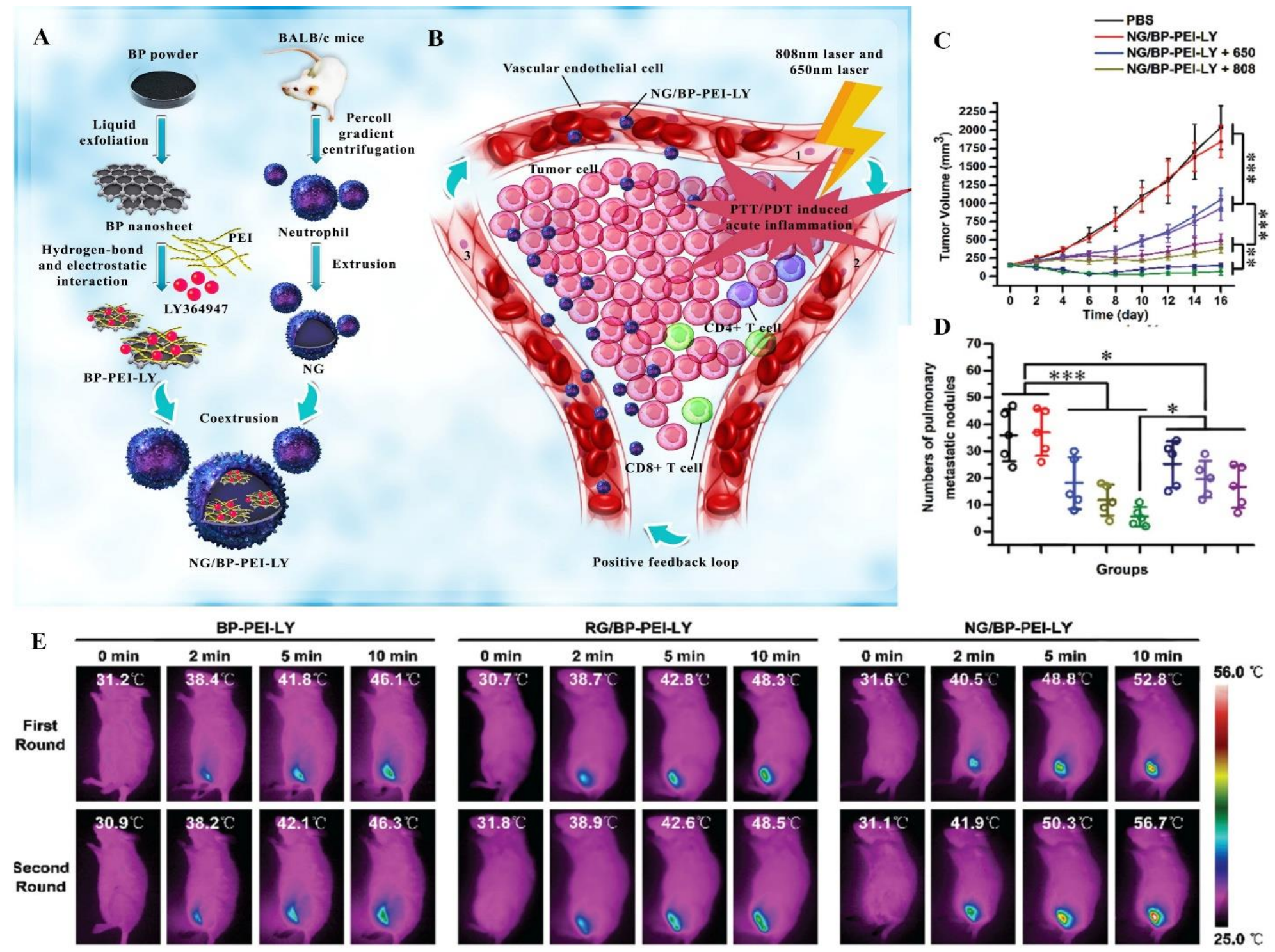


\section{WILEY-VCH}

Figure 7. A) Schematic of synthesis of NG/BP-PEI-LY complexes. B) Synergistic antitumor activity of NG/BP-PEI-LY with PDT, PTT, and immunotherapy. Adapted with permission. ${ }^{[157]}$ C) Tumor growth curve, and D) microscopic images of lungs in mice under various treatments. E) The mice were treated with different compounds and subsequently laser $(808 \mathrm{~nm})$ irradiated for two cycles. Finally, infrared thermographic maps were recorded ${ }^{[157]}$.

Naumenko et al. utilized NMs to assemble a system for transporting short-circulating magnetic NPs into cancerous cells, which resulted in the effective recruitment of the NPs (in the form of cubes and clusters) to 4T1 (breast) and CT26 (colon) cancer cells. Due to rapid uptake by circulating neutrophils, these NPs had a short life span in the bloodstream; instead, they were highly concentrated in tumor tissues via neutrophil-mediated transportation across vascular walls. The potential role of neutrophils as anti-tumor drug carriers was further confirmed by a drop in NPs concentration following Ly6G and Gr1 depletion, especially in the case of short vs. long-circulating NPs. The effectiveness of neutrophils as drug carriers, however, is influenced by variables such as cancer type. In this regard, higher efficiency is expected in tumors harboring more numerous neutrophils. In general, other influencing host and environmental factors should be identified for developing more efficient drug carriers to treat various cancers. ${ }^{[158]}$

Glioma is the most frequent malignancy of the cerebral tissue. Due to invasive nature and high metastatic rate, routine therapies (e.g., surgery) usually fail to eradicate these tumors, conferring an unfavorable prognosis and high mortality rate ${ }^{[159,160]}$. Chemotherapeutic agents have limited capability to reach these tumors due to the actions of the blood-brain barrier (BBB) and the blood-tumor barrier (BTB). ${ }^{[161]}$

Drug delivery systems which are based on NPs have been developed to cross BBB and BTB either by target-specific binding or passive transportation). ${ }^{[162]}$ Nanoparticle-based drug delivery systems (NDDSs) were designed in an endeavor to debilitate the BBB/BTB in tumors via either active ligand-mediated transport or facilitated passive diffusion. ${ }^{[26,162]}$ The limitations of these 


\section{WILEY-VCH}

delivery systems include short circulatory lifetime, delivering low drug concentration to tumors, and unacceptable toxicity.

Using alive cells as drug carriers offers a great opportunity for treating cancer. Indeed, living cells such as neutrophils have unique and intrinsic features conferring them the ability to specifically target tumors. In a report, $\mathrm{Wu}$ et al. applied neutrophils with internalized doxorubicin-loaded magnetic mesoporous silica nanoparticles (ND-MMSNs) to target brain tumors after surgery (Figure 8A). This system provided the possibility to monitor the distribution of drug-containing cells by imaging techniques (in this case by magnetic resonance (MR) imaging), which are necessary to approve the efficiency of these carrier systems. The obtained images revealed a high dose of the drug within tumors, which reflected both the high carrying capacity and targeting efficiency of the neutrophil-internalized D-MMSNs. Furthermore, D-MMSNs had no adverse effects on the survival of neutrophils and delayed the disease recurrence after surgery. This study highlighted the great potential of living cells and NPbased carriers in cancer treatment.

Post-surgery T2-weighted MR images showed that intravenously infused ND-MMSNs accumulated in brain tumor tissues in mice models of glioma as evidenced by the strong fluorescent signals observed at the surgically removed tumor location in the animals treated with ND-MMSNs and NI-MMSNs, but not D-MMSNs at 60 minutes after administration (Figure 8B). In the animals treated with NI-MMSNs compared with free ICG and I-MMSNs, fluorescent signals were detected even 24 hours after the exposition (Figure 8C). Flow cytometry analysis confirmed that the strong anti-tumor activity of ND-MMSNs was, in part, executed through accelerating apoptosis. The number of apoptotic cancer cells was significantly higher (i.e., lower 


\section{WILEY-VCH}

tumor burden) in the mice exposed to ND-MMSN than controls or the animals treated with MMSN (Figures 8D and 8E). ${ }^{[160]}$ 
WILEY-VCH
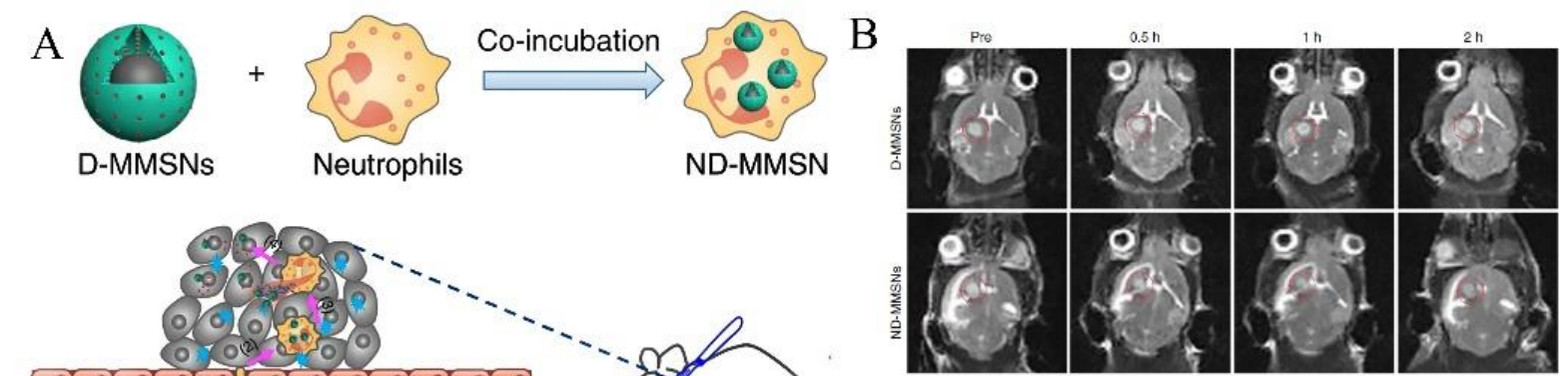

C Free ICG I-MMSNs NI-MMSNs

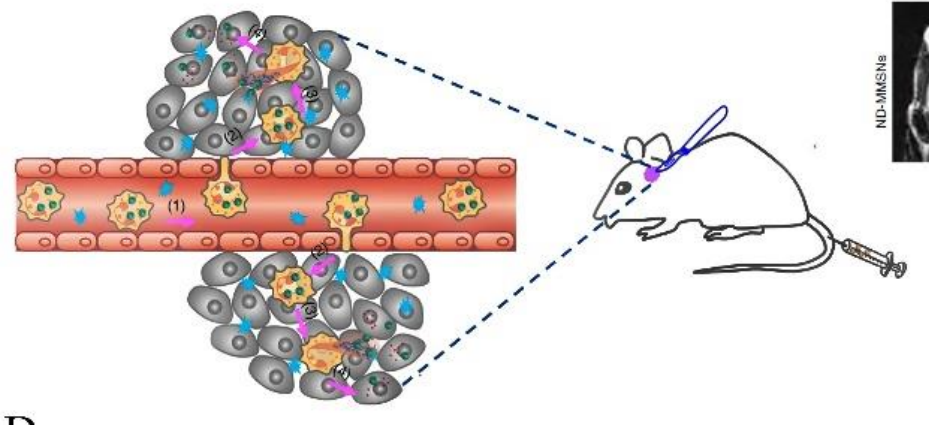

$\mathrm{D}$

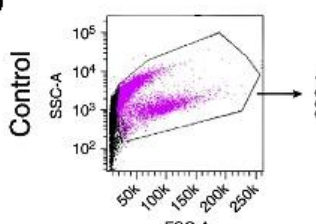

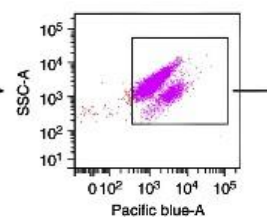
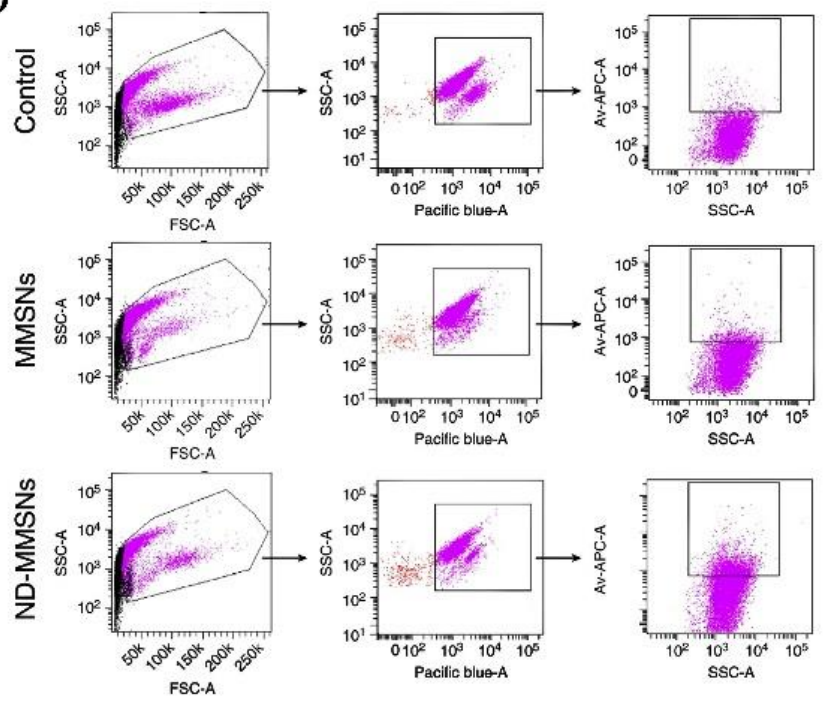
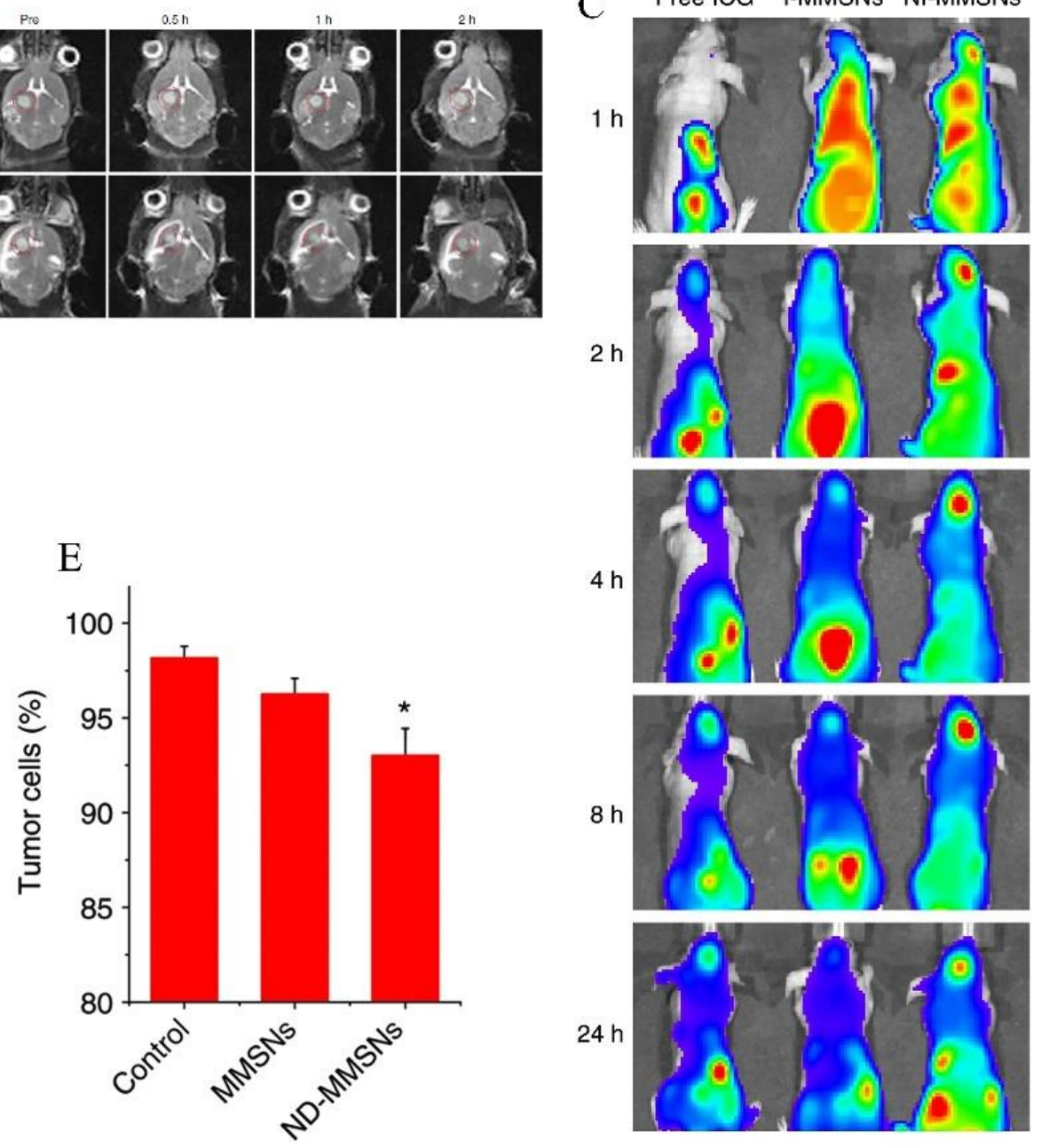

Figure 8. A) a Schematic of the inflammation promoted the accumulation of ND-MMSNs at the location of surgically removed glioma tumors. Phagocytized D-MMSNs were released to deliver residual tumor theranostics. B) Post-surgery T2-weighted MR images from D-MMSNs and NDMMSNs treated mice models of glioma confirmed drug accumulation at tumor sites (red circular spots). C) Post-surgery fluorescence images of tumor locations in mice models of glioma at specific times following i.v. injection of free ICG, I-MMSNs, and NI-MMSNs. D, E) D-luciferin potassium salt staining for single tumor cells and APC-labeled Annexin V apoptosis assay. Flow cytometry was used to determine tumor cell ratio and the apoptosis rate. Tumor cells (represented by Luciferin fluorescence) appeared in the Pacific blue channel. Reproduced with permission. ${ }^{[160]}$ 


\section{WILEY-VCH}

Utilizing native cells to carry drugs into cerebral tissues, especially to treat brain neoplasms, has attained noteworthy attention. ${ }^{[154,163]}$ Xue et al., in order to prevent glioma recurrence after surgery, applied neutrophils (NE) as carriers of paclitaxel (PTX)-loaded liposomes (Figure 9A). ${ }^{[154]}$ They first inserted PTX into cationic liposomes (PTX-CL), which then this complex was internalized by neutrophils to form a PTX-CL/NEs vehicle. Tissue damage induced by surgical tumor resection triggers an inflammatory process characterized by the systemic production of a variety of inflammatory mediators. Among these cytokines, there are a number of chemokines that, in parallel to the chemotactic gradient, direct PTX-CL/NEs complexes from the blood circulation toward the cerebral tissues invaded by cancerous cells. Following this, neutrophil extracellular traps (NETs) are released from the PTX-CL/NEs complexes, which are activated through various stimulatory signals. This phenomenon then leads to the release of PTX-CL and the effective delivery of PTX to neoplastic cells, where the drug finally promotes its cytotoxic effects and suppresses tumor progression (Figure 9B).

The findings of the recent study highlighted the capability of NEs to effectively carry PTX-CL complexes and deliver PTX to the brain, which prevented glioma recurrence in the mice undergoing surgical tumor resection. The role of the chemoattractants released postinflammation is supposed to be essential in the correct targeting of NEs toward inflamed cerebral areas. The release of the drug from NEs was shown to be dependent on the extent of stimulatory signals which are supposed to be potent at the inflammation site. After being released, PTX can specifically target and eradicate remaining cancerous cells and significantly, but not completely, delay tumor recurrence and prolong survival rates. 


\section{WILEY-VCH}

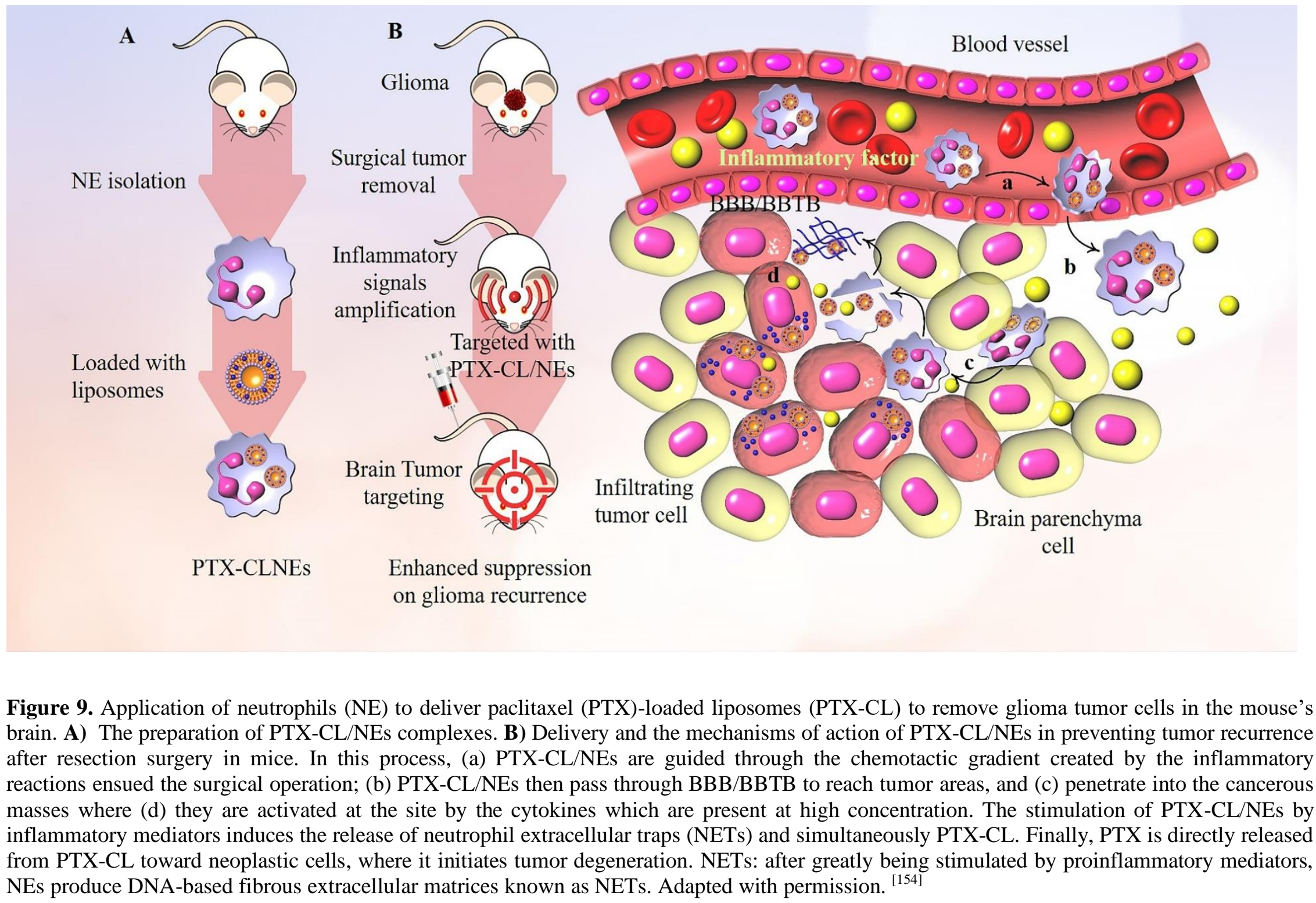




\section{WILEY-VCH}

Zhao and their coworkers, in order to treat ulcerative colitis, which is a gastrointestinal (GI) inflammatory condition exaggerating the risk of GI cancers, first filled liposomes with

keratinocyte growth factor (KGF) (Figure 10) ${ }^{[164]}$ Next, they employed lipopolysaccharides to activate neutrophils in mice and then isolated activated neutrophils' membranes in the form of vesicles. The incorporation of KGF-loaded liposomes with activated neutrophil liposomes resulted in a structure named neutrophil-like liposome (KGF-Neus). Loading of KGF into liposomes increased the drug stability, and this structure was shown to be easily encapsulated into activated neutrophil-derived liposomes with an efficiency of $95.3 \pm 0.72 \%$. The KGF-Neus was also shown to interact with and cross human umbilical vein endothelial cells via the inflammatory surface receptors expressed on both endothelial cells and activated neutrophils' membranes on KGF-Neus. In accordance, intravenously administered KGF-Neus effectively guided the drug toward the inflamed GI tract and alleviated inflammatory reactions and histopathological lesions in the mice exposed to dextran sulfate sodium, a colitis model. Some examples of neutrophil membrane camouflaged NPs for targeting of cancer cells are reviewed in Table 2. 


\section{WILEY-VCH}

Table 2. Summary of neutrophil membrane camouflaged NPs for targeting of cancer cells.

\begin{tabular}{|c|c|c|c|c|}
\hline NP cores & Therapeutics & Type of Cancer & Properties & Ref. \\
\hline $\begin{array}{l}\text { Neutrophil } \\
\text { membrane-coated } \\
\text { PEG-PLGA NPs }\end{array}$ & Celastrol & $\begin{array}{l}\text { Pancreatic } \\
\text { carcinoma } \\
\text { Orthotopic and } \\
\text { ectopic tumor } \\
\text { models }\end{array}$ & $\begin{array}{l}\text { - Selective accumulation at the tumor site following systemic } \\
\text { administration } \\
\text { - Preventing tumor regression and liver metastasis and } \\
\text { significantly prolonging the survival of tumor-bearing mice }\end{array}$ & [147] \\
\hline $\begin{array}{l}\text { Magnetic NPs } \\
\text { (Cubes-Cy5) }\end{array}$ & Cy5 & $\begin{array}{l}\text { - A mouse model of } \\
\text { breast cancer (4T1) } \\
\text { - Mouse model of } \\
\text { colon cancer } \\
\text { (CT26) models }\end{array}$ & -Efficient cell-mediated drug delivery & [158] \\
\hline $\begin{array}{l}\text { Magnetic NPs } \\
\text { (clusters- Cy5) }\end{array}$ & Сy5 & $\begin{array}{l}\text { - A mouse model of } \\
\text { breast cancer (4T1) } \\
\text { - Mouse model of } \\
\text { colon cancer } \\
\text { (CT26) models }\end{array}$ & -Efficient cell-mediated drug delivery. & [158] \\
\hline $\begin{array}{l}\text { Neutrophil- } \\
\text { membrane coated } \\
\text { PLGA NPs }\end{array}$ & $\begin{array}{l}\text { Carfilzomib } \\
\text { (CFZ) }\end{array}$ & $\begin{array}{l}\text { Mouse model of } \\
\text { breast cancer }\end{array}$ & $\begin{array}{l}\text { - Efficient cellular immunity in } 4 \mathrm{~T} 1 \text { bearing mice } \\
\text { - High in vivo CTC-capturing efficiency } \\
\text { - Selective depletion of blood CTCs } \\
\text { - Preventing the formation of new metastatic lesions and the } \\
\text { progression of previously-formed nodules } \\
\text { - Preventing the formation of metastatic niches by depleting } \\
\text { circulatory CTCs }\end{array}$ & [149] \\
\hline $\begin{array}{l}\text { Neutrophils-coated } \\
\text { liposomes }\end{array}$ & Paclitaxel (PTX) & $\begin{array}{l}\text { Mouse model of } \\
\text { malignant glioma }\end{array}$ & - Recruitment of NEs to the inflamed brain via surgery-induced & [154] \\
\hline
\end{tabular}




\section{WILEY-VCH}

\begin{tabular}{|c|c|c|c|c|}
\hline & & & $\begin{array}{l}\text { inflammatory mediators } \\
\text { - Release of PTX via the inflammatory mediators which have a } \\
\text { high local concentration } \\
\text { - PTX delivery to remaining tumor cells post-surgery } \\
\text { - Significant improvement in survival rate }\end{array}$ & \\
\hline $\begin{array}{l}\text { Neutrophils } \\
\text { internalized } \\
\text { doxorubicin-loaded } \\
\text { magnetic } \\
\text { mesoporous silica } \\
\text { NPs }\end{array}$ & Doxorubicin & $\begin{array}{l}\text { Mouse model of } \\
\text { glioma }\end{array}$ & $\begin{array}{l}\text { - Significant drug loading capability of phagocytized D-MMSNs } \\
\text {-Prolonged viability of neutrophils which results in high-dose drug } \\
\text { delivery and delayed relapse after surgery } \\
\text {-Employing living cells and NP-based carriers which effectively } \\
\text { synergize to eradicate cancer theranostics }\end{array}$ & [160] \\
\hline $\begin{array}{l}\text { Denatured BSA } \\
\text { NPs }\end{array}$ & $\begin{array}{l}\text { Pyropheophorbid } \\
\text { e-a }\end{array}$ & $\begin{array}{l}\text { Mouse model of } \\
\text { melanoma }\end{array}$ & $\begin{array}{l}\text {-High-dose drug delivery to tumors following the injection of } \\
\text { TA99 antibody bound albumin-NPs } \\
\text { - Neutrophil-mediated accumulation of NPs at the tumor site } \\
\text {-Efficient drug delivery to tumors }\end{array}$ & [72] \\
\hline $\begin{array}{l}\text { Neutrophils- } \\
\text { simulated } \\
\text { liposomes }\end{array}$ & $\begin{array}{l}\text { Keratinocyte } \\
\text { growth factor } \\
(\mathrm{KGF})\end{array}$ & $\begin{array}{l}\text { Ulcerative colitis, a } \\
\text { risk factor for } \\
\text { cancer of the colon, } \\
\text { rectum or bowel. }\end{array}$ & $\begin{array}{l}\text {-Significant improvements in the morphological and functional } \\
\text { features of bowel }\end{array}$ & [164] \\
\hline
\end{tabular}




\section{WILEY-VCH}

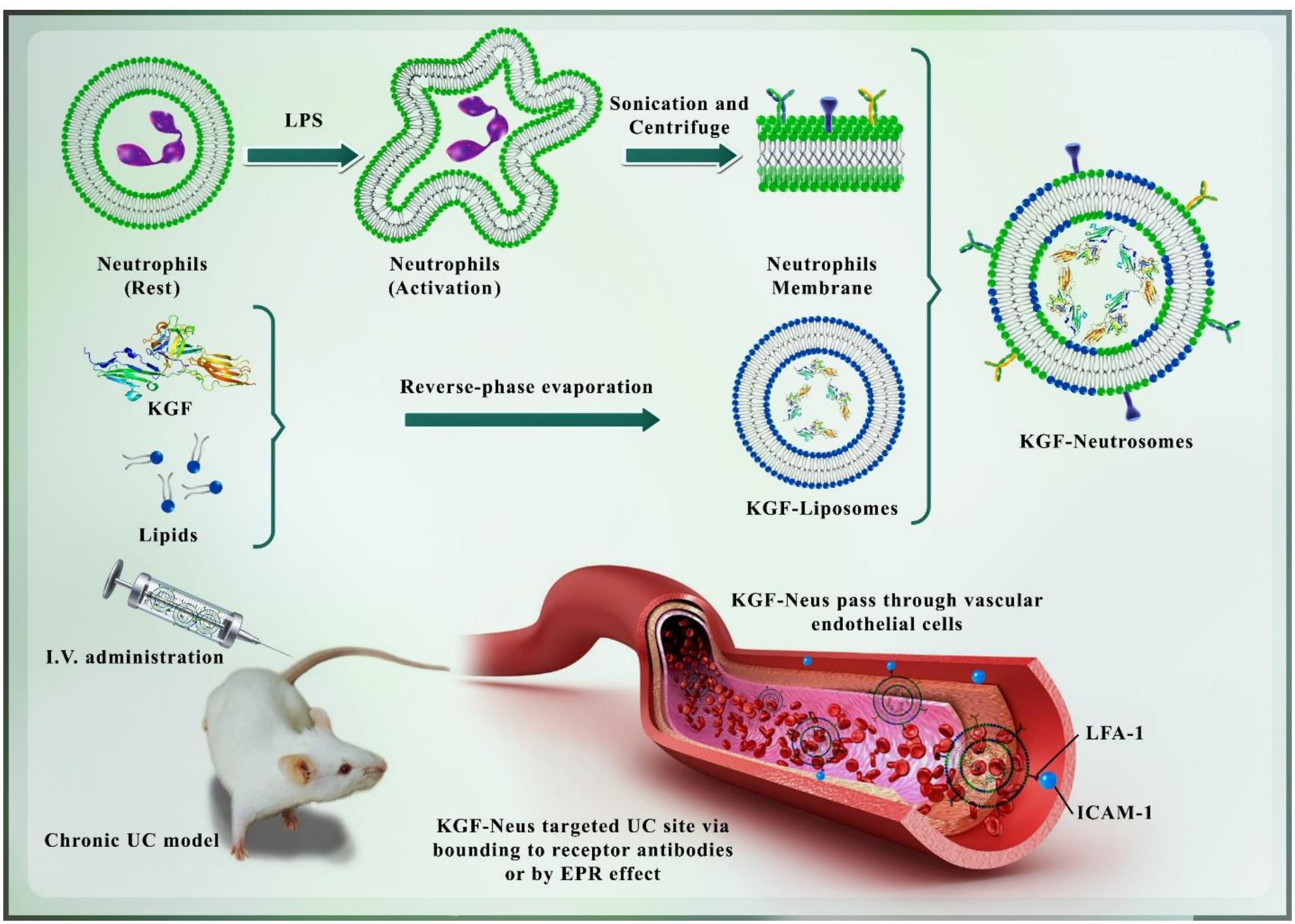

Figure 10. Schematic design of developing neutrophil-simulated liposomes for targeted delivery of keratinocyte growth factor to treat ulcerative colitis. Adapted with permission. ${ }^{[164]}$ 


\section{WILEY-VCH}

\subsection{Dendritic cells}

The antigen-presenting activity of dendritic cells (DC) (i.e., antigen-presenting cells; APCs), which primarily requires the recognition, internalization, and process of antigens, is a requisite for the activation of antigen-specific T cells. DCs also play essential roles in innate immunity. ${ }^{[165,}$ ${ }^{166]}$ Although other cells may, in part, participate in antigen presentation, DCs are by far the most important APCs in mammals. To effectively present antigens, DCs recruit major histocompatibility complexes (MHCs), which are the major membrane proteins involved in the formation of antigen presentation complexes between DCs and immune cells (i.e., lymphocytes and natural killer cells). For fulfilling their function, DCs need to be present at the tissues where they are more likely to encounter foreign organisms, and after being differentiated from their progenitors in the bone marrow, they migrate to such tissues (e.g., intestine, lungs, nose, skin, etc.). ${ }^{[167]}$ From a maturation point of view, various subtypes of DCs may be either mature or immature. Like hunters, the later forms of DCs constantly screen their environment looking for possible invading microorganisms. Foreign antigens from various sources (viruses, bacteria, vaccines, cancerous cells, disease-associated antigens, etc.) and pathogen-associated danger signals are major activators of DCs, which after activation, engulf and process the antigen to create presentable antigenic determinants. Then DCs find their ways toward lymph nodes (LNs) where $\mathrm{T}$ cells await to receive stimulating signals, as well as the processed antigenic signatures. After receiving stimulating signals, $\mathrm{T}$ cells differentiate to either helper, regulatory, or killer cytotoxic (CTLs) cells. ${ }^{[168]}$

Based on their role, DCs can be key participants in the immunotherapy of cancer ${ }^{[169,170]}$. To obtain an adequate number of DCs for such purposes and due to the low number of DCs in peripheral blood ${ }^{[171]}$ mature DCs (mDCs) should be developed in vitro by stimulating bone 


\section{WILEY-VCH}

marrow-derived progenitors or peripheral blood-derived monocytes via appropriate growth stimulating factors. ${ }^{[171]}$

Recently, dendritic cell (DC)-based vaccines have become important parts of cancer immunotherapy. Actually, the Food and Drug Administration (FDA) has already approved one DC-based vaccine to be employed for treating prostate cancer (PC) ${ }^{[172]}$ The DCs exploited to develop anti-cancer vaccines are generally autologous cells which have been exposed to and primed with either TAAs or whole tumor cell lysates ex vivo. This strategy delivers more efficient DCs to promote potent anti-cancer immune responses by activating both naïve and tumor-specific memory T lymphocytes. For inducing T cells, DCs should first migrate from the injection site to draining lymph nodes (dLNs) (Figure 11). The effectiveness of DC-based vaccination in promoting a proficient anti-cancer immunity has been validated in preclinical, clinical, and in vivo experimental studies. Nevertheless, there has been a paucity in the clinical trials employing DC vaccines, and they have been tested on a limited number of cancer patients over the two recent decades. ${ }^{[173,174]}$ Although DCs vaccines have been effective in boosting immunity against tumors as evidenced by preclinical and clinical in vivo studies, a few clinical trials have been conducted on the effectiveness of DC vaccination over the past 20 years. ${ }^{[173-176]}$ Potent immune responses (either innate or adaptive) require stimulatory signals from cytokines and other important immune regulators. The applicability of the systemic administration of cytokines may be compromised by challenges such as side effects, low circulatory stability, and a relatively quick excretion from the body. Although experimental studies on mice have shown the efficiency of cytokines in boosting antitumor immune responses, studies on humans have been restricted because of unacceptable cytotoxicity of this strategy. ${ }^{[177,178]}$ Here, one can bring up the role of nanotechnology and the fact that it is possible to obviate these problems by 


\section{WILEY-VCH}

infusing cytokines in cooperation with liposome-based or polymer-based NPs. In addition, to be safe, these strategies improve the circulatory kinetics, as well as anti-tumor and anti-microbial activities of cytokines even in much smaller doses in comparison with free cytokines. ${ }^{[179]}$ 


\section{WILEY-VCH}

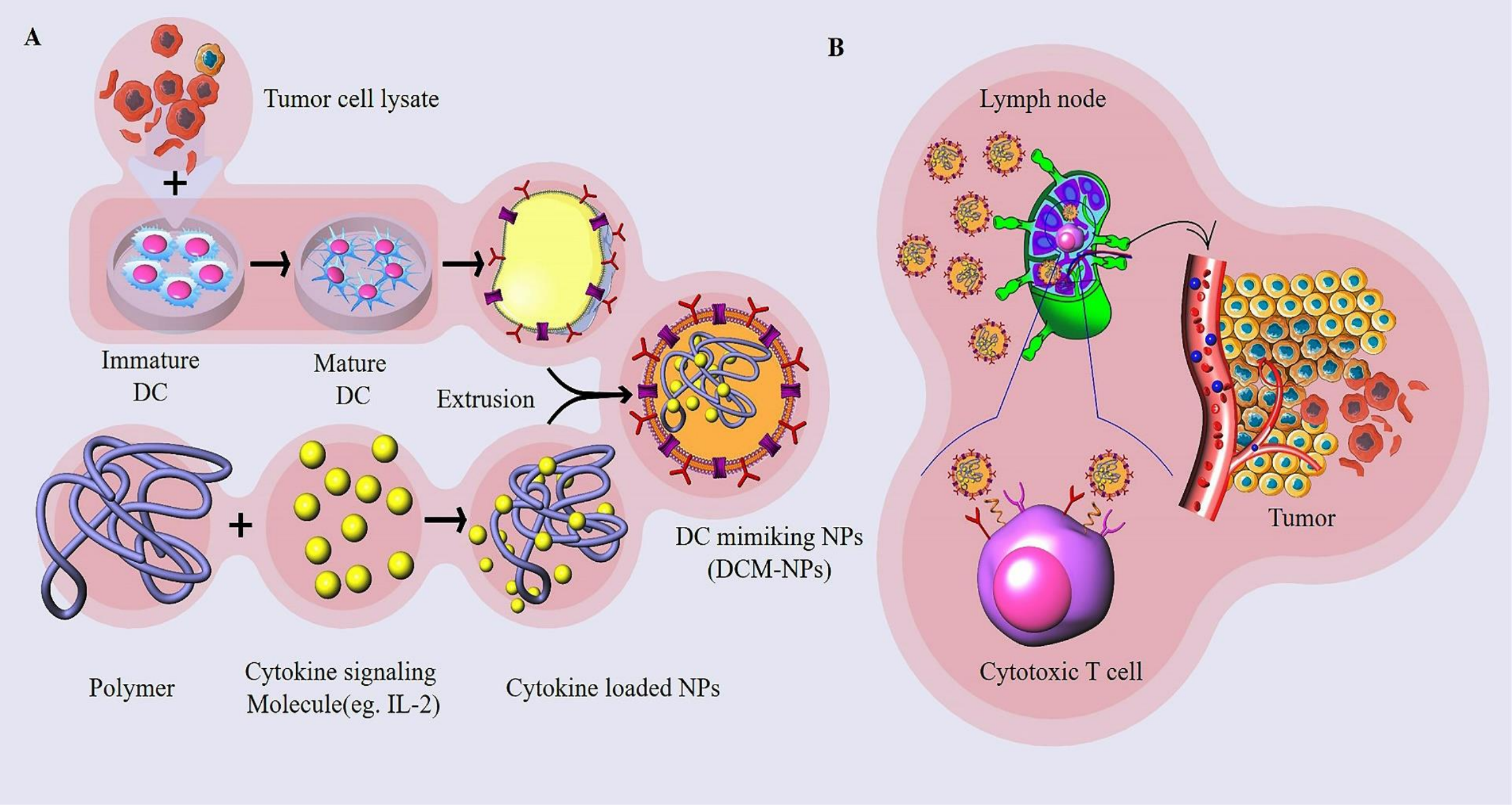

Figure 11. A) Constructing nanoparticles with functional and structural characteristics of DCs (i.e., DC mimicking NPs), B) The mechanisms of action of DC-like NPs in expanding antitumor T cell populations in cancer immunotherapy. 


\section{WILEY-VCH}

Cheng et al. designed a DC-based nano-vaccine applying cell-membrane coating technology. ${ }^{[175]}$ The formed vaccines, which were called "mini DC", delivered remarkable efficiency to present antigens to and stimulate $\mathrm{T}$ cells both in vivo and in vitro. The nano-vaccine developed in the recent study consisted of IL-2-loaded PLGA-NPs surrounded by a membrane derived from the DCs activated by being exposed to the tumor cell lysate. Therefore, because of having intact surface proteins, the developed DCs could effectively present tumor antigens to T lymphocytes, provide them with potent and unique stimulatory signals, and support a strong T-cell response both in vivo and in vitro. As cellular interactions need appropriate orientations of the involved molecules, the nano-dimension of the molecules of "minDCs" may be an important contributor to the enhanced $\mathrm{T}$ cell response by obviating the spatial hindrance during antigen presentation. Furthermore, non-alive mini DCs have a longer half-life, and in particular, show insensitivity to the negative impacts of immunosuppressants, which are among the main challenges of working with available DC-based vaccines. Because of these features, mini DCs were particularly effective in suppressing ovarian tumor growth and metastasis in an animal model. Therefore, they have been suggested as efficient vaccines to augment the effectiveness of immunotherapy in patients with cancer.

In a study that was conducted by Zhang et al., a combination of photochemical internalization (PCI) and a nanoparticle-based antigen delivery system was applied to induce tumor-specific CTLs. ${ }^{[180]}$ The combination of polyethyleneimine and Pheophorbide A (a hydrophobic photosensitizer) (PheoA-PEI) was shown to present both the ability to escape endosomal degradation and also the capability of near-infrared imaging. Furthermore, grafting the synthesized complex (i.e., PheoA-PEI) with ovalbumin (OVA), as a model antigen, resulted in 


\section{WILEY-VCH}

the formation of light-sensitive PheoA-PEI/OVA nanoparticles (PheoA-PEI/OVA NPs) (Figure 12).

The chemical; 2',7'-dichlorodihydrofluorescein diacetate (DCFH-DA), has been effective to induce oxidative stress in DC2.4 cells by promoting the production of reactive oxygen species (ROS). The light sensitivity of the produced PheoA-PEI/OVA NPs was effective in stimulating the release of antigens into the cytoplasm following exposition to light, as evidenced by confocal laser scanning microscopy (CLSM). Likewise, being exposed to light augmented the capability of the DC2.4 cells treated with PheoA-PEI/OVA NPs (compared to the cells induced by free OVA) for the cross-presentation of antigens to B3Z T hybridoma cells in vitro. Accordingly, the mice treated with light-stimulated PheoA-PEI/OVA NPs-primed DCs showed a significant elevation in the number of intratumor CTLs, which inhibited the growth of E.G7 tumor in these animals. These observations highlighted the effectiveness of using light-responsive NP-based vaccines to enhance the quantity and functional quality of tumor-specific $\mathrm{CD} 8^{+} \mathrm{CTLs}$ in cancer immunotherapy. 


\section{WILEY-VCH}

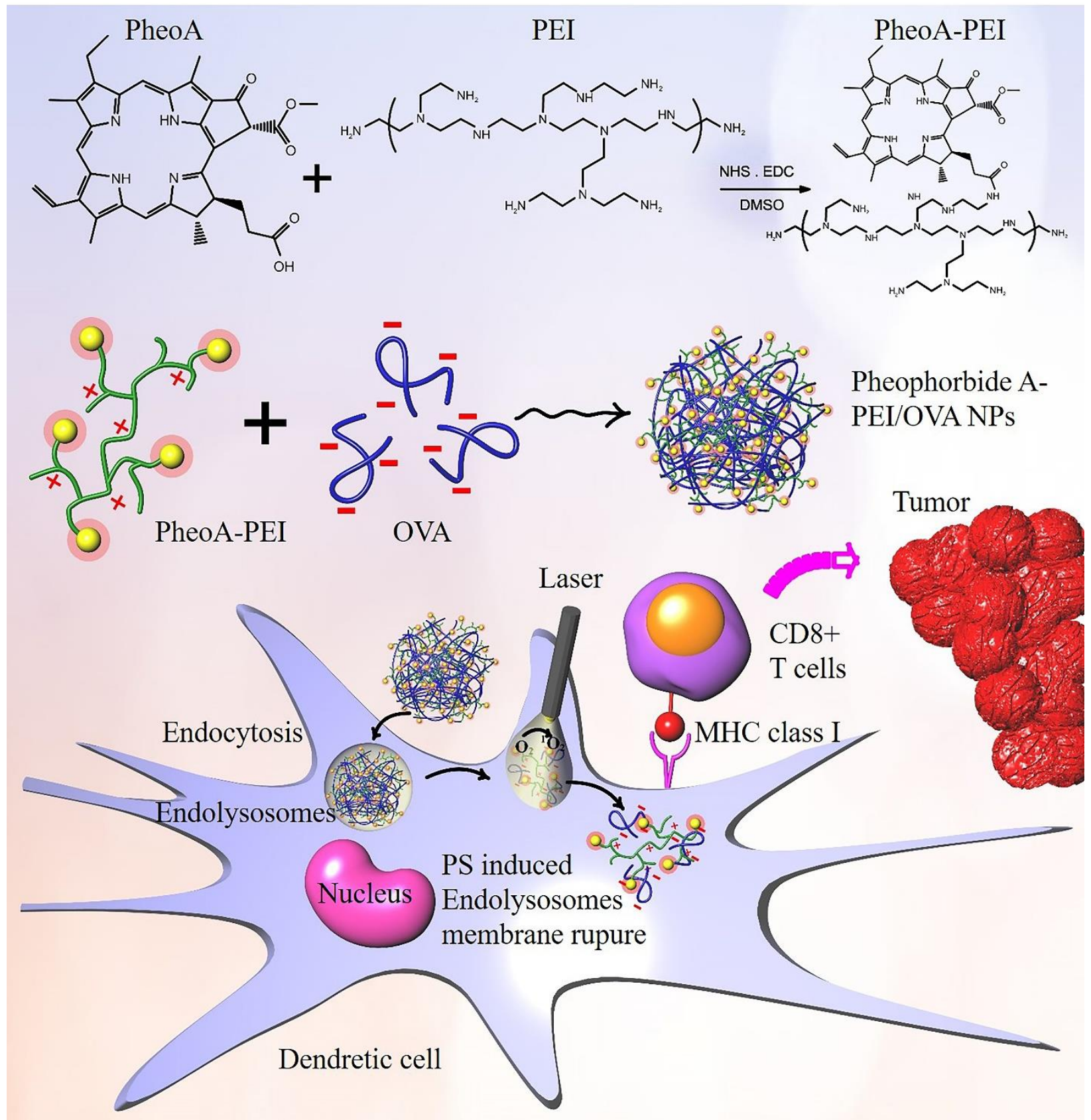

Figure 12. The production process of PheoA-PEI/OVA NPs. These NPs were shown to be potent stimulators for the immune system, in particular expanding specific anti-tumor $\mathrm{CD} 8^{+}$ cytotoxic T lymphocytes. Adapted with permission. ${ }^{[180]}$

\section{4. $T$ cells}




\section{WILEY-VCH}

Unlike the majority of leukocytes, thymus supports a major part of T lymphocytes' life cycle after their initial migration from the bone marrow at early developmental stages. In fact, $\mathrm{T}$ lymphocytes proliferate and differentiate to effector cells (i.e., helper, regulatory, or cytotoxic) in the thymus. A number of these cells also transform into memory cells engaged in a second encounter with foreign antigens. Until capturing an antigen, naïve $\mathrm{T}$ cells either circulate in blood or home in lymphatic tissues. After antigen stimulation, $\mathrm{T}$ cells differentiate mainly into either $\mathrm{CD} 4^{+}$helper or $\mathrm{CD} 8^{+}$cytotoxic cells. The former type participates in the production of a variety of growth factors, cytokines, and other inflammatory mediators and induces the differentiation of antibody-producing plasma cells from B lymphocytes. On the other hand, regulatory $\mathrm{T}$ lymphocytes are important to prevent exaggerated immune responses. The main killer cells are CD8 ${ }^{+}$CTLs, which eradicate target (e.g., infected, tumor) cells by secreting potent cytotoxic molecules. There is a vast repertoire of $\mathrm{T}$ and $\mathrm{B}$ cells' receptors (i.e., TCRs and BCRs) to ensure that the immune system can project appropriate responses to all potential antigens. ${ }^{[181]}$ Due to the presence of TCRs, T lymphocytes have highly specific antigen-binding features. ${ }^{[124,}$ ${ }^{182]}$ The TCR complex expressed on T lymphocytes can specifically detect and bind to tumorderived antigens and target cancer cells with a high affinity. The highly specific and efficient tumor detection capability of $\mathrm{T}$ cells suggests that their membranes can be used to create competent nanocarriers for targeted drug delivery in cancer immunotherapy. Applying natural and unmodified $\mathrm{T}$ cell membranes for this purpose (i.e., a single targeting strategy) may somehow reduce the carrier's detecting capability due to the great heterogeneity of tumors. So, incorporating complementary molecules into the membranes of $\mathrm{T}$ cell (i.e., a dual-targeting strategy) can provide a more competent carrier for targeting and delivering nano-based drugs and vaccines to cancerous tissues. ${ }^{[75]}$ 


\section{WILEY-VCH}

Regarding this issue, the incorporation of Azide (N3) and bicyclo [6.1.0] nonyne (BCN), the former being a synthetic sugar, with tumor-derived glycans has been suggested to enhance the efficiency of single tumor-targeting strategy by forming artificial receptors on tumor cells. These artificial receptors (i.e., $\mathrm{BCN}$ receptors) expressed on tumor cells along with other natural tumor surface determinants were shown in a study by Han et al. that can be recognized (via bioorthogonal chemistry and immune recognition, respectively) by N3(Azid)-labeled $\mathrm{T}$ cell membrane (N3-TINPs) coated with indocyanine green NPs (INPs). The fluorescent signals emitted from the tumors of mice administered with N3-TINPs were significantly higher (1.5fold) in comparison with the animals treated with TINPs alone. Without imposing any unwanted adverse effect, the N3-TINPs accumulated in cancerous lesions enhanced the effectiveness of photothermal therapy. Collectively, the NP-based $\mathrm{T}$ cell membranes constructed based on the chemical principles of bio-orthogonal phenomenon can role as potential artificial carriers to promote the efficiency of targeting cancer cells in photothermal therapy (Figure 13). ${ }^{[74]}$ 


\section{WILEY-VCH}
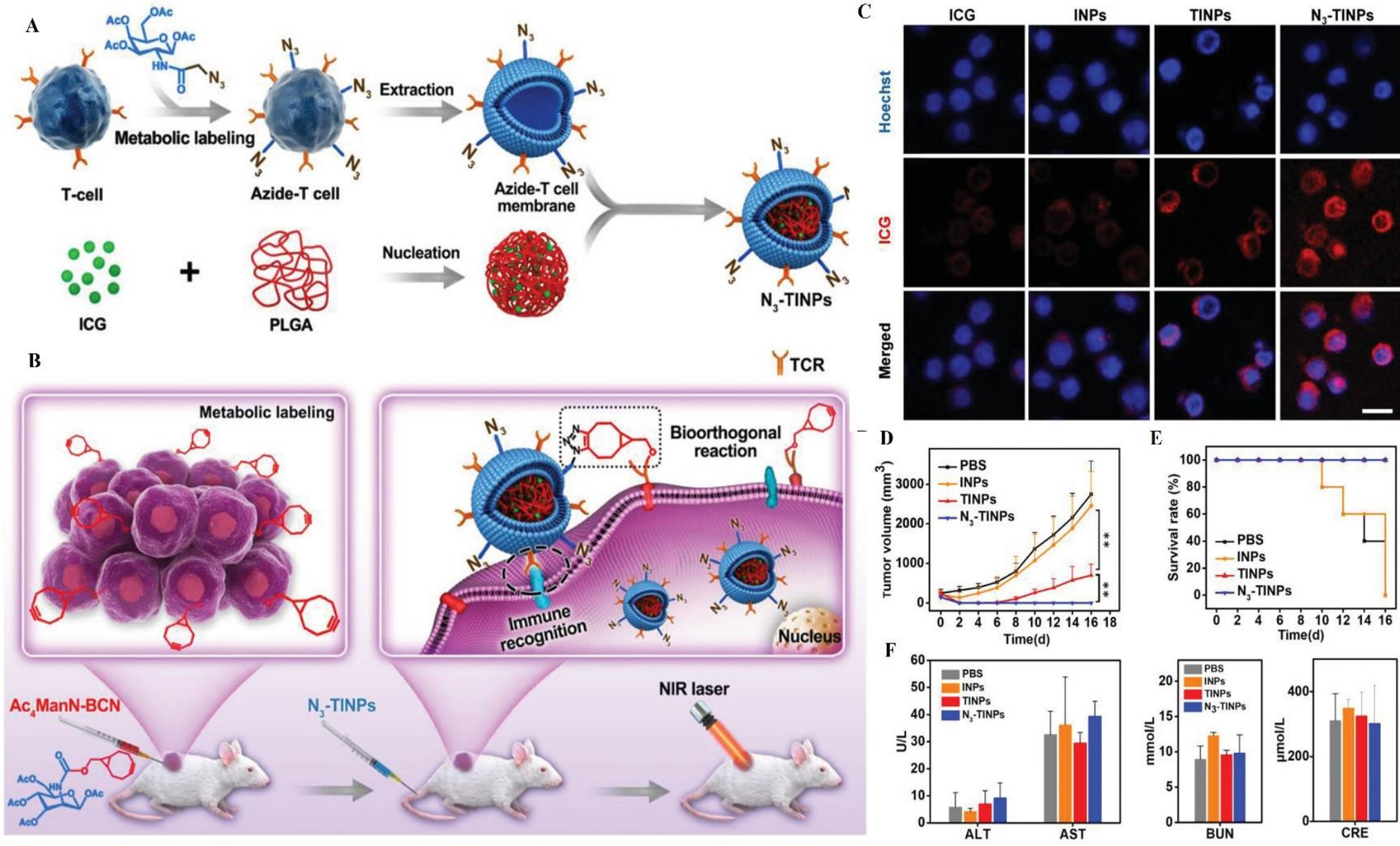

Figure 13. Developing nanoparticle-based N3-labeled $T$ cell membranes (N3-TINPs) exploiting a dual-targeting strategy in photothermal therapy of cancer. A) For producing N3-TINPs, ICG-PLGA polymers were initially used to coat N3-labeled T cell membranes by extrusion. B) The N3 groups on the surface of N3-TINPs participate in a bio-orthogonal interaction with the bicyclo [6.1.0] nonyne BCN groups incorporated on the surface of neoplastic cells via natural glycometabolic labeling and preincubation with Ac4ManN-BCN. This reaction markedly enhances the removal of cancer cells and tumors in mice via the ICG-mediated photothermal phenomenon. C) Confocal microscopy images showing the uptake of ICG by Raji cells (Scale bar: $25 \mu \mathrm{m}$. D) The tumor growth curves of Raji cells, E) survival rates, and F) liver and kidney serum functional parameters in the mice treated with various strategies. Reproduced with permission ${ }^{[74]}$. 


\section{WILEY-VCH}

In another experiment to develop a nano-based carrier, Ma et al. incorporated mesoporous silica containing IR780 NPs with the membranes of chimeric antigen receptor T (CAR-T) cells to specifically target GPC3 expressing hepatocellular carcinoma cells (HCCs) (Figure 14). They designed the nano-carrier applying CAR-T cells in a way that it could detect the HCCs expressing GPC3. After extracting intact membranes from CAR-T cells, they were used to engulf mesoporous silica containing IR780, and the efficiency of this process was verified by TEM. The researchers accomplished their experiment by showing that the NP-coated CAR-T cell membranes were more efficient in targeting HCC cells than IR780 loaded mesoporous silica both in vivo and in vitro. ${ }^{[183]}$ 
WILEY-VCH
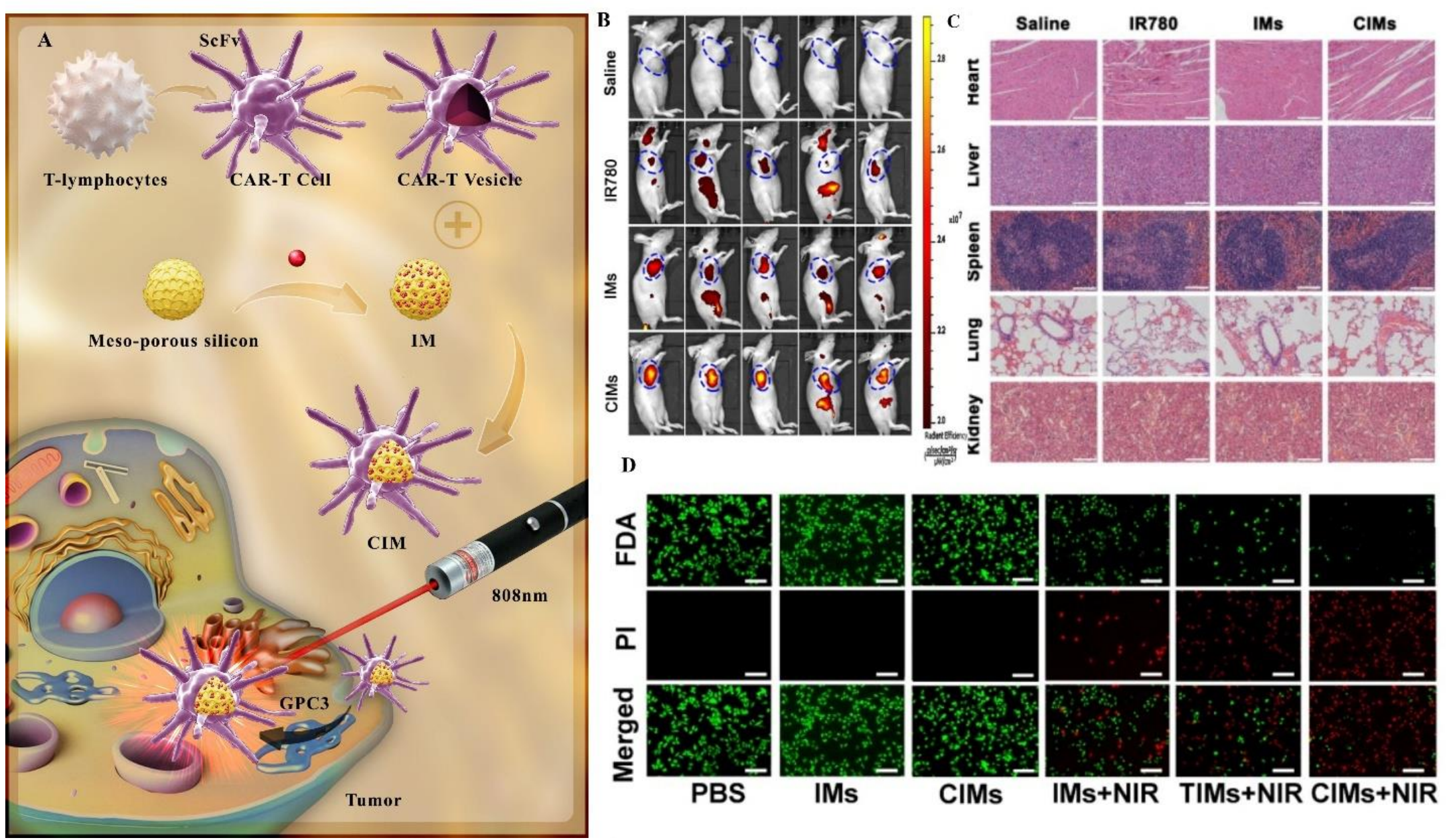

Figure 14. A) Constructing NP- CAR-T membrane for targeted photothermal cancer therapy. Adapted with permission. ${ }^{\text {[183] }}$ Systemic cytotoxicity and bio-distribution in a mouse's body. C) Ex vivo accumulation of IR780 in the tumors from the mice treated with either IMs, CIMs, or free IR780. B3) Histologic sections from the spleen, kidneys, lungs, and liver from the nude mice intravenously administered with either saline, IR780, IMs, or CIMs for 19 days. D) Images to evaluate the toxicity of NP-based photothermal therapy against Huh-7 cells (green spots indicate alive cells emitting fluorescein diacetate, and red spots (propidium iodide) show nonalive cells. ${ }^{[183]}$ 


\section{WILEY-VCH}

Another nanocarrier-based targeted drug delivery system was developed by Zhang et al. employing the membranes derived from human CTLs. The utilized nanoplatform PLGA NPs were coated with membranes from CTLs, and the synthesized therapeutic complex was targeted toward intended tissues by local low-dose irradiation (LDI). The researchers applied dynamic light scattering (DLS), TEM, and confocal laser scanning microscopy to show the efficiency of the membrane coating process. This strategy significantly prevented the carrier from being detected and engulfed by macrophages (a phagocytosis rate of $23.99 \%, \mathrm{P}=0.002$ ). The growth of tumors significantly reduced (up to56.68\%) in nude Balb/c mice models of gastric cancer fowling the delivery of PTX via PTX-loaded T cell membrane-coated NPs (Figure 14). The tumor growth suppression activity was also significantly enhanced (up to $88.50 \%$ ) by employing LDI at the tumor site and even ended up in complete remission in two of the experimental animals. This significant boost may be explained by the augmenting effects of LDI on the expression and activation of adhesion receptors on tumor's vascular beds, and therefore a higher recruitment of the NPs encapsulated in T-lymphocyte membranes to tumor tissues (via lymphocyte-tumor endothelium interactions). In general, this novel nano-based drug carrier system showed long circulatory half-life and efficient recruitment to tumor sites following local LDI because of interactions between the adhesion molecules expressed on $\mathrm{T}$ cells' membranes and in the tumor environment. ${ }^{[77]}$ For example, Zhang et al. ${ }^{[77]}$ coated PLGA NPs with the membranes derived from cytotoxic $\mathrm{T}$ cells to develop a biomimetic delivery platform. For directing the particles to the target site, they applied local LDI. In this study, membrane coated NPs showed both prolonged half-life in blood circulation and favorable specific accumulation within tumor. These properties could be attributed to the ability of cytotoxic $\mathrm{T}$ cells to recognize 


\section{WILEY-VCH}

cancerous cells and accumulate in tumor tissues, an ability that was remarkably enhanced by

\section{local LDI.}

In the patients suffering from leukemia or melanoma, the adoptive transferring of tumor-specific $\mathrm{T}$ cells has been shown to induce tumor regression and, even in some cases, full and long-lasting responses. ${ }^{[184,185]}$ Experimental and clinical pieces of evidence indicate that the therapeutic efficiency of tumor-specific $\mathrm{T}$ cells can be enhanced in association with either stimulatory cytokines (such as interleukins) or the mediators affecting the biology of the tumor microenvironment. Nevertheless, caution should be taken on how and when to present synergistic adjuvant mediators to avoid the adverse effects of high-dose intravenously infused immunomodulators. ${ }^{[69,186]}$ A solution to these concerns has been provided by producing genetically manipulated $\mathrm{T}$ cells that are able to inherently express stimulatory cytokines by recruiting specific transcription factors downstream to TCR signaling. Nevertheless, this strategy has also shown unacceptable toxicity in clinical studies, which is supposed to be related to intraindividual variations in gene expression profiles following TCR activation. ${ }^{[187]}$

Despite these drawbacks, researchers are still eagerly working on ways to increase the anti-tumor activity, particularly in solid tumors, of T cells in parallel to keeping an acceptable safety profile. Protein nanogels have been developed and employed in order to provide numerous stimulatory and synergistic signals for $\mathrm{T}$ cells. The advantages of nanogels is that they deliver a gradual and selective drug release process following the activation of TCRs. In their experiment, Tang et al. implemented nanogels on the surface of $\mathrm{T}$ cells, where they were responsive to an elevation in the reduction potential of $\mathrm{T}$ cell membrane following the binding of TCRs to target antigens. The incorporated nanogels therefore allowed drug release only at the site of antigen recognition (for example, tumor microenvironment). A super-agonist complex containing IL-15 was designed 


\section{WILEY-VCH}

based on nanogel technology in the recent study, which resulted in remarkably high and selective expansion of intra-tumor $\mathrm{T}$ cells (as high as 16-fold) in comparison with systemic free IL-15 administration. In this strategy, an excellent therapeutic effect of IL-15 was delivered to tumors because of the possibility of safe use of at least 8 times higher cytokine doses with no toxicity and effective in vivo tumor eradication mediated by T and CAR-T cells. ${ }^{[69]}$ Although the results of CAR-TC therapy have been promising in hematologic neoplasms, the applicability of this strategy in solid tumors has been limited. The reasons for the relatively unsuccessful attempts on solid tumors may root in the presence of immunosuppressive mediators in solid tumors' microenvironments, the low accessibility of $\mathrm{T}$ cells to tightly packed tumor cells, cellular heterogeneity of solid tumors, and finally, the development of tumor cells that can hide themselves from being detected by CAR-TCs. To resolve these problems, researchers have tried to design more efficient CAR-TCs and to favorably manipulate tumor microenvironment. ${ }^{[188]}$

\subsection{NK cells}

Natural killer (NK) cells are important cells of the innate immunity in fighting against tumor cells. A unique feature of these cells is that unlike T lymphocytes, they do not require to be presensitized to recognize and eradicate abnormal (including tumor and stem) cells. ${ }^{[189,}$ 190] Granzymes and perforin are among important cytolytic components of granules of NK cells, which are released toward target cells upon being recognized by and attached to the immune cells (i.e. immune synapse formation). NK cells have already been used in several studies to induce adoptive cancer immunity in a variety, in particular hematologic, tumors. ${ }^{[82]} \mathrm{NK}$ cells are a first line defense against cancer and infections. ${ }^{[67]}$ They have gain considerable attraction for tumor immunotherapy researches for the following reasons: 


\section{WILEY-VCH}

a) They regulate the immune responses via secretion of different cytokines like tumor necrosis factor $(\mathrm{TNF}-\alpha) \cdot{ }^{[73,191]}$ b) Target cells are killed spontaneously by NK cells without previous antigen- specific excitation and restriction of the MHCs. ${ }^{[67]}$ C) They start the maturation of antigen- presenting cells (APCs) and in following activation of $\mathrm{T}$ cells for killing tumor cells. ${ }^{[67}$, 82]

Wu et al. in a study covered NK cells with magnetic NPs and implemented a magnetic device in animal models' bodies in order to target the immune cells toward lung tumor cells. In order to develop a magnetic-based delivery system, superparamagnetic iron oxide NPs consisting of a magnetic $\mathrm{Fe} 3 \mathrm{O} 4$ core covered with polydopamine (PDA) [Fe3O4@PDA] have also been employed. These NPs are physiologically stable and biologically safe, and have been shown to be readily recognized and engulfed by NK cells, without significantly affecting the metabolism and viability of these immune cells. The NK cells labeled with Fe3O4@PDA NPs exerted remarkable anti-growth and anti-proliferative effects (evidenced by decreased Ki-67 expression) against tumor cells in vitro. Furthermore, the A549 cancerous cells challenged with the modified NK cells showed an elevated apoptotic rate. Under a magnetic field and after H\&E staining, the NK cells conjugated with Fe3O4@PDA NPs promoted the recruitment of CD56 expressing NK cells and the precipitation of iron within tumor microenvironment. The findings of the recent study supported the potential role of magnetic nano-compounds (e.g. Fe3O4@PDA NPs as shown here) in developing efficient anti-tumor immune cells. ${ }^{[192]}$

Deng and their co-workers, used NK cell membrane cloaked photosensitizer 4,4',4",4'"(porphine-5,10,15,20-tetrayl) tetrakis (benzoic acid) (TCPP)-loaded NPs (NK-NPs), that was able to eliminate primary tumors and inhibited distant tumors (Figure 15A) ${ }^{[67]}$ In their study the extracted NK cell membrane were coated onto photosensitizer TCPP-loaded polymeric NPs by 


\section{WILEY-VCH}

extrusion. NK cell membrane enabled the NK-NPs to elicit pro-inflammatory M1-macrophage polarization in tumor for generating cell-membrane immunotherapy. NK-NPs could elicit dying tumor cells to generate DAMPs (CRT exposure, ATP secretion, and HMGB1 release) through PDT-induced immunogenic cell death (ICD) for enhancing the NK cell-membrane immunotherapy effect. Specifically, immunogenic PDT enhanced NK cell-membranes immunotherapy, which significantly improved the infiltration of effector $\mathrm{T}$ cells $\left(\mathrm{CD} 4^{+} \mathrm{T}\right.$ cells and $\mathrm{CD}^{+} \mathrm{T}$ cells) in tumors for the highly efficient inhibition of both primary tumors and abscopal tumors (Figure 15B-D). 


\section{WILEY-VCH}

A

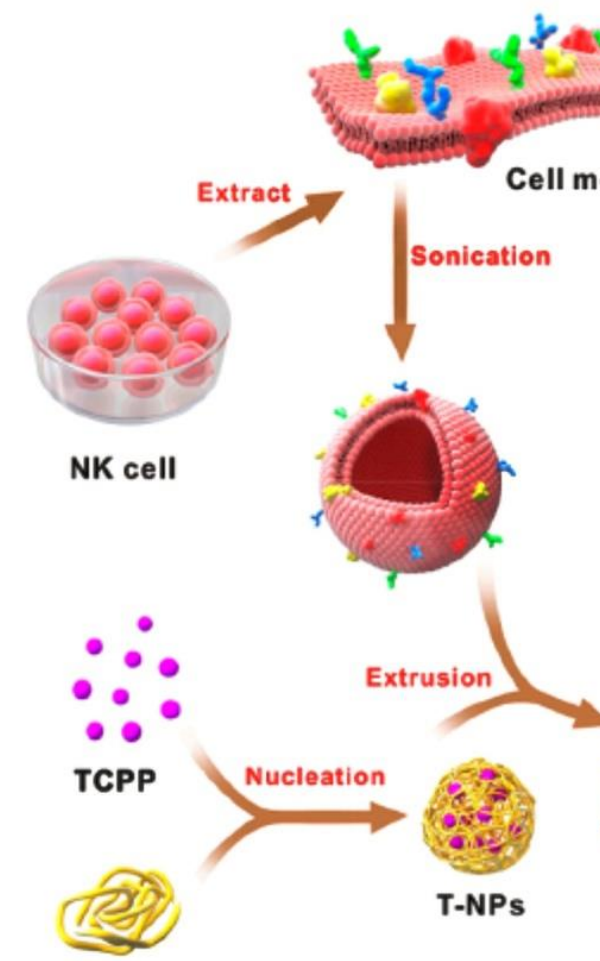

IPEG-PLGA

B

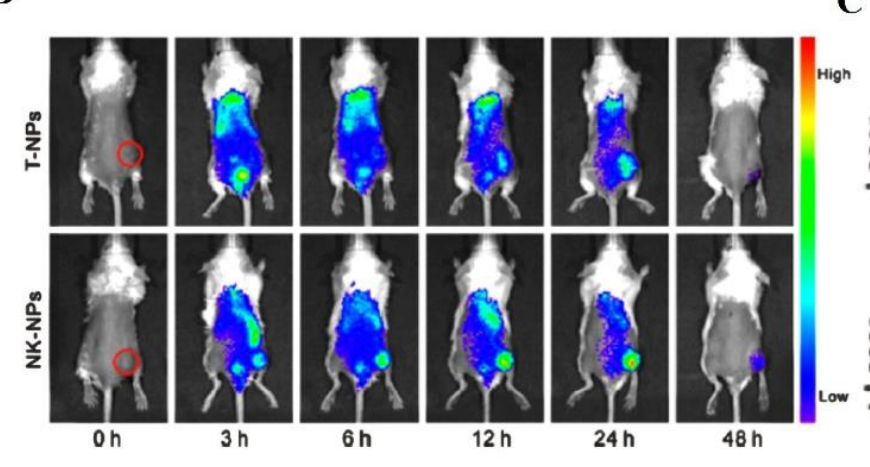

C

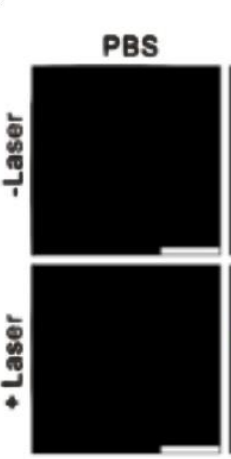

- CRT Immunogenic 1 CRT $\nabla$ ATP $\Rightarrow$ - 2 \% $49>0$ Antigen

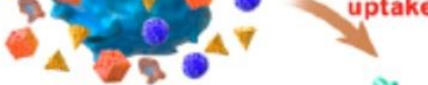

Dying tumor cell
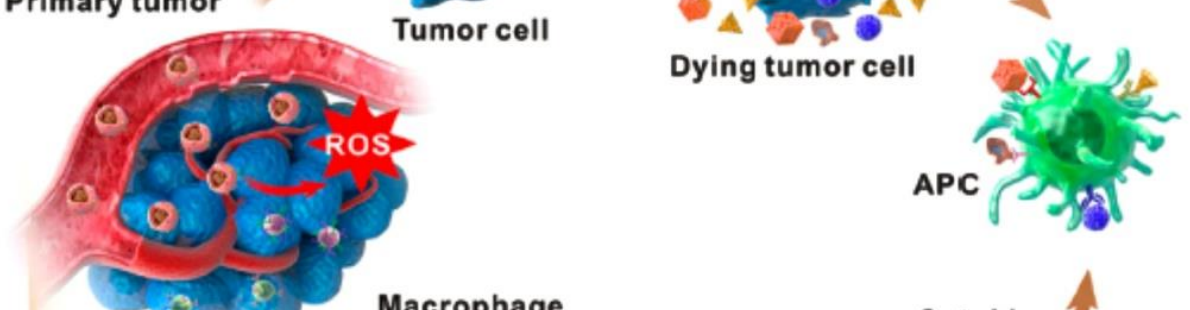

APC $50,31^{\circ}$
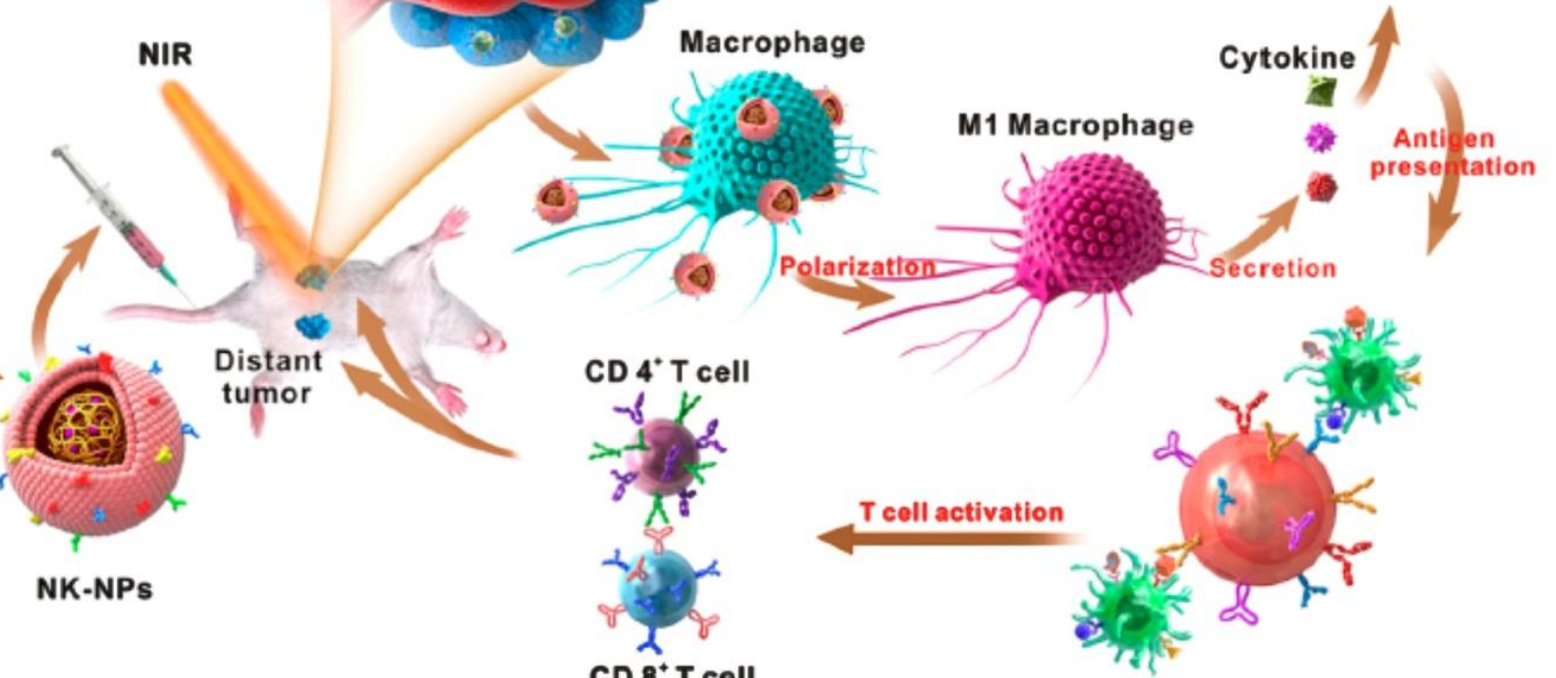

CD $8^{+} T$ cell

T-NPs
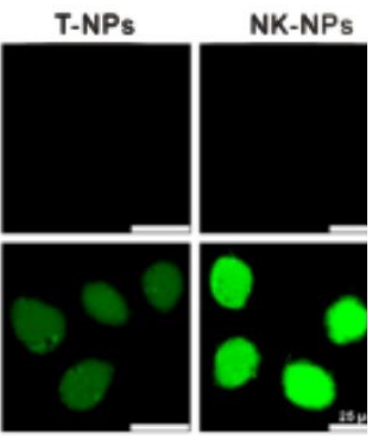

D

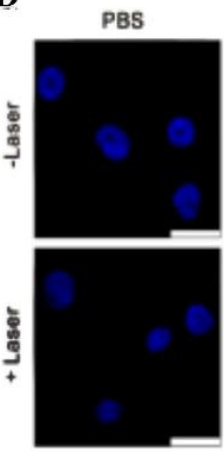

T-NPs

NK-NPs

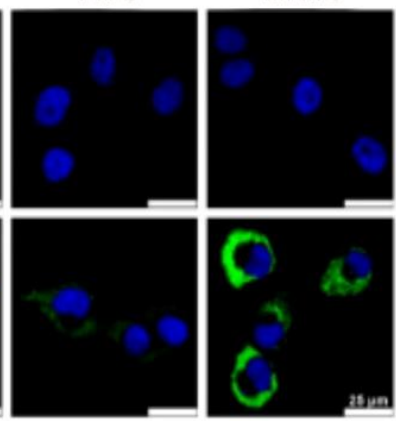




\section{WILEY-VCH}

Figure 15. A) PDT-Enhanced Cell-Membrane Immunotherapy and the role of NK CellMembranes-Cloaked Nanoparticles. Reproduced with permission. ${ }^{[67]}$ 4T1 tumor-bearing $\mathrm{BALB} / \mathrm{c}$ mice were subjected to time-lapse NIR fluorescent imaging. C) Following exposition to $660 \mathrm{~nm}$ laser, changes in the cellular fluorescence intensity $(100 \mathrm{~mW} / \mathrm{cm} 2)$ of DCFH-DA were recorded, reflecting the production of reactive oxygen species by murine NK- NPs and T-NPs. D) Confocal microscopy images after the exposition of tumor cells to T-NPs, murine NK-NPs, and laser $(660 \mathrm{~nm}, 100 \mathrm{~mW} / \mathrm{cm} 2)$ radiotherapy following exposure to CRT.

\section{Conclusions and Future Perspectives}

For the first time, our lessons from nature led us to introduce the concept of biomimetic in the context of cancer immunotherapy and targeted drug delivery. Actually, we learned how to send biological systems to fight their counterparts. The concept is currently intercalated with drug delivery systems in anti-tumor treatments. By being encapsulated in cellular membranes (i.e., cell membrane-coating technology), biomimetic immune cell-based NPs have been developed to resemble the functional features of normal cells, obviate the limitations of nano-based materials (e.g., fast removal from blood circulation), and augment the clinical efficacy of nanodrugs. As the functional features and components (proteins, receptors, etc.) of biological membranes are preserved during the membrane-coating process, cell membrane-based NPs can effectively interact and engage with various molecules within the tumor microenvironment. The efficiency of biomimetic drug delivery systems, in particular those that are based on membrane-coating technology, largely depends on the types of cells from which the membranes are derived and also the strategies employed to target tumors.

Especially, using membranes which are derived from immune cells has revolutionized the field of targeted drug delivery because they have both high biocompatibility and specificity. Although some immune cells may non-specifically gather in tumors (especially immediate cellular accumulations following injection), the best outcome is observed in systems that can warrant a long-term accumulation of immune cells in tumors. ${ }^{[193]}$ Overall, the membrane-coated NPs 


\section{WILEY-VCH}

loaded with anti-tumor drugs are increasingly gaining attention and are yet to be more developed and optimized to target tumors with high efficiency and specificity.

Here, we discussed the technology of using immune cells to design drug delivery systems. These cells are unique because of their special functional features from highly specific and efficient detecting capabilities for tumor cells and antigens of various types (proteins, carbohydrates, DNA, etc.) and sources (intrinsic, extrinsic, pathogenic) to having the ability to travel all over the body and enter any tissue. These cells are also very efficient in antigen processing and presentation, as well as activating or suppressing other cells via stimulatory/inhibitory signals. Based on the nature of their components, there are currently five main recognizable classes of immune cell-based therapeutics. These platforms are those recruiting 1) alive immune cells, 2) surface-modified immune cells, 3) immune cells' membranes, 4) leukocyte-secreted extracellular vesicles, and finally 5) artificial immune cells. As complex biological systems consisting of major biological molecules such as proteins, lipids, nucleic acids, etc., immune cell-based systems have excellent compatibility and efficiency in vivo and can be used as independent therapeutics, and drug carriers in targeted therapy approach.

Among immune cells, macrophages that are widely present in most tissues have optimal properties for being used in immune-based therapeutic or drug delivery systems. These cells are always on high alert and upon activation via appropriate stimulatory signals, recognize and engulf any pathogen immediately. ${ }^{[194]}$ Macrophage-derived membranes have been suggested as appropriate materials to coat NPs and synthesize biomimetic systems for drug delivery and other purposes.

Neutrophils are numerically the main blood leukocytes and key components of the innate immune system, which can penetrate into extravascular spaces by a phenomenon known as 


\section{WILEY-VCH}

diapedesis. ${ }^{[152]}$ During tissue injury, inflammation, and infections, a variety of chemokines are released by damaged tissues, pathogens, and other inflammatory cells that are present at the site. These chemokines are sensed by sophisticated membrane receptors of neutrophils, which directs them toward the inflamed tissue. This feature dedicates neutrophils' membranes with great potential for being used in designing efficient and specific biomimetic NPs as nano-drug carriers. TCRs expressed on $\mathrm{T}$ lymphocytes are among biological receptors with the greatest specificity and affinity for targeting the antigenic determinants derived from pathogens, microorganisms, and tumor cells. Based on this, the T cell-biomimetic drug delivery systems expressing tumorspecific TCRs can deliver highly specific drug vehicles in cancer immunotherapy approaches.

DCs, because of expressing specific co-stimulatory/inhibitory molecules on their membranes and proficient antigen processing and presenting features, can also be used for developing biomimetic systems, especially DC-based vaccines. Because of the low number in the blood; however, DCs should be expanded in vitro by being exposed to growth factors from bone marrow-derived hematopoietic progenitors or peripheral blood-derived monocytes.

In general, it seems that designing biomimetic immune cell-based NPs for delivering drugs will continue to develop for clinical applications, especially in cancer immunotherapy. In fact, these nano-based approaches are expected to revolutionize cancer targeted therapies in the future.

The concept of "cell-factories" refers to a platform designed for producing drugs, and such platforms can be integrated with cell-mediated targeted drug delivery systems. It is also possible to create genetic circuits that can provide the opportunity to enforce the expression of target genes applying appropriate triggers. The genes or gene clusters of interest are selected based on the nature of diseases and then inserted adjacent to specific promoters. These genes, which are expressed upon being exposed to the trigger, are expected to systemically deliver a therapeutic 


\section{WILEY-VCH}

protein. A variety of triggers can be used in this approach to induce the expression of target genes. Overall, this technology can ensure an effective therapeutic dose of the target protein and also a better clinical outcome, as well as higher patient satisfaction.

Using immune cell membrane to modify NPs can enable these particles to remain for a longer period in the blood circulation and provides better and more accurate migration to inflamed sites or tumor locations. This property (i.e., specific targeting) is mainly attributed to the immune receptors expressed on the cell membranes. Despite this benefit, since immune membranes are currently deriving from immortal cells, they can result in unwanted biological effects, limiting their widespread application. In addition, the expression of major histocompatibility complex (MHC) molecules on the membranes derived from immune cells brings immunogenicity issues, which need to be further investigated. Therefore, it is important to switch to cell membrane extraction from the patients for their own use after coating on the NPs. In fact, autologous cell membranes can be used as highly efficient and controllable drug-carrying machines in the near future. Other limitations around membrane coated NPs include varied efficiencies of membrane fusion protocols, which raise the necessity of developing adjustable methods to ensure desirable output of these approaches. We also need to define standard quality control criteria for immune cell membrane coated particles to ensure they are free of microorganisms, such as viruses, bacteria, or toxins (e.g., pyrogens). In addition, the proteins expressed on membranes must be functionally and structurally intact to avoid poor efficiency, as well as immune reactions against denatured surface proteins. Moreover, costs of cell membrane isolation and characterization should be taken into account for scale up production. Overall, despite numerous experimental evidences that show this approach can be used for therapeutic purposes in many diseases, we still face some hurdles to widely employ cell-mediated targeted delivery systems in clinical practice. 


\section{WILEY-VCH}

\section{Acknowledgements}

The authors are grateful for financial supports from the Immunology Research Center, Tabriz University of Medical Sciences, and North Khorasan University of Medical Sciences. M.-A.

Shahbazi acknowledges the financial support from the Academy of Finland (grant no. 317316).

\section{Conflict of Interest}

The authors declare no conflict of interest.

Received: ((will be filled in by the editorial staff))

Revised: ((will be filled in by the editorial staff)) Published online: ((will be filled in by the editorial staff)) 


\section{WILEY-VCH}

\section{References}

[1. Adiseshaiah, P. P.; Crist, R. M.; Hook, S. S.; McNeil, S. E., Nature reviews Clinical oncology 2016, 13 (12), 750.

2. $\quad$ Chen, G.; Roy, I.; Yang, C.; Prasad, P. N., Chemical reviews 2016, 116 (5), 2826-2885.

3. Alibakhshi, A.; Kahaki, F. A.; Ahangarzadeh, S.; Yaghoobi, H.; Yarian, F.; Arezumand, R.; Ranjbari, J.; Mokhtarzadeh, A.; de la Guardia, M., Journal of Controlled Release 2017, 268, 323-334.

4. $\quad$ Mosafer, J.; Abnous, K.; Tafaghodi, M.; Mokhtarzadeh, A.; Ramezani, M., European journal of pharmaceutics and biopharmaceutics 2017, 113, 60-74.

5. Soltani, F.; Parhiz, H.; Mokhtarzadeh, A.; Ramezani, M., Current pharmaceutical design 2015, 21 (42), 6214-6235.

6. Ebrahimian, M.; Taghavi, S.; Mokhtarzadeh, A.; Ramezani, M.; Hashemi, M., Applied biochemistry and biotechnology 2017, 183 (1), 126-136.

7. Mokhtarzadeh, A.; Vahidnezhad, H.; Youssefian, L.; Mosafer, J.; Baradaran, B.; Uitto, J., Trends in molecular medicine 2019, 25 (12), 1066-1079.

8. $\quad$ Huang, Y.; Gao, X.; Chen, J., Acta Pharmaceutica Sinica B 2018, 8 (1), 4-13.

9. Shukla, T.; Upmanyu, N.; Pandey, S. P.; Sudheesh, M., Site-specific drug delivery, targeting, and gene therapy. In Nanoarchitectonics in Biomedicine, Elsevier: 2019; pp 473-505.

10. Khansarizadeh, M.; Mokhtarzadeh, A.; Rashedinia, M.; Taghdisi, S.; Lari, P.; Abnous, K.; Ramezani, M., Human \& experimental toxicology 2016, 35 (4), 377-387.

11. Ahmadi, H.; Ramezani, M.; Yazdian-Robati, R.; Behnam, B.; Azarkhiavi, K. R.; Nia, A. H.; Mokhtarzadeh, A.; Riahi, M. M.; Razavi, B. M.; Abnous, K., Chemico-biological interactions 2017, 275, 196-209.

12. Matsumura, Y.; Maeda, H., Cancer research 1986, 46 (12 Part 1), 6387-6392.

13. Liu, Y.; He, Q., The route of nanomaterials entering brain. In Neurotoxicity of Nanomaterials and Nanomedicine, Elsevier: 2017; pp 33-57.

14. Wang, Y.-L.; Yao, J.; Chakhoyan, A.; Raymond, C.; Salamon, N.; Liau, L. M.; Nghiemphu, P. L.; Lai, A.; Pope, W. B.; Nguyen, N., American Journal of Neuroradiology 2019, 40 (6), 979-986.

15. Munn, L. L., Drug discovery today 2003, 8 (9), 396-403.

16. Maeda, H., Advanced drug delivery reviews 2015, 91, 3-6.

17. Attia, M. F.; Anton, N.; Wallyn, J.; Omran, Z.; Vandamme, T. F., Journal of Pharmacy and Pharmacology 2019, 71 (8), 1185-1198.

18. Nel, A.; Ruoslahti, E.; Meng, H., New insights into "permeability" as in the enhanced permeability and retention effect of cancer nanotherapeutics. ACS Publications: 2017.

19. Fang, J.; Nakamura, H.; Maeda, H., Advanced drug delivery reviews 2011, 63 (3), 136-151.

20. Bae, Y. H.; Park, K., Journal of controlled release 2011, 153 (3), 198.

21. Han, X.; Xu, Y.; Geranpayehvaghei, M.; Anderson, G. J.; Li, Y.; Nie, G., Biomaterials 2020, 232, 119745.

22. Rashidi, A.; Omidi, M.; Choolaei, M.; Nazarzadeh, M.; Yadegari, A.; Haghierosadat, F.; Oroojalian, F.; Azhdari, M. In Electromechanical properties of vertically aligned carbon nanotube, Advanced Materials Research, Trans Tech Publ: 2013; pp 332-336.

23. Aghdam, M. A.; Bagheri, R.; Mosafer, J.; Baradaran, B.; Hashemzaei, M.; Baghbanzadeh, A.; de la Guardia, M.; Mokhtarzadeh, A., Journal of Controlled Release 2019, 315, 1-22.

24. Mokhtarzadeh, A.; Parhiz, H.; Hashemi, M.; Abnous, K.; Ramezani, M., Expert opinion on drug delivery 2016, 13 (4), 477-491.

25. Mokhtarzadeh, A.; Hassanpour, S.; Vahid, Z. F.; Hejazi, M.; Hashemi, M.; Ranjbari, J.; Tabarzad, M.; Noorolyai, S.; de la Guardia, M., Journal of Controlled Release 2017, 266, 166-186.

26. Oroojalian, F.; Charbgoo, F.; Hashemi, M.; Amani, A.; Yazdian-Robati, R.; Mokhtarzadeh, A.; Ramezani, M.; Hamblin, M. R., Journal of controlled release 2020, 321, 442-462.

27. Leserman, L. D.; Barbet, J.; Kourilsky, F.; Weinstein, J. N., Nature 1980, 288 (5791), 602-604. 
28. Kamaly, N.; Xiao, Z.; Valencia, P. M.; Radovic-Moreno, A. F.; Farokhzad, O. C., Chemical Society Reviews 2012, 41 (7), 2971-3010.

29. Wang, X.; Li, S.; Shi, Y.; Chuan, X.; Li, J.; Zhong, T.; Zhang, H.; Dai, W.; He, B.; Zhang, Q., Journal of Controlled Release 2014, 193, 139-153.

30. Taraballi, F.; Bauza, G.; McCulloch, P.; Harris, J.; Tasciotti, E., Stem cells translational medicine 2017, 6 (12), 2186-2196.

31. Sedó, J.; Saiz-Poseu, J.; Busqué, F.; Ruiz-Molina, D., Advanced Materials 2013, 25 (5), 792-792.

32. García-Gareta, E.; Hua, J.; Orera, A.; Kohli, N.; Knowles, J. C.; Blunn, G. W., Biomedical Materials 2017, 13 (1), 015008.

33. Grupi, A.; Ashur, I.; Degani-Katzav, N.; Yudovich, S.; Shapira, Z.; Marzouq, A.; Morgenstein, L.; Mandel, Y.; Weiss, S., Small 2019, 15 (52), 1903006.

34. Mey, I.; Steinem, C.; Janshoff, A., Journal of Materials Chemistry 2012, 22 (37), 19348-19356.

35. Fontana, F.; Shahbazi, M. A.; Liu, D.; Zhang, H.; Mäkilä, E.; Salonen, J.; Hirvonen, J. T.; Santos, H. A., Advanced Materials 2017, 29 (7), 1603239.

36. Biagiotti, S.; Paoletti, M. F.; Fraternale, A.; Rossi, L.; Magnani, M., IUBMB life 2011, 63 (8), 621-631.

37. Zhen, X.; Cheng, P.; Pu, K., Small 2019, 15 (1), 1804105.

38. Choi, B.; Park, W.; Park, S.-B.; Rhim, W.-K.; Han, D. K., Methods 2020, 177, 2-14.

39. Jiao, M.; Zhang, P.; Meng, J.; Li, Y.; Liu, C.; Luo, X.; Gao, M., Biomaterials science 2018, 6 (4), 726-745.

40. Shi, J.; Kantoff, P. W.; Wooster, R.; Farokhzad, O. C., Nature Reviews Cancer 2017, 17 (1), 20.

41. Fusciello, M.; Fontana, F.; Tähtinen, S.; Capasso, C.; Feola, S.; Martins, B.; Chiaro, J.; Peltonen, K.; Ylösmäki, L.; Ylösmäki, E., Nature communications 2019, 10 (1), 1-13.

42. $\quad$ Coussens, L. M.; Werb, Z., Nature 2002, 420 (6917), 860-867.

43. Mantovani, A.; Allavena, P.; Sica, A.; Balkwill, F., nature 2008, 454 (7203), 436-444.

44. Pang, L.; Qin, J.; Han, L.; Zhao, W.; Liang, J.; Xie, Z.; Yang, P.; Wang, J., Oncotarget 2016, 7 (24), 37081.

45. $\quad$ Fang, R. H.; Jiang, Y.; Fang, J. C.; Zhang, L., Biomaterials 2017, 128, 69-83.

46. Li, R.; He, Y.; Zhang, S.; Qin, J.; Wang, J., Acta Pharmaceutica Sinica B 2018, 8 (1), 14-22.

47. Hasanzadeh, M.; Tagi, S.; Solhi, E.; Shadjou, N.; Jouyban, A.; Mokhtarzadeh, A., International journal of biological macromolecules 2018, 118, 1082-1089.

48. Saadati, A.; Hassanpour, S.; de la Guardia, M.; Mosafer, J.; Hashemzaei, M.; Mokhtarzadeh, A.; Baradaran, B., TrAC Trends in Analytical Chemistry 2019, 114, 56-68.

49. Eivazzadeh-Keihan, R.; Chenab, K. K.; Taheri-Ledari, R.; Mosafer, J.; Hashemi, S. M.; Mokhtarzadeh, A.; Maleki, A.; Hamblin, M. R., Materials Science and Engineering: C 2020, 107, 110267.

50. Hasanzadeh, M.; Sahmani, R.; Solhi, E.; Mokhtarzadeh, A.; Shadjou, N.; Mahboob, S., International journal of biological macromolecules 2018, 119, 913-925.

51. Hafezi Ghahestani, Z.; Alebooye Langroodi, F.; Mokhtarzadeh, A.; Ramezani, M.; Hashemi, M., Artificial cells, nanomedicine, and biotechnology 2017, 45 (5), 955-960.

52. van der Meel, R.; Sulheim, E.; Shi, Y.; Kiessling, F.; Mulder, W. J.; Lammers, T., Nature nanotechnology 2019, 14 (11), 1007-1017.

53. Hasanzadeh, M.; Nahar, A. S.; Hassanpour, S.; Shadjou, N.; Mokhtarzadeh, A.; Mohammadi, J., Enzyme and microbial technology 2017, 105, 64-76.

54. Jahanafrooz, Z.; Baradaran, B.; Mosafer, J.; Hashemzaei, M.; Rezaei, T.; Mokhtarzadeh, A.; Hamblin, M. R., Drug Discovery Today 2020, 25 (3), 552-560.

55. $\quad \mathrm{Ng}, \mathrm{C} . \mathrm{W} . ; \mathrm{Li}, \mathrm{J} . ;$ Pu, K., Advanced Functional Materials 2018, 28 (46), 1804688.

56. Jiang, Y.; Li, J.; Zeng, Z.; Xie, C.; Lyu, Y.; Pu, K., Angewandte Chemie International Edition 2019, 58 (24), 8161-8165.

57. $\quad$ Li, J.; Zhen, X.; Lyu, Y.; Jiang, Y.; Huang, J.; Pu, K., Acs Nano 2018, 12 (8), 8520-8530.

58. Li, J.; Pu, K., Chemical Society Reviews 2019, 48 (1), 38-71. 
59. Lutz, H.; Hu, S.; Dinh, P.-U.; Cheng, K., Medicine in Drug Discovery 2019, 3, 100014.

60. Xu, P.; Zuo, H.; Chen, B.; Wang, R.; Ahmed, A.; Hu, Y.; Ouyang, J., Scientific Reports 2017, 7, 44974.

61. Yadav, D.; Sandeep, K.; Pandey, D.; Dutta, R. K., J. Biotechnol. Biomater 2017, 7, 276.

62. Mokhtarzadeh, A.; Tabarzad, M.; Ranjbari, J.; de la Guardia, M.; Hejazi, M.; Ramezani, M., TrAC Trends in Analytical Chemistry 2016, 82, 316-327.

63. Vijayan, V.; Uthaman, S.; Park, I.-K., Polymers 2018, 10 (9), 983.

64. Liu, Y.; Luo, J.; Chen, X.; Liu, W.; Chen, T., Nano-Micro Letters 2019, 11 (1), 100.

65. Visser, J. G.; Van Staden, A. D. P.; Smith, C., Frontiers in pharmacology 2019, 10, 22.

66. Jin, Y.; Hu, G.; Guo, M.; Xu, J.; Wu, F.; Fan, J.; Huang, Q.; Yang, G.; Lv, Z.; Wang, X., Frontiers in Immunology 2019, 10, 1998.

67. Deng, G.; Sun, Z.; Li, S.; Peng, X.; Li, W.; Zhou, L.; Ma, Y.; Gong, P.; Cai, L., ACS nano 2018, 12 (12), 12096-12108.

68. $\mathrm{Hu}$, Q.; Sun, W.; Qian, C.; Wang, C.; Bomba, H. N.; Gu, Z., Advanced Materials 2015, 27 (44), 7043-7050.

69. Tang, L.; Zheng, Y.; Melo, M. B.; Mabardi, L.; Castaño, A. P.; Xie, Y.-Q.; Li, N.; Kudchodkar, S. B.; Wong, H. C.; Jeng, E. K., Nature biotechnology 2018, 36 (8), 707-716.

70. Zhang, X.; Wang, J.; Chen, Z.; Hu, Q.; Wang, C.; Yan, J.; Dotti, G.; Huang, P.; Gu, Z., Nano Letters 2018, 18 (9), 5716-5725.

71. Lu, Y.; Hu, Q.; Jiang, C.; Gu, Z., Current opinion in biotechnology 2019, 58, 81-91.

72. Chu, D.; Zhao, Q.; Yu, J.; Zhang, F.; Zhang, H.; Wang, Z., Advanced healthcare materials 2016, 5 (9), 1088-1093.

73. Davies, J. O.; Stringaris, K.; Barrett, A. J.; Rezvani, K., Cytotherapy 2014, 16 (11), 1453-1466.

74. Han, Y.; Pan, H.; Li, W.; Chen, Z.; Ma, A.; Yin, T.; Liang, R.; Chen, F.; Ma, Y.; Jin, Y., Advanced Science 2019, 6 (15), 1900251.

75. YoungáYhee, J., Nanoscale 2014, 6 (22), 13383-13390.

76. Yaman, S.; Ramachandramoorthy, H.; Oter, G.; Zhukova, D.; Nguyen, T.; Sabnani, M. K.; Weidanz, J. A.; Nguyen, K. T., Frontiers in Bioengineering and Biotechnology 2020, 8, 943.

77. Zhang, L.; Li, R.; Chen, H.; Wei, J.; Qian, H.; Su, S.; Shao, J.; Wang, L.; Qian, X.; Liu, B., International journal of nanomedicine 2017, 12, 2129.

78. Zhang, D.; Lee, H.; Wang, X.; Rai, A.; Groot, M.; Jin, Y., Molecular Therapy 2018, 26 (9), 21192130.

79. Kojima, R.; Bojar, D.; Rizzi, G.; Charpin-El Hamri, G.; El-Baba, M. D.; Saxena, P.; Ausländer, S.; Tan, K. R.; Fussenegger, M., Nature communications 2018, 9 (1), 1-10.

80. Ye, M.; Gong, S., Matter 2019, 1 (5), 1104-1105.

81. Wen, D.; Wang, J.; Van Den Driessche, G.; Chen, Q.; Zhang, Y.; Chen, G.; Li, H.; Soto, J.; Liu, M.; Ohashi, M., Matter 2019, 1 (5), 1203-1214.

82. $\quad \mathrm{Hu}, \mathrm{W} . ;$ Wang, G.; Huang, D.; Sui, M.; Xu, Y., Frontiers in Immunology 2019, 10, 1205.

83. Berasaluce, A.; Matthys, L.; Mujika, J.; Antoñana-Díez, M.; Valero, A.; Agirregabiria, M., Rsc Advances 2015, 5 (29), 22350-22355.

84. Di Carlo, D.; Jeong, K.-H.; Lee, L. P., Lab on a Chip 2003, 3 (4), 287-291.

85. Kido, H.; Micic, M.; Smith, D.; Zoval, J.; Norton, J.; Madou, M., Colloids and Surfaces B: Biointerfaces 2007, 58 (1), 44-51.

86. Tsougeni, K.; Papadakis, G.; Gianneli, M.; Grammoustianou, A.; Constantoudis, V.; Dupuy, B.; Petrou, P.; Kakabakos, S.; Tserepi, A.; Gizeli, E., Lab on a Chip 2016, 16 (1), 120-131.

87. Buser, J. R.; Zhang, X.; Byrnes, S.; Ladd, P.; Heiniger, E.; Wheeler, M.; Bishop, J.; Englund, J.; Lutz, B.; Weigl, B., Analytical Methods 2016, 8 (14), 2880-2886.

88. Kashyap, A.; Autebert, J.; Delamarche, E.; Kaigala, G. V., Scientific reports 2016, 6, 29579.

89. Huang, S.-H.; Hung, L.-Y.; Lee, G.-B., Lab on a Chip 2016, 16 (8), 1447-1456.

90. Wan, W.; Yeow, J. T., Biomedical microdevices 2011, 13 (3), 527-532. 


\section{WILEY-VCH}

91. Reboud, J.; Bourquin, Y.; Wilson, R.; Pall, G. S.; Jiwaji, M.; Pitt, A. R.; Graham, A.; Waters, A. P.; Cooper, J. M., Proceedings of the National Academy of Sciences 2012, 109 (38), 15162-15167.

92. Shehadul Islam, M.; Aryasomayajula, A.; Selvaganapathy, P. R., Micromachines 2017, 8 (3), 83.

93. Taskova, R. M.; Zorn, H.; Krings, U.; Bouws, H.; Berger, R. G., Zeitschrift für Naturforschung C 2006, $61(5-6), 347-350$.

94. Ho, C. W.; Tan, W. S.; Yap, W. B.; Ling, T. C.; Tey, B. T., Biotechnology and Bioprocess engineering 2008, 13 (5), 577-583.

95. Harrison, S. T., Biotechnology advances 1991, 9 (2), 217-240.

96. Rao, L.; Cai, B.; Bu, L.-L.; Liao, Q.-Q.; Guo, S.-S.; Zhao, X.-Z.; Dong, W.-F.; Liu, W., Acs Nano 2017, 11 (4), 3496-3505.

97. Silva, A. K. A.; Di Corato, R.; Pellegrino, T.; Chat, S.; Pugliese, G.; Luciani, N.; Gazeau, F.; Wilhelm, C., Nanoscale 2013, 5 (23), 11374-11384.

98. Loos, M., Chapter 6-Processing of Polymer Matrix Composites Containing CNTs. Carbon Nanotube Reinforced Composites. Oxford: William Andrew Publishing: 2015.

99. Fabiilli, M. L.; Haworth, K. J.; Fakhri, N. H.; Kripfgans, O. D.; Carson, P. L.; Fowlkes, J. B., IEEE transactions on ultrasonics, ferroelectrics, and frequency control 2009, 56 (5), 1006-1017.

100. Loskutova, K.; Grishenkov, D.; Ghorbani, M., BioMed Research International 2019, 2019.

101. Fan, C.-H.; Lin, Y.-T.; Ho, Y.-J.; Yeh, C.-K., Theranostics 2018, 8 (20), 5731.

102. Blum, N. T.; Yildirim, A.; Chattaraj, R.; Goodwin, A. P., Theranostics 2017, 7 (3), 694.

103. Gagne, F., Biochemical ecotoxicology: principles and methods. Elsevier: 2014.

104. Ong, S. G. M.; Chitneni, M.; Lee, K. S.; Ming, L. C.; Yuen, K. H., Pharmaceutics 2016, 8 (4), 36.

105. Repka, M. A.; Majumdar, S.; Kumar Battu, S.; Srirangam, R.; Upadhye, S. B., Expert opinion on drug delivery 2008, 5 (12), 1357-1376.

106. Breitenbach, J., European journal of pharmaceutics and biopharmaceutics 2002, 54 (2), 107-117.

107. Andrews, G. P.; Jones, D. S.; Abu Diak, O.; Margetson, D. N.; McAllister, M., Pharmaceutical Technology Europe 2009, 21 (1), 24-27.

108. Ren, Y.; Mei, L.; Zhou, L.; Guo, G., AAPS PharmSciTech 2019, 20 (3), 92.

109. Ihler, G. M.; Glew, R. H.; Schnure, F. W., Proceedings of the National Academy of Sciences 1973, 70 (9), 2663-2666.

110. $\quad$ Fang, R. H.; Kroll, A. V.; Gao, W.; Zhang, L., Advanced Materials 2018, 30 (23), 1706759.

111. DeCaprio, J.; Kohl, T. O., Cold Spring Harbor Protocols 2019, 2019 (7), pdb. prot098574.

112. Xia, Q.; Zhang, Y.; Li, Z.; Hou, X.; Feng, N., Acta Pharmaceutica Sinica B 2019, 9 (4), 675-689.

113. Chu, Y.; Zhang, J.; Pan, H.; Shi, J.; Wang, J.; Chen, L., Drug delivery and translational research 2020.

114. Rahman, M. A.; Wang, J.; Zhang, C.; Olah, A.; Baer, E., European Polymer Journal 2016, 83, 99-113.

115. Liu, C.; Zhang, W.; Li, Y.; Chang, J.; Tian, F.; Zhao, F.; Ma, Y.; Sun, J., Nano letters 2019, 19 (11), 7836-7844.

116. Li, T.; Qin, X.; Li, Y.; Shen, X.; Li, S.; Yang, H.; Wu, C.; Zheng, C.; Zhu, J.; You, F., Frontiers in Bioengineering and Biotechnology 2020, 8.

117. Liu, W. L.; Zou, M. Z.; Liu, T.; Zeng, J. Y.; Li, X.; Yu, W. Y.; Li, C. X.; Ye, J. J.; Song, W.; Feng, J., Advanced Materials 2019, 31 (18), 1900499.

118. Fan, Z.; Li, P. Y.; Deng, J.; Bady, S. C.; Cheng, H., Nano research 2018, 11 (10), 5573-5583.

119. Nimesh, S.; Chandra, R.; Gupta, N., Advances in nanomedicine for the delivery of therapeutic nucleic acids. Woodhead Publishing: 2017.

120. Reim, D. F.; Speicher, D. W., Current protocols in protein science 1997, 8 (1), 11.10. 1-11.10. 38.

121. Johnson, L.; Tarr, G., C-terminal sequence of proteins: rapid isolation and Edman sequencing of C-terminal peptides from digests. In Methods in Protein Sequence Analysis. 1986, Springer: 1987; pp 351-358. 
122. Sanderson, M. J.; Smith, I.; Parker, I.; Bootman, M. D., Cold Spring Harbor Protocols 2014, 2014 (10), pdb. top071795.

123. De Caro, C.; Haller, C., Mettler-Toledo International 2015.

124. Zhai, Y.; Su, J.; Ran, W.; Zhang, P.; Yin, Q.; Zhang, Z.; Yu, H.; Li, Y., Theranostics 2017, 7 (10), 2575.

125. Ren, X.; Zheng, R.; Fang, X.; Wang, X.; Zhang, X.; Yang, W.; Sha, X., Biomaterials 2016, 92, $13-24$.

126. Olingy, C. E.; Dinh, H. Q.; Hedrick, C. C., Journal of leukocyte biology 2019, 106 (2), 309-322.

127. Mitchell, M. J.; King, M. R., Expert opinion on drug delivery 2015, 12 (3), 375-392.

128. Sica, A.; Allavena, P.; Mantovani, A., Cancer letters 2008, 267 (2), 204-215.

129. Franklin, R. A.; Liao, W.; Sarkar, A.; Kim, M. V.; Bivona, M. R.; Liu, K.; Pamer, E. G.; Li, M. O., Science 2014, 344 (6186), 921-925.

130. Xuan, M.; Shao, J.; Dai, L.; He, Q.; Li, J., Advanced healthcare materials 2015, 4 (11), 16451652.

131. Parodi, A.; Quattrocchi, N.; Van De Ven, A. L.; Chiappini, C.; Evangelopoulos, M.; Martinez, J. O.; Brown, B. S.; Khaled, S. Z.; Yazdi, I. K.; Enzo, M. V., Nature nanotechnology 2013, 8 (1), 61-68.

132. Wang, Q.; Ren, Y.; Mu, J.; Egilmez, N. K.; Zhuang, X.; Deng, Z.; Zhang, L.; Yan, J.; Miller, D.; Zhang, H.-G., Cancer research 2015, 75 (12), 2520-2529.

133. Rao, L.; He, Z.; Meng, Q. F.; Zhou, Z.; Bu, L. L.; Guo, S. S.; Liu, W.; Zhao, X. Z., Journal of Biomedical Materials Research Part A 2017, 105 (2), 521-530.

134. Xuan, M.; Shao, J.; Dai, L.; Li, J.; He, Q., ACS applied materials \& interfaces 2016, 8 (15), 9610-9618.

135. Zhou, J.; Tang, Z.; Gao, S.; Li, C.; Feng, Y.; Zhou, X., Frontiers in Oncology 2020, 10, 188.

136. Dandekar, R. C.; Kingaonkar, A. V.; Dhabekar, G. S., Annals of maxillofacial surgery 2011, 1 (2), 150 .

137. Ostuni, R.; Kratochvill, F.; Murray, P. J.; Natoli, G., Trends in immunology 2015, 36 (4), 229-

239.

138. Nielsen, S. R.; Schmid, M. C., Mediators of inflammation 2017, 2017.

139. Fontana, F.; Albertini, S.; Correia, A.; Kemell, M.; Lindgren, R.; Mäkilä, E.; Salonen, J.; Hirvonen, J. T.; Ferrari, F.; Santos, H. A., Advanced Functional Materials 2018, 28 (22), 1801355.

140. Bhattacharyya, S.; Ghosh, S. S., ACS omega 2020, 5 (3), 1572-1580.

141. Li, Y.; Yan, T.; Chang, W.; Cao, C.; Deng, D., Biomaterials science 2019, 7 (9), 3652-3661.

142. Zhang, Y.; Cai, K.; Li, C.; Guo, Q.; Chen, Q.; He, X.; Liu, L.; Zhang, Y.; Lu, Y.; Chen, X., Nano letters 2018, 18 (3), 1908-1915.

143. Meng, Q.-F.; Rao, L.; Zan, M.; Chen, M.; Yu, G.-T.; Wei, X.; Wu, Z.; Sun, Y.; Guo, S.-S.; Zhao, X.-Z., Nanotechnology 2018, 29 (13), 134004.

144. Lehman, H.; Segal, B. H., Journal of Allergy and Clinical Immunology 2020.

145. Ricchi, P.; Zarrilli, R.; Di Palma, A.; Acquaviva, A., British journal of cancer 2003, 88 (6), 803-

807.

146. Gash, K.; Chambers, A.; Cotton, D.; Williams, A.; Thomas, M., British journal of cancer 2017, 117 (2), 210-219.

147. Cao, X.; Hu, Y.; Luo, S.; Wang, Y.; Gong, T.; Sun, X.; Fu, Y.; Zhang, Z., Acta Pharmaceutica Sinica B 2019, 9 (3), 575-589.

148. Coffelt, S. B.; Kersten, K.; Doornebal, C. W.; Weiden, J.; Vrijland, K.; Hau, C.-S.; Verstegen, N. J.; Ciampricotti, M.; Hawinkels, L. J.; Jonkers, J., Nature 2015, 522 (7556), 345-348.

149. Kang, T.; Zhu, Q.; Wei, D.; Feng, J.; Yao, J.; Jiang, T.; Song, Q.; Wei, X.; Chen, H.; Gao, X., Acs Nano 2017, 11 (2), 1397-1411.

150. He, Z.; Zhang, Y.; Feng, N., Materials Science and Engineering: C 2020, 106, 110298.

151. Hu, C.-M. J.; Fang, R. H.; Wang, K.-C.; Luk, B. T.; Thamphiwatana, S.; Dehaini, D.; Nguyen, P.; Angsantikul, P.; Wen, C. H.; Kroll, A. V., Nature 2015, 526 (7571), 118-121. 
152. Lim, K.; Hyun, Y.-M.; Lambert-Emo, K.; Capece, T.; Bae, S.; Miller, R.; Topham, D. J.; Kim, M., Science 2015, 349 (6252).

153. Wang, K.; Lei, Y.; Xia, D.; Xu, P.; Zhu, T.; Jiang, Z.; Ma, Y., Colloids and Surfaces B: Biointerfaces 2020, 188, 110755.

154. Xue, J.; Zhao, Z.; Zhang, L.; Xue, L.; Shen, S.; Wen, Y.; Wei, Z.; Wang, L.; Kong, L.; Sun, H., Nature nanotechnology 2017, 12 (7), 692.

155. Coffelt, S. B.; Wellenstein, M. D.; de Visser, K. E., Nature Reviews Cancer 2016, 16 (7), 431.

156. Zhang, Q.; Dehaini, D.; Zhang, Y.; Zhou, J.; Chen, X.; Zhang, L.; Fang, R. H.; Gao, W.; Zhang, L., Nature nanotechnology 2018, 13 (12), 1182-1190.

157. Su, Y.; Wang, T.; Su, Y.; Li, M.; Zhou, J.; Zhang, W.; Wang, W., Materials Horizons 2020, 7 (2), 574-585.

158. Naumenko, V.; Nikitin, A.; Garanina, A.; Melnikov, P.; Vodopyanov, S.; Kapitanova, K.; Potashnikova, D.; Vishnevskiy, D.; Alieva, I.; Ilyasov, A., Acta Biomaterialia 2020, 104, 176-187.

159. Wen, P. Y.; Kesari, S., New England Journal of Medicine 2008, 359 (5), $492-507$.

160. Wu, M.; Zhang, H.; Tie, C.; Yan, C.; Deng, Z.; Wan, Q.; Liu, X.; Yan, F.; Zheng, H., Nature communications 2018, 9 (1), 1-13.

161. Cuddapah, V. A.; Robel, S.; Watkins, S.; Sontheimer, H., Nature Reviews Neuroscience 2014, 15 (7), 455-465.

162. Neuwelt, E. A.; Bauer, B.; Fahlke, C.; Fricker, G.; Iadecola, C.; Janigro, D.; Leybaert, L.; Molnár, Z.; O'donnell, M. E.; Povlishock, J. T., Nature Reviews Neuroscience 2011, 12 (3), 169-182.

163. Gu, L.; Mooney, D. J., Nature Reviews Cancer 2016, 16 (1), 56-66.

164. Zhao, Y.-Z.; ZhuGe, D.-L.; Tong, M.-Q.; Lin, M.-T.; Zheng, Y.-W.; Jiang, X.; Yang, W.-G.; Yao, Q.; Xiang, Q.; Li, X.-K., Journal of Controlled Release 2019, 299, 90-106.

165. Randolph, G. J.; Jakubzick, C.; Qu, C., Current opinion in immunology 2008, 20 (1), 52-60.

166. Fliervoet, L. A.; Mastrobattista, E., Advanced drug delivery reviews 2016, 106, 63-72.

167. Paulis, L. E.; Mandal, S.; Kreutz, M.; Figdor, C. G., Current opinion in immunology 2013, 25 (3), 389-395.

168. Granot, T.; Senda, T.; Carpenter, D. J.; Matsuoka, N.; Weiner, J.; Gordon, C. L.; Miron, M.; Kumar, B. V.; Griesemer, A.; Ho, S.-H., Immunity 2017, 46 (3), 504-515.

169. Saxena, M.; Balan, S.; Roudko, V.; Bhardwaj, N., Nature biomedical engineering 2018, 2 (6), 341-346.

170. Cancel, J.-C.; Crozat, K.; Dalod, M.; Mattiuz, R., Frontiers in immunology 2019, 10, 9.

171. Jin, P.; Han, T. H.; Ren, J.; Saunders, S.; Wang, E.; Marincola, F. M.; Stroncek, D. F., Journal of translational medicine 2010, 8 (1), 4.

172. Gardner, A.; Ruffell, B., Trends in immunology 2016, 37 (12), 855-865.

173. Bol, K. F.; Schreibelt, G.; Gerritsen, W. R.; De Vries, I. J. M.; Figdor, C. G., Dendritic cell-based immunotherapy: state of the art and beyond. AACR: 2016.

174. Sabado, R. L.; Balan, S.; Bhardwaj, N., Cell research 2017, 27 (1), 74-95.

175. Cheng, S.; Xu, C.; Jin, Y.; Li, Y.; Zhong, C.; Ma, J.; Yang, J.; Zhang, N.; Li, Y.; Wang, C., Advanced Science 2020, 7 (7), 1903301.

176. Zeng, Z.; Pu, K., Advanced Functional Materials 2020, 2004397.

177. Pan, J.; Wang, Y.; Zhang, C.; Wang, X.; Wang, H.; Wang, J.; Yuan, Y.; Wang, X.; Zhang, X.; Yu, C., Advanced Materials 2018, 30 (8), 1704408.

178. Dong, X.; Liang, J.; Yang, A.; Wang, C.; Kong, D.; Lv, F., ACS applied materials \& interfaces 2018, 10 (26), 21861-21875.

179. Luo, M.; Samandi, L. Z.; Wang, Z.; Chen, Z. J.; Gao, J., Journal of Controlled Release 2017, 263, 200-210.

180. Zhang, C.; Zhang, J.; Shi, G.; Song, H.; Shi, S.; Zhang, X.; Huang, P.; Wang, Z.; Wang, W.; Wang, C., Molecular pharmaceutics 2017, 14 (5), 1760-1770.

181. Lugli, E., T-cell Differentiation: Methods and Protocols. Springer: 2017. 


\section{WILEY-VCH}

182. de Melo-Diogo, D.; Pais-Silva, C.; Dias, D. R.; Moreira, A. F.; Correia, I. J., Advanced Healthcare Materials 2017, 6 (10), 1700073.

183. Ma, W.; Zhu, D.; Li, J.; Chen, X.; Xie, W.; Jiang, X.; Wu, L.; Wang, G.; Xiao, Y.; Liu, Z., Theranostics 2020, 10 (3), 1281.

184. Rosenberg, S. A.; Restifo, N. P., Science 2015, 348 (6230), 62-68.

185. Corrigan-Curay, J.; Kiem, H.-P.; Baltimore, D.; O'reilly, M.; Brentjens, R. J.; Cooper, L.; Forman, S.; Gottschalk, S.; Greenberg, P.; Junghans, R., Molecular Therapy 2014, 22 (9), 1564-1574.

186. Conlon, K. C.; Lugli, E.; Welles, H. C.; Rosenberg, S. A.; Fojo, A. T.; Morris, J. C.; Fleisher, T. A.; Dubois, S. P.; Perera, L. P.; Stewart, D. M., Journal of clinical oncology 2015, 33 (1), 74.

187. Zhang, L.; Morgan, R. A.; Beane, J. D.; Zheng, Z.; Dudley, M. E.; Kassim, S. H.; Nahvi, A. V.; Ngo, L. T.; Sherry, R. M.; Phan, G. Q., Clinical cancer research 2015, 21 (10), 2278-2288.

188. Gowrishankar, K.; Birtwistle, L.; Micklethwaite, K., Mammalian Genome 2018, 29 (11-12), 739-

756.

189. O’Sullivan, T. E.; Sun, J. C.; Lanier, L. L., Immunity 2015, 43 (4), 634-645.

190. Grossenbacher, S. K.; Canter, R. J.; Murphy, W. J., Journal for immunotherapy of cancer 2016, 4 (1), 19.

191. Garber, K., Natural killer cells blaze into immuno-oncology. Nature Publishing Group: 2016.

192. Wu, L.; Zhang, F.; Wei, Z.; Li, X.; Zhao, H.; Lv, H.; Ge, R.; Ma, H.; Zhang, H.; Yang, B., Biomaterials science 2018, 6 (10), 2714-2725.

193. Combes, F.; Meyer, E.; Sanders, N. N., Journal of Controlled Release 2020.

194. Christie, C.; Madsen, S. J.; Peng, Q.; Hirschberg, H., Therapeutic Delivery 2015, 6 (3), 371-384. 